Mississippi State University

Scholars Junction

5-3-2019

\title{
Establishing healthy habits in early childhood: Lessons learned from early care professionals
}

Connie B. Clay

Follow this and additional works at: https://scholarsjunction.msstate.edu/td

\section{Recommended Citation}

Clay, Connie B., "Establishing healthy habits in early childhood: Lessons learned from early care professionals" (2019). Theses and Dissertations. 5052.

https://scholarsjunction.msstate.edu/td/5052

This Dissertation - Open Access is brought to you for free and open access by the Theses and Dissertations at Scholars Junction. It has been accepted for inclusion in Theses and Dissertations by an authorized administrator of Scholars Junction. For more information, please contact scholcomm@msstate.libanswers.com. 
Establishing healthy habits in early childhood: Lessons learned from early care professionals

By

Connie B. Clay

\begin{abstract}
A Dissertation
Submitted to the Faculty of

Mississippi State University

in Partial Fulfillment of the Requirements

for the Degree of Doctor of Philosophy

in Human Development \& Family Science

in the Department of Human Sciences
\end{abstract}

Mississippi State, Mississippi

May 2019 
Copyright by

Connie B. Clay

2019 
Establishing healthy habits in early childhood: Lessons learned from early care professionals

By

Connie B. Clay

Approved:

Lori D. Elmore-Staton

(Major Professor)

Gail Lindsey

(Committee Member)

Brittney D. Oliver

(Committee Member)

Julie C. Parker

(Committee Member)

Tommy M. Phillips

(Graduate Coordinator)

George M. Hopper

Dean

College of Agriculture and Life Sciences 
Name: Connie B. Clay

Date of Degree: May 3, 2019

Institution: Mississippi State University

Major Field: Human Development \& Family Science

Select Appropriate Title: Lori D. Elmore-Staton

Title of Study: Establishing healthy habits in early childhood: Lessons learned from early care professionals

Pages in Study 170

Candidate for Degree of Doctor of Philosophy

This dissertation is comprised of two studies, which taken together aim to enhance healthy lifestyle habits of young children. In the first study, early childhood professionals $(N=39)$ identified their beliefs and values regarding the role of physical activity and sleep in child development, and their role in assisting children with establishing healthy behaviors. Analyses were conducted to examine if early childhood professionals' beliefs and values were associated with an array of demographic characteristics (e.g., age, gender, and ethnicity) and/or the early care professional's perceived personal health and body mass index. Descriptive analyses revealed that early care professionals believe physical activity and sleep are important contributors to the healthy development of young children, yet place less value on their role in assisting children with establishing healthy habits. Demographic and health variables of the early childhood professional were not associated with their beliefs and values.

Using the results from Study 1 to address gaps in professional development on healthy habits in early childhood, Study 2 involved the development, implementation, and evaluation of two, 3-hour professional development trainings each focused on a 
contributor to the obesity epidemic (i.e., physical activity and sleep). Both trainings included an overview of the state of the science on the topic as it relates to early childhood and the area, recommendations for obesity prevention in the classroom, specific, hands-on examples of the early care professionals' role (i.e., behavioral and environmental) in establishing healthy habits. Pre- and post-surveys were used to assess the effectiveness of the training on knowledge of physical activity and/or sleep as it relates to early childhood. Additionally, two researchers conducted classroom observations prior to and following $(M=4.5$ weeks) the training to assess potential behavior change within the classroom. Paired-samples $t$ tests indicated that early care professionals improved their general knowledge of physical activity and sleep in child development. Results indicated minimal behavioral and environmental changes in the classroom following the professional development. 


\section{DEDICATION}

Dedicated to the ones who inspire me to be a better person every day ... my grandchildren. "Children are a message we send to a time we will not see." John F. Kennedy. 


\section{ACKNOWLEDGEMENTS}

I would like to express my sincere appreciation to Dr. Lori Elmore-Staton, my

major professor, for not giving up on me and for her support and encouragement. I could not have completing this endeavor without her.

I would also like to thank each of my committee members, Dr. Gail Lindsey, Dr. Brittney Oliver, and Dr. Julie Parker for their contribution to the completion of my research.

Thank you to my children, Adam and Carrie, for always believing in me and offering encouragement throughout the process.

Last, but certainly not least, thank you to my husband, Bob. Your support, encouragement and love has allowed me to reach my goal! 


\section{TABLE OF CONTENTS}

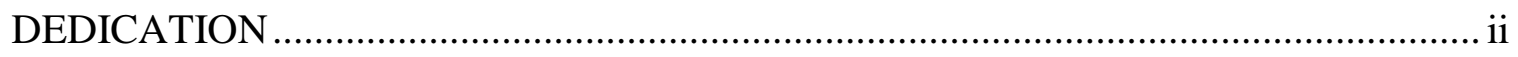

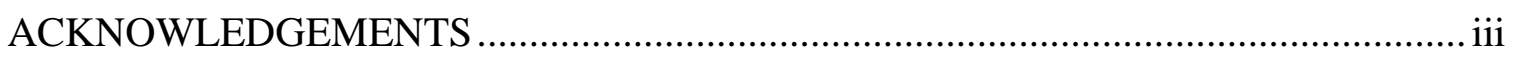

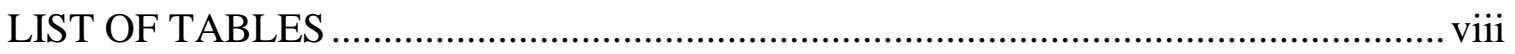

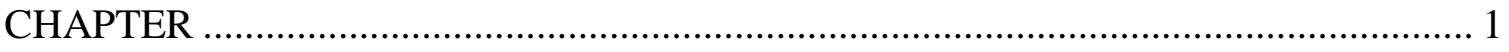

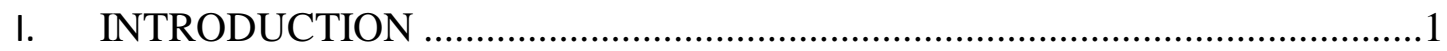

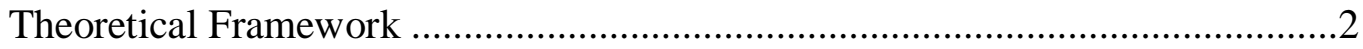

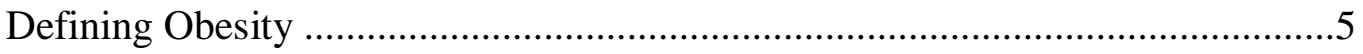

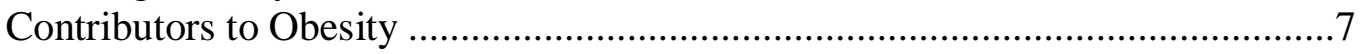

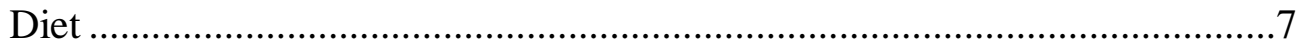

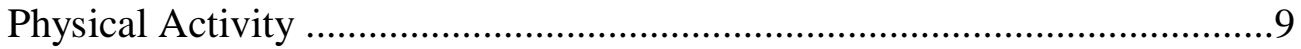

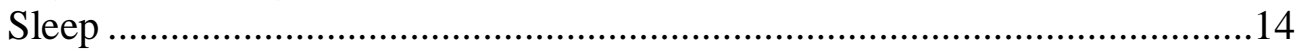

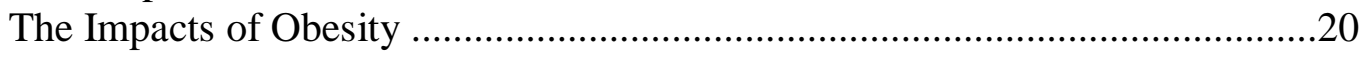

Motor Development..............................................................................21

Social-Emotional Development...............................................................22

School Readiness and Academic Achievement ………................................23

Early Education Programs and the Promotion of Healthy Lifestyle

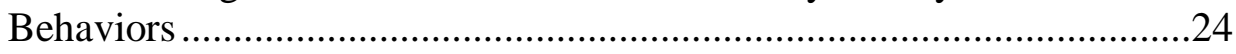

The Importance of Establishing Healthy Habits Early in Life .............................26

Early Childhood Professionals and the Promotion of Healthy Lifestyle

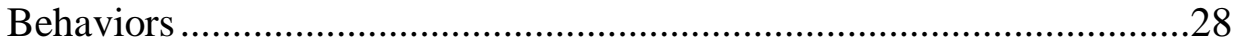

Licensing Regulations and the Impact on Healthy Lifestyle Behaviors .............29

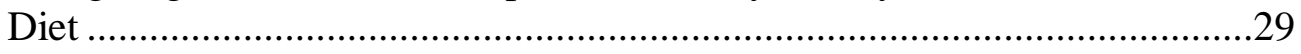

Physical Activity ....................................................................................

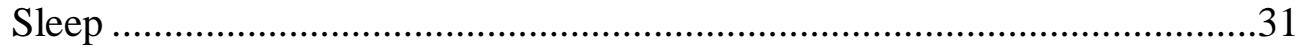

The Role and Influence of Early Care Professionals' Beliefs ...............................33

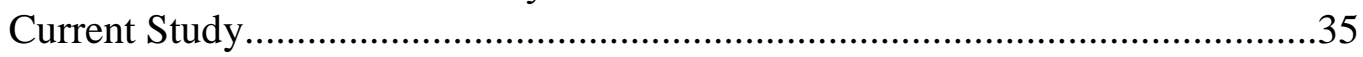

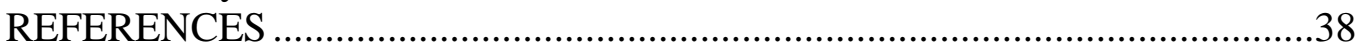

II. EARLY CARE PROFESSIONALS' BELIEFS AND VALUES REGARDING PHYSICAL ACTIVITY AND SLEEP ..........................52

Abstract Manuscript 1 .............................................................................52

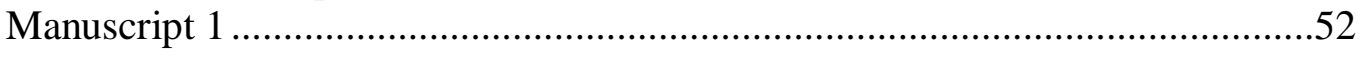


Early Care Professionals' Beliefs and Values ..............................................54

Early Care Professional's Health and the Classroom .....................................56

Head Start and the Development of Health Habits ......................................58

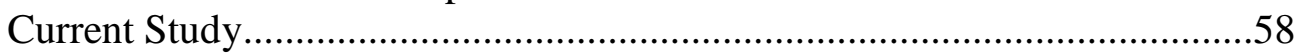

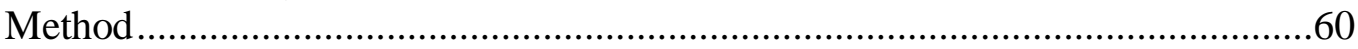

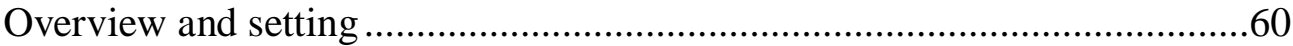

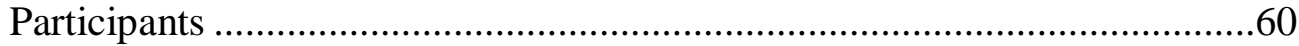

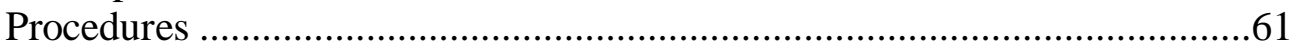

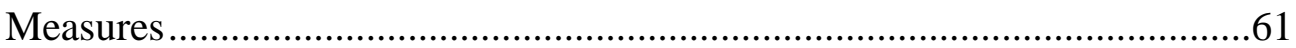

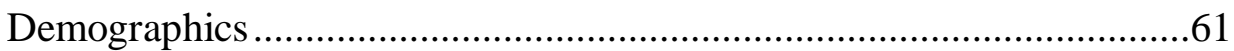

Early Care Professional Health Rating .................................................62

Early Childhood Professionals' Beliefs and Values .................................62

Results

Early Care Professionals Characteristics ......................................................65

Importance of Physical Activity for Child Development ...............................66

Statement 1 . Physical activity makes important contributions to the whole child ..............................................................................66

Statement 2. Physical activity allows children a fun break from regular classroom activities...............................................................66

Statement 3. Taking away children's opportunities for physical activity is an appropriate form of discipline ....

Statement 4. Physical activity provides children with opportunities to learn about health and fitness

Statement 5. Physical activity is as important as other curriculum areas, such as reading, math, and science

Statement 6. Physical activity teaches children motor skills, such as running, jumping, and throwing

Statement 8. Physical activity helps children develop social skills, such as sharing, taking turns, and cooperating with classmates

Importance of Sleep for Child Development

Statement 12. Sleep makes important contributions to the development of the whole child

Statement 13. Naps influence classroom behaviors

Statement 14. The classroom environment (e.g., noise, placement of cots, light) can impact a child's sleep behaviors

Early care professionals' role in assisting children in establishing

healthy habits

Statement 7. My lesson plans impact children's opportunities for physical activity .70

Statement 9. Part of my job is to make sure that children get a healthy amount of physical activity .70

Statement 10. Providing children with opportunities to be physically active is an important aspect of my job 
Statement 11. When I make an effort to encourage children to be active, they get a lot of physical activity......................................71

Statement 15. Part of my job is to make sure that children get a healthy amount of sleep ........................................................... 71

Statement 16. My lesson plans impact children's opportunities for sleep .72

Statement 17. Providing children with opportunities to rest is an important aspect of my job

Early care professionals' demographic characteristics associated with

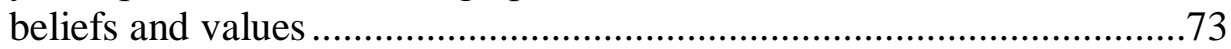

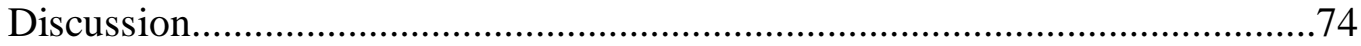

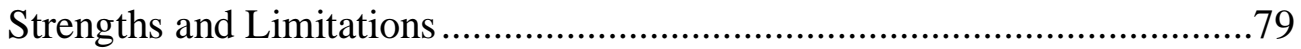

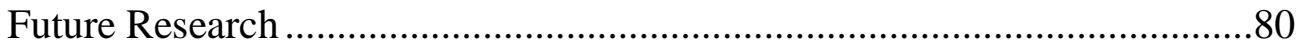

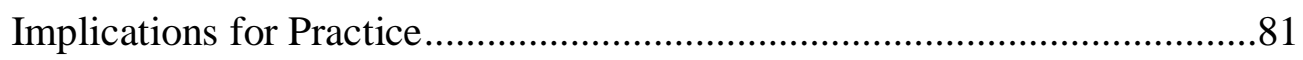

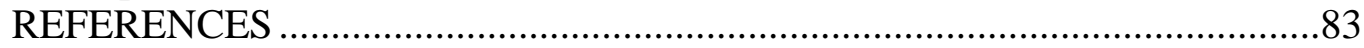

III. LESSONS ON ESTABLISHING HEALTHY HABITS IN EARLY

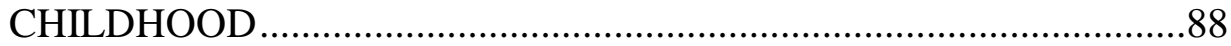

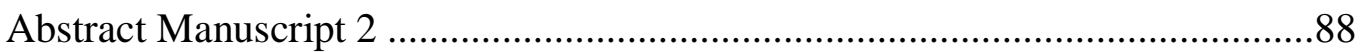

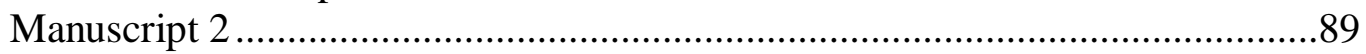

The Role of Head Start ...........................................................................99

Physical Activity and Sleep in the Early Childhood Program ....................92

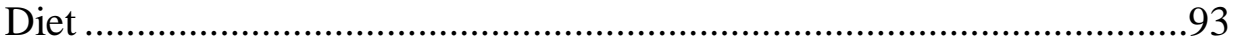

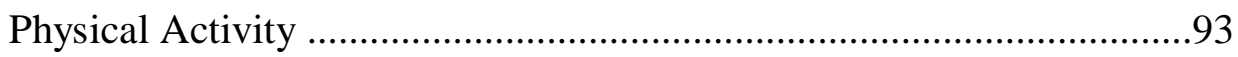

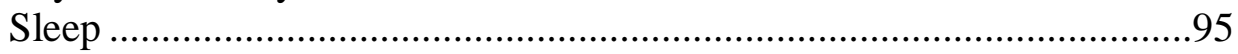

Staff Development on Healthy Lifestyle Habits ..........................................97

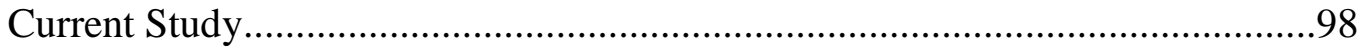

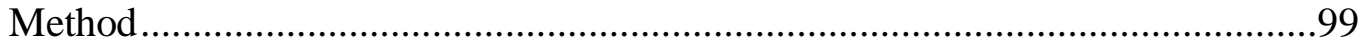

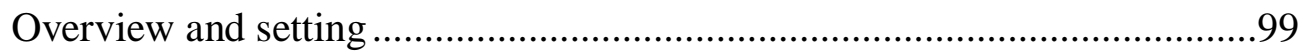

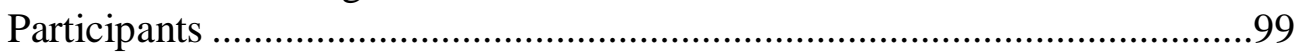

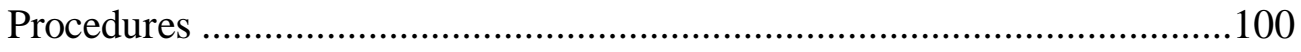

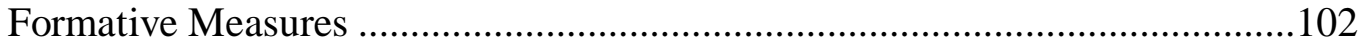

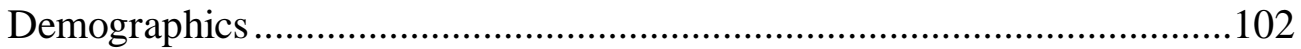

Early Childhood Professionals' Beliefs and Values ..................................102

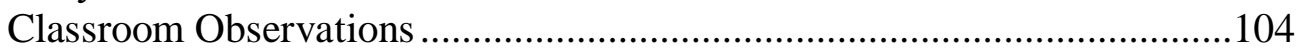

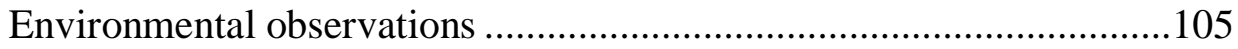

Early childhood professional engagement........................................106

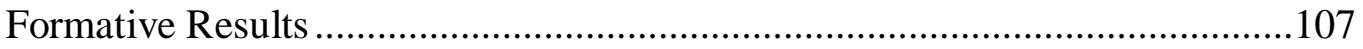

Teachers' Perceptions of Healthy Lifestyle Values and Beliefs

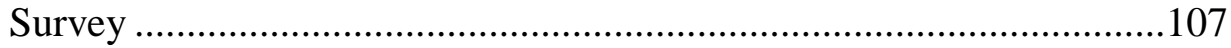

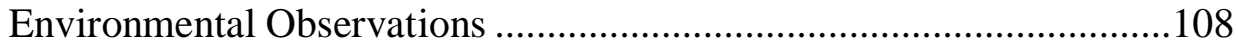

Early Care Professional Engagement Observations ............................110

Development of Training Modules ......................................................112

Physical Activity Training ............................................................113

Sleep Training ....................................................................... 121 
Process Evaluation Measures for Physical Activity and Sleep ..................125

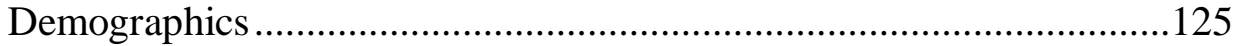

Education Session Evaluation ...........................................................126

Physical Activity Training Measures ....................................................126

Early Care Professional Physical Activity Knowledge Rating .............126

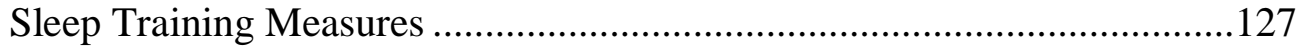

Early Care Professional Sleep Knowledge Rating ..............................127

Early Care Professional Sleep Beliefs Rating .....................................127

Evaluation Results ...................................................................................128

Early Care Professionals Characteristics - Physical Activity Training ......128

Early Care Professional Physical Activity Knowledge Rating ..................128

Classroom Observations for Physical Activity.........................................129

Education Session Evaluation for Physical Activity ................................129

Early Care Professionals Characteristics - Sleep Training ........................130

Early Care Professional Sleep Knowledge Rating ....................................131

Early Care Professional Sleep Beliefs Rating ..........................................131

Classroom Observations for Sleep Training............................................131

Education Session Evaluation for Sleep Training ....................................132

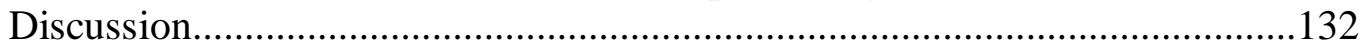

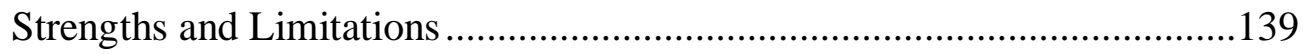

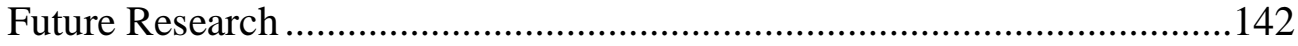

Implications for Practice........................................................................ 143

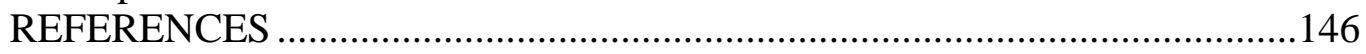

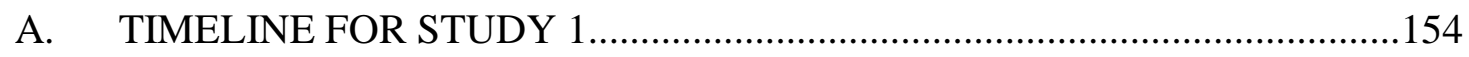

B. PROGRAM EVALUATION ................................................................... 160

C. EARLY CARE PROFESSIONAL PHYSICAL ACTIVITY KNOWLEDGE RATING ..............................................................163

D. EARLY CARE PROFESSIONAL SLEEP KNOWLEDGE RATING ............166

E. EARLY CARE PROFESSIONAL SLEEP BELIEFS RATING....................169 


\section{LIST OF TABLES}

Table 1 Early Care Professionals Beliefs and Values of Healthy Lifestyle Habits .63

Table 2 Correlations among Beliefs and Values of Healthy Lifestyle Habits .64

Table 3 Means and Standard Deviations of Beliefs and Values of Physical Activity .68

Table 4 Means and Standard Deviations of Beliefs and Values of Sleep ....................70

Table 5 Means and Standard Deviations of Beliefs and Values Regarding Role in Assisting Children in Establishing Health Habits

Table 6 Correlations among Demographics and Beliefs and Values of Healthy Lifestyle Habits

Table 7 Design for assigning coders to classrooms for fully crossed IRR design......104

Table 8 Early Care Professionals Beliefs and Values of Healthy Lifestyle Habits

Table 9 Means and Standard Deviations for Program Evaluation of Physical Activity Training 130

Table 10 Means and Standard Deviations for Program Evaluation of Sleep Training. 


\section{CHAPTER I}

\section{INTRODUCTION}

Obesity is a critical health concern for the United States (U.S.) population beginning with the youngest citizens. The percentage of children under the age of 5 years in the U.S. who are classified as obese is $13.9 \%$ (State of Obesity, 2018). States such as Mississippi have even higher rates for children under the age of 5 (i.e., 14.5\%), with certain areas of the state higher than the state average (e.g., 15.7\% Holmes County). These staggering rates of children who are obese or overweight are a cause for concern given the well-established links between childhood obesity and adult obesity (Cloutier, Wiley, Wang, Grant, \& Gorin, 2015; Temple \& Robinson, 2014), and the connections between obesity and a multitude of adverse health outcomes (Ogden et al., 2016; Sahoo et al., 2015; Xu \& Xue, 2016).

A number of potential contributors to obesity have been identified, which include but are not limited to poverty, ethnicity, diet, physical activity levels, sleep, and the influence of adults, the latter of which is critical during early childhood when the foundation for healthy habits is laid (Natale et al., 2014). Holmes County in Mississippi, for example, ranks $80^{\text {th }}$ for health outcomes, $82^{\text {nd }}$ for health factors, and $82^{\text {nd }}$ for healthy behaviors out of 82 counties (Liveability, 2018). The poverty rate for the county is $45 \%$ compared to the national average of $14 \%$, with females between the age of $25-34$ years being the largest population living in poverty. The average annual household income of 
Holmes County residents is $\$ 20,800$ compared to $\$ 40,000$ in Mississippi and $\$ 55,000$ in the United States (DataUSA, 2018). The health of a county is often measured by access to affordable, quality health care, but it also takes into consideration the health choices citizens make putting Holmes County in last place out of 82 counties for healthy behaviors (e.g., smoking, physical activity; Livability, 2018). Health issues reported by adults 18 years or older in Holmes County include high blood pressure reported by $53.4 \%$ compared to $41.3 \%$ in the state and Type 2 diabetes reported by $21.4 \%$ compared to $13 \%$ in the state (Mississippi State Department of Health, 2018). The life expectancy for males in Holmes County is 67 years compared to 71.9 in Mississippi and 76.7 in the U.S. (Institute for Health Metrics and Evaluation, 2018).

The dire situation facing young children in places such as Holmes County points to the need for research to identify avenues to improve outcomes. Early care and education classrooms, specifically guided by the early care professional, have been identified as settings where healthy lifestyle habits are developed (De Marco, Zeisel, \& Odom, 2015; Henry, Umoren, Kim, Zittel, \& Derscheid, 2017). Thus, it is important to understand what early care professionals believe and know about healthy lifestyle habits in early childhood and how those beliefs translate into classroom designs and activities that either promote or limit healthy habits in the classroom.

\section{Theoretical Framework}

Bronfenbrenner's ecological theory (Bronfenbrenner, 1977) is an appropriate framework for the study of early care professionals' beliefs and values of healthy lifestyle behaviors and the impact their beliefs have on the classroom environment.

Bronfenbrenner's Ecological Model of Development considers the various environments 
(e.g., home, early care and education center, community) children experience and the adults who influence their lives. Bronfenbrenner's model has the child at the center of the environment with a variety of adults influencing behaviors (Preskill, Jones, \& Tengue, 2013). After a child's own family members, the adult most likely to spend large amounts of time with and influence development is the early care professional (Story, Kaphingst, \& French, 2006; Brown, Googe, McIver, \& Rathel, 2009; Neelon, Ostbye, Hales, Vaughn, \& Ward, 2016). Therefore, early care professionals who understand the importance of establishing healthy lifestyle behaviors and the role they play in a positive life trajectory are more likely to model appropriate behaviors and provide activities that promote the development of healthy habits (U.S. Department of Health and Human Services \& U.S. Department of Education, 2016); ultimately leading to children establishing healthy habits early in life.

Bronfenbrenner's original theory of human development first proposed in the 1970s underwent several changes prior to his death in 2005, and even though it was described as a theory of human development, the developing individual was always viewed as being influenced by others as well as influencing others (Rosa \& Tudge, 2013). The ecological model is represented by circles with the inner most circle being the most proximal setting in which a child is located and able to interact with others (e.g., home, early care and learning center) and is referred to as the microsystem (Bronfenbrenner, 1974). The microsystem includes the immediate environments a child has direct contact with and the interactions within these environments serve to influence development. For the current study, the microsystem is the early care and education facility where early care professionals provide supervision and activities for young children. 
Bronfenbrenner's second circle is called the mesosystem, which represents the interactions found within two or more microsystems. For example, if sleep in the home environment is suboptimal, then it may influence the behaviors and sleep of the child in the early education facility. If and how the early care professional works with the family to improve the child's sleep has an impact on the child's development. The reciprocal relation between the early care facility and the home provides opportunities to improve child outcomes in both environments.

The next component of Bronfenbrenner's theory is the exosystem, which includes settings that the individual does not have direct contact with but still influences their development. For example, children who attend Head Start centers are influenced by the decisions of Head Start administrators. The administration makes decisions related to curriculum as well as classroom and playground equipment that influence a child's opportunities for healthy interactions.

The macrosystem, the broadest layer of Bronfenbrenner's model, includes the values, ideas, and attitudes of a culture (Bronfenbrenner, 1977). For example, in early care and education programs, state governments set rules and regulations regarding the amount of physical activity and sleep a child should have during the day. The state government also sets the number of required professional development hours an early childhood professional must obtain each year to remain eligible to teach. These rules and regulations play a large role in the early childhood setting, including practices related to children's health. Additionally, the values and customs of the area a child grows up in can influence their health habits. That is, the culture of the early care professional (e.g., early care and education center, professional development, health habits) may not value 
healthy habits and as a result the individual may not place importance on these in their classroom, thus having a significant impact on the development of the children. This impact is particularly important given that children learn health habits early in life (Freedman \& Alvarez, 2010; Muckelbauer, Kalhoff, Muller-Nordhorn, \& Kersting, 2011) that will influence their development over time.

Time is the final component of the theory, which is referred to as the chronosystem. The chronosystem considers all the events and changes a person experiences in life and how these facilitate development over time or how a person develops within a certain time in history (e.g., the depression). For this project, the chronosystem could include components such as the timing of exposure to health habits or children living in a time period in which early care and education programs such as Head Start is recognized as an important safety net for at-risk children. Bronfenbrenner's ecological model provides a clear lens to examine how the early care professional's beliefs and values regarding healthy lifestyle behaviors may impact the environment by the interactions, characteristics of each individual, the location of the interactions, and the fact that encounters are ongoing and occur over longer periods of time.

\section{Defining Obesity}

Individuals who do not practice healthy lifestyle habits are at an increased risk of developing obesity, so it is important to understand obesity, the potential contributors, and the impacts. The Centers for Disease Control and Prevention (CDC) defines obesity as weight that is greater than what is considered healthy for a person's height (Centers for Disease Control, 2018). Obesity is a medical condition in which unnecessary body fat accumulates to the point that it can adversely affect a person's overall health. The CDC 
uses body mass index (BMI) as the measure to determine obesity and overweight in adults and children. BMI is determined by dividing a person's weight in kilograms by the square of height in meters. In adults, a BMI of $30 \mathrm{~kg} / \mathrm{m}$ is considered obese, with the range from $25-30 \mathrm{~kg} / \mathrm{m}$ considered overweight. For children and adolescents, BMI is ageand gender-specific and is referred to as BMI-for-age. A child's weight status is determined by age- and gender-specific percentile rather than the BMI categories for adults due to the fact that a child's body composition varies by age and between genders. Children are considered overweight when BMI is at or above the $85^{\text {th }}$ percentile and below the $95^{\text {th }}$ percentile when compared to children of the same age and gender (Centers for Disease Control, 2018).

Recent research from Ogden and colleagues (2014) shows that 34.9\% of U.S. adults are obese impacting approximately 78.6 million people, with estimated rates of obesity as high as $47.8 \%$ in African American populations (U.S. Department of Health and Human Services, 2018). While obesity among children aged 2 to 5 years was $13.9 \%$ in 2003-2004, and then decreased to $9.4 \%$ in 2013-2014, it remains a concern for large numbers of preschool children (Ogden et al., 2016). For example, obesity rates among Latino preschool children are $15.6 \%$, with African American at 10.4\%, compared to Caucasian children at 5.2\% and Asian children at 5\% (NHANES, 2011-2014 data). Obesity is of particular concern for ethnic minorities living in poverty. Women, Infants, and Children (WIC), a national program which provides nutritional support throughout the U.S. to low-income pregnant, postpartum, and breastfeeding women, infants, and children up to age 5 who are at increased risk for inadequate nutrition due to poverty, reports that approximately $14 \%$ of the children enrolled in the program are obese (State 
of Obesity, 2018). These numbers are even more concerning for a state like Mississippi, where more than half of working minority families fall below $200 \%$ of the poverty level (Working Poor Families Project, 2018).

\section{Contributors to Obesity}

Behavioral factors, such as diet, physical activity, and sleep contribute to the overall health of the general population (Sahoo et al., 2015) and are known contributors to obesity (Xu \& Xue, 2016). Obesity is relatively easy to identify, but difficult to overcome due to the complexity of the causes, which may include genetics, biological, behavioral and cultural factors (American Academy of Child \& Adolescent Psychiatry, 2011). Thus, it is important to understand and address the roles of behavioral factors, which may be altered by intervention.

\section{Diet}

It is well documented that the amount and type of food people consume is important for weight control and health (Ford, Slining, \& Popkin, 2013; Hill, Drougas, \& Peters, 1993; Larson, Ward, Neelon, \& Story, 2011). The U.S. government has promoted this knowledge through large campaigns since 1916, with the newest version called MyPlate. The MyPlate food guidance system emphasizes the importance of healthy eating patterns to maintain health and lower risk of disease (see www.choosemyplate.gov for more information) through a visual of a well-balanced nutritional plate. Balanced nutrition, such as including fruits and vegetables as half of your plate per meal, and appropriate portion sizes are considered to be essential to a healthy diet. 
While the government has promoted a healthy diet message since the early 1900s, research shows that the majority of Americans do not consistently consume the recommended daily amounts of the dietary guidelines set forth by the U. S. Department of Agriculture (USDA; Moore \& Thompson, 2015). Balanced nutrition is even less likely to be obtained for certain segments of the population, specifically children who live in low-income households (Braveman, Cubbin, Egerter, Williams, \& Pamuk, 2010). Often, accessibility to fresh and nutritious foods and higher prices of nutritious foods within impoverished communities (Larson et al., 2011; Liu et al., 2014) are reported as reasons that children living in poverty are at greatest risk. To ameliorate this discrepancy, the government has implemented programs for lower income populations, including free/reduced school meals, WIC, and the supplemental nutrition assistance program (SNAP). These programs, in addition to government regulations, are put in place to ensure school nutrition standards align with the latest nutrition science, and are showing success in improving the eating habits of Americans. For example, SNAP-Ed programs delivered through land-grant universities find more than half of the participants reported consuming closer amounts of recommended nutrition following the program (National Academy of Sciences, 2013).

Given the importance of diet in the prevention of childhood obesity, it has been researched in early care and education programs throughout the U.S. (Ford et al., 2013; Fox, Condon, Briefel, Reidy, \& Deming, 2010; Summerbell et al., 2012; Yavuz, van Ijzendoorn, Mesman, \& van der Veek, 2015) and from these studies guidelines have been developed. For example, Caring for Our Children - National Health and Safety Performance Standards: Guidelines for Out-of-Home Child Care Programs (CFOC) 
provides five standards regarding menus: (1) must be posted or made available to parents, (2) must be dated, (3) must reflect food served, (4) must be planned in advance, and (5) must be kept on file. Research of state licensing regulations reveals that $14 \%$ of states included regulations on all five standards, $25 \%$ had regulations on four of the five standards, and 20\% did not have regulations on any of the five standards (Benjamin et al., 2009). Mississippi is one of the states that meets all five standards of CFOC helping to ensure healthy nutrition for children enrolled in licensed early childhood education programs. Each state has specific standards related to nutrition regarding the provisions of meals and snacks that must be met (Larson et al., 2011; Story et al., 2006). The Child and Adult Care Food Program (CACFP), which provides funding to reimburse child early care and education providers for meals and snacks, shows an increase in the consumption of both milk and vegetables, which may also reduce overweight and underweight prevalence in young children (Korenman, Abner, Kaestner \& Gordon, 2013). Centers participating in the CACFP program must follow strict standards for meal and snack components from the USDA leaving early care professionals in the classroom unable to implement changes for the children in their care (Bucholz, Desai \& Rosenthal, 2011). Of the three factors previously mentioned (i.e., diet, physical activity, sleep) that are known to contribute to the healthy development of young children, early care professionals have the least amount of influence on nutrition, and thus this will not be assessed in this study.

\section{Physical Activity}

Research supports physical activity as beneficial for health and development across the lifespan, even in the youngest age groups (Hesketh et al., 2015). Physical activity is a highly regarded intervention to improve health conditions (e.g., obesity) and 
promote health and optimal development in both adults and children (Gagne \& Harnois, 2014; Centers for Disease Control, 2018). While information on physical activity has not been as widely promoted as the role of nutrition in the U.S., it is becoming more widespread. In 2008, the first-ever national guidelines for physical activity were released, which included recommended amounts of physical activity for children, adolescents, adults, and older adults along with suggestions for increasing physical activity (Office of Disease Prevention and Health, 2018). A decade later research shows that 52\% of Americans adults are meeting the physical activity guideline for aerobic activity (at least 30 minutes a day), while only $28 \%$ are meeting the guidelines for both aerobic and muscle-strengthening activity (State of Obesity, 2018). Low-income individuals engage in less physical activity than the general population putting them more at risk for health problems (Active Living by Design: Low Income Populations, 2017). Often, the opportunities for physical activity are limited within impoverished communities due to safety concerns, lack of parks and funds to participate in organized sports; all reasons that children living in poverty are more at risk than their peers from higher socioeconomic families for obesity (Fan \& Jin, 2013).

Some portions of the adult population are at greater risk for not obtaining recommended levels of physical activity, and one of those is adults with young children in the home (Adamo, Langlois, Brett, \& Colley, 2012; Bellows-Riecken \& Rhodes, 2008). These findings suggest physical activity is not necessarily being modeled within many homes and a significant predicator of a child's physical activity is the physical activity of the parent (Adamo et al., 2012; Bellows-Riecken \& Rhodes, 2008). Therefore, 
low levels of physical activity are not just a concern in adult populations, but also with children of all ages.

Research on the physical activity levels of preschool children (2 - 6 years of age) confirms that $54 \%$ of 10,316 participants achieved the suggested minimum of 60 minutes of physical activity a day, with boys consistently being more physically active than girls (Tucker, 2008). In addition, research shows that $61.5 \%$ of 4,500 children aged $9-13$ years of age do not participate in any organized physical activity outside of school and $22.9 \%$ do not engage in any physical activity during their free time (National Institute of Health, 2018). A total of $28 \%$ of Americans over the age of 6 are physically inactive (U.S. Department of Health and Human Services, 2018). These levels may be even less optimal for children from low-income families (Dolinsky, Namenek Brouwer, Evenson, Siega-Riz, \& Ostbye, 2011). For example, children from low-income neighborhoods may have less opportunities to run and play outside due to unsafe neighborhood environments (Sahoo et al., 2015), which highlights the potential importance of physical activity within the early childhood center. Additionally, research shows that parents perceive their child as being more physically active than they actually are (Corder, Crespo, van Sluijs, Lopez, \& Elder, 2012). For instance, parents in the Corder and colleagues (2012) study reported that their children had obtained recommended amount of physical activity for the day, however, accelerometer data indicated children had obtained less than 60 minutes of physical activity on $75 \%$ of the days assessed. These findings regarding the family suggest that parents of young children may not be encouraging physical activity.

Research with 3- to 5-year-old preschoolers indicates the 5-year-old children in the study engage in greater amounts of physical activity than the younger children and in 
general, children engage in more activity on the weekends than during the week (Dawson-Hahn, Fesinmeyer, \& Mendoza, 2015). These findings raise a question about the preschool environment and what modeling and encouragement for physical activity is provided during the week by early care professionals. Research suggests that early care professionals often recognize the importance of physical activity for preschool children, but tend to overestimate the activity levels in their classroom (Dyment \& Coleman, 2012; Hesketh et al., 2015; Tucker, van Zandvoort, Burke \& Irwin, 2011). For example, research with 16 early care professionals in Australia shows that teachers all agree physical activity is extremely important for preschool children, but 13 of those surveyed believed the children in their care were receiving sufficient physical activity even though the children were involved in sedentary activities for $46.1 \%$ of the outdoor time (Dyment $\&$ Coleman, 2012). This pattern is similar in Ontario where $96 \%$ of early care professionals in the study were aware of the importance of physical activity for young children, but believed that children were active enough on their own and that they did not need to provide structured activities to facilitate physical activity (Tucker et al., 2011).

Data from 203 early care professionals representing 32 early care and education programs in Massachusetts indicated that $97 \%$ of early care professionals recognized their role in encouraging physical activity of children in their care, but $13.3 \%$ reported being too tired to exercise (Hesketh et al., 2015). Research with 82 early care professionals in Mississippi indicated that $83 \%$ of them recognized early childhood as the period in life when children are learning healthy lifestyle habits and $92 \%$ felt the nutrition and activity practices of the early care and education setting could negate less healthy habits children are learning within the home environment. However, $44 \%$ of the early 
care professionals did not recognize that their own nutrition and physical activity habits may impact the children they work with on a daily basis (Elmore-Staton \& Parker, 2015). It may be that early care professionals think children are receiving enough physical activity on their own or that early care professionals themselves are tired and unmotivated to participate in physical activity, so they do not feel the need to encourage or provide additional opportunities to promote movement. Research shows that early care professionals tend to give more priority to unstructured play opportunities than providing games and structured movement activities designed to promote physical activity during outside time (Coleman \& Dyment, 2013). When adults join children in movement activities demonstrating a positive attitude, children tend to spend more time in gross motor activity and gain vital gross motor skills (Odom, Pungello, \& Gardner-Neblett, 2012). Taken together, the data suggest that early care professionals may not recognize (1) the role their own health habits have on children's physical activity levels and (2) that how they structure the classroom and outside environments may contribute to the amount of physical activity a child receives each day.

A variety of environmental factors may also impact the amount of physical activity young children experience on a daily basis. Focus groups with 49 early care professionals identified teacher-reported barriers to active physical play, which included adverse weather conditions (e.g., rain, cold, extreme heat), potential sickness, teacher discomfort with the outdoors (e.g., getting sweaty, insects, noise and chaos), workload required to take the children outside (e.g., putting on coats, applying sunscreen, taking portable equipment outside), supervision of inappropriate playground equipment (e.g., too high, broken), and personal ailments (e.g., asthma, allergies, obesity; Copeland, 
Sherman, Kendeigh, Kalkwarf, \& Saelens, 2012). Financial issues such as lack of playground equipment and no indoor space for active play also limit the amount of physical activity children experience in the early childhood environment (Copeland et al., 2012). Early care and education programs are expensive to operate due in part to the labor intensity of the industry. Even in centers where tuition is high, it is hard to maintain a profit margin, which makes it difficult to ensure a safe and developmentally appropriate playground (Child Care Aware of America, 2015). Dyment and Coleman (2012) show that early care professionals feel limited in their ability to facilitate active physical play based on the number of children they supervise on the playground and the lack of training in physical activity. Research finds that early care professionals feel that additional resources and equipment along with staff development could increase physical activity for young children (Tucker et al., 2011). Thus, additional training on how to overcome barriers, such as space and funding, as well as more information on how to facilitate greater activity levels is imperative.

\section{Sleep}

Sleep plays a vital role in overall health, as it promotes mental as well as physical health in both adults and children (Gutierrez-Repiso et al., 2014; Spruyt, Alaribe, \& Nwabara, 2015). Sleep is a complex behavior that serves a multitude of functions, including regulation of appetite hormones (Knutson Spiegel, Penev, \& Van Cauter, 2007), glucose (Gooley, 2014) and blood pressure. For example, the body perceives short sleep as a stressor, and it attempts to store energy to ward off the stressor. One of the ways that it does this is by increasing hunger hormones and decreasing the hormones that tell your brain that your stomach is full (Gangwisch, Malaspina, Bodlen-Albala, \& 
Heymsfield, 2005). Research shows that sleep loss in the short-term results in decreased glucose tolerance and increased blood pressure, while long-term sleep loss is associated with a higher BMI and increased risk for diabetes and hypertension (Gooley, 2014; Van Cauter \& Spiegel, 1999) and reduced physical activity levels (Knutson, et al., 2007). For children in particular, poor sleep (i.e., short or fragmented) can lead to an array of healthrelated problems such as obesity (Halal et al., 2016) and unintentional injury (Dahl, 2008).

While research has noted the critical role of sleep in health, the importance of sleep has not been widely promoted to the general public by health care professionals in the U.S. until the last few years. For example, a study of 121 primary health care clinics found that $100 \%$ of health screeners contained questions related to smoking and alcohol use, $93 \%$ contained questions related to healthy diet, and $86 \%$ contained questions related to physical activity compared to only $43 \%$ containing questions on sleep (Perry, Patli, \& Presley-Cantrell, 2013). Sleep health is beginning to receive more national attention as it is now included in the Healthy People 2020 goals and will be included in the next Behavioral Risk Factor Surveillance System (BRFSS; Morgenthaler, et al., 2015). The National Sleep Foundation promotes an annual Sleep Awareness Week and the American Academy of Sleep Medicine has launched the National Healthy Sleep Awareness Project (American Academy of Sleep Medicine, 2018) in efforts to educate the public about sleep. However, in 2014, it was estimated that 35.2\% of Americans had short sleep duration (less than 7 hours per night), with Native Hawaiians/Pacific Islanders having the highest rate at $46.3 \%$ followed closely by African Americans at $45.8 \%$ (Centers for 
Disease Control, 2018). The rate for shortened sleep for adults in Mississippi (37.2\%) is higher than the national average at 35.2\% (Centers for Disease Control, 2018).

The National Sleep Foundation recently altered its recommendations of sleep amount for preschoolers (3- to 5-years old) from 11-13 hours to 10-13 hours (Hirshkowitz et al., 2015). Research shows that few children obtain the recommended amount of sleep (Acebo et al., 2005; Bagley, Kelly, Buckhalt, El-Sheikh, 2015). For example, Scharf and DeBoer (2014) found that in 2013, the average nighttime sleep for a 4-year-old was 10.47 hours, which is an hour less than the average for children of that age in the $1970-80$ s. Results of a recent study indicate less than 10 hours of sleep per night between the ages of 1 and 4 years is associated with a $32 \%$ higher risk of being overweight or obese by the age of 4 years when compared to children without short nighttime sleep (Anderson, Andridge, \& Whitaker, 2016; Gutierrez-Repiso et al., 2014; Halal et al., 2016). Shortened nighttime sleep for preschoolers also increases the likelihood of obesity at later ages compared to peers receiving adequate nighttime sleep, which highlights the significant role of sleep in obesity (Anderson et al., 2016; Magee, Caputi, \& Iverson, 2014; Scharf \& DeBoer, 2014). Short sleep duration is linked to obesity in adults and children, but the association between sleep and body weight appears to be stronger in children than adults (McNeil, Doucet, \& Chaput, 2013). Results from a nationally representative sample of children between ages 3- to 12- years-old at baseline indicates, after controlling for initial levels of BMI, children who woke earlier, had a later sleep onset time, or experienced shorter sleep duration, had higher BMIs in five years with a greater likelihood of being overweight (Snell, Adam, \& Duncan, 2007). 
One reason sleep is strongly linked to obesity is that appetite hormones are regulated during sleep (Taheri, Lin, Austin, Young, \& Mignot, 2004). Specifically, loss of sleep results in a significant decrease in leptin, a hormone that indicates to the brain that one is full and satisfied. Sleep loss also affects the production of ghrelin, which is an appetite stimulant, signaling to the brain that one is hungry. For example, a study by Knutson and colleagues (2007) reports that sleeping four hours instead of nine hours resulted in a $28 \%$ increase in ghrelin production and an $18 \%$ reduction in leptin. The reduction of leptin and the elevation of ghrelin are likely to increase appetite, which may in part explain the shortened sleep-obesity link (Taheri et al., 2004). Thus, children and adults who receive less sleep are at a higher risk for obesity than their counterparts who obtain higher levels of sleep.

Another pathway that partially explains the sleep-obesity link is the impact of sleep on physical activity levels (Atkinson \& Davenne, 2007). Research indicates that individuals who experience short sleep at night participate in less physical activity during the day and report typical work requirements to be more intense (Gutierrez-Repiso et al., 2014). These findings suggest that sleep duration could impact the amount of physical activity children experience in the early childhood classroom not only through the reduced sleep amount they receive, but also because the early care professional may not be providing opportunities for physical activity as a result of their own sleep habits.

Sleep consolidation, going from multiple sleep episodes across the day to one long sleep period, is a normative developmental task for young children and typically occurs as children reach 3- to 5-years of age (Acebo et al., 2005; Galland, Taylor, Elder, \& Heribson, 2012; Weissbluth, 1995). Early care and education programs often have a 
scheduled naptime of up to two hours for all age children. However, a negative association exists between the length of napping and the duration and quality of young children's nighttime sleep (Chen, 2017; Staton, Smith, \& Thorpe, 2015). This data supports that there is a delicate balance that early care professionals need to know and understand regarding individual children's sleep needs and ways to provide appropriate opportunities.

The early care professional has the unique opportunity to recognize and identify children who are not getting enough sleep at night by the behaviors exhibited in the classroom, unlike parents who expect their child to be tired at the end of the day (Hall, Scher, Zardman-Zait, \& Espezl-Warnock, 2011). The signs of inadequate nighttime sleep in young children differ from the signs in adults and early care professionals could benefit from training to recognize these differences (Burnham, Gaylor, \& Wei, 2016). That is, whereas adults usually yawn and become still when they are tired, children often become hyperactive, uncooperative with others, and misbehave. Not all adults recognize these behaviors as potentially stemming from shortened or disruptive sleep, yet this is critical for early care professionals to identify and communicate with parents.

Evidence from research studies support the importance of early care professionals making accommodations for individual differences in daytime sleep. Diversity in the culture (e.g., ethnicity; Chen, 2017) and environmental factors (e.g., socioeconomic factors; Williams et al., 2016) and the timing of brain development (Burnham et al., 2016; Staton et al., 2015) are correlates of sleep. For example, data show African American children habitually sleep a suboptimal amount compared to Caucasian children and therefore napping might be more important for these children (Spruyt et al., 2015). 
According to research on a large sample of 2-year-olds $(N=3,050)$, African American children napped 17 minutes longer than Caucasian children (Burnham et al., 2016). This finding supports research by Crabtree et al. (2005) that shows African American children have later bedtimes than Caucasian children, which may influence the duration of their naps. Research suggests that children from low-income homes (Hughes et al., 2007) and of ethnic minority groups (Natale et al., 2014) are at a greater risk for obesity than children from higher socioeconomic status or Caucasian backgrounds (U.S. Department of Health and Human Services, 2018). Additionally, some research has suggested that children who stop napping at an earlier age than typical (usually by age 5) may do so because of a faster pace in brain development (Spencer et al., 2016). Given that children living in poverty or from ethnic minority backgrounds are at greater risk for obesity, research and interventions should specifically target these populations. Early care professionals also need to be aware of these individual differences and be prepared to deal with them within the group setting.

While early care professionals can share information with families about appropriate sleep requirements, they are not able to impact the amount of sleep children receive at night. However, they can play a role in promoting age-appropriate naps in their classroom. Recent research supports that naps have a benefit on learning and emotional behavior in young children and may promote the overall goals of early childhood education (Spencer et al., 2016). However, with the increased focus on curriculum by policy makers, naps are not being valued as an important part of the early childhood day and are sometimes eliminated to allow more time for academics (Kurdziel, Duclos, \& Spencer, 2013). 
Child care regulations in Mississippi specify that children should nap during the day, but the requirement is not closely monitored to ensure it is being met (Mississippi State Department of Health, 2018). Most state regulations do not give specifics on napping, but address infant sleep position, crib safety, supervision of nap, and sudden infant death syndrome risk protection (Burnham et al., 2016). Early care professionals can encourage age-appropriate sleep habits by providing low lighting, comfortable bedding, soft music, and a calm routine just prior to naptime (see National Sleep Foundation website for sleep hygiene tips). For children who are not receiving adequate sleep at night, naptime at the early childhood education center may help to bridge the gap to ensure healthy development.

\section{The Impacts of Obesity}

Given the high rates of childhood obesity, it is important to acknowledge the effects both immediate and long-term on health and well-being. Obese children and youth are more likely to have prediabetes (Sahoo et al., 2015) and are at a greater risk for bone and joint problems (Xu \& Xue, 2016), sleep apnea (Lo et al., 2013), and social and psychological problems such as poor self-esteem and stigmatization (Ogden et al., 2016). Long-term effects of obesity in children include being obese as an adult (Esquivel et al., 2016), which leads to a greater risk for adult health problems such as heart disease, type 2 diabetes, stroke, several types of cancer, and osteoarthritis (Lanigan, 2012; Natale et al., 2014). Further, adult obesity and the medical conditions associated with obesity result in increased cost for health care provisions creating a financial burden on society (Yavuz et al., 2015). 


\section{Motor Development}

Piaget's theory of child development emphasizes the importance of physical movement in a child's capacity to learn about the environment and supports allowing children to actively move to develop not only physically, but also cognitively and socially (Gehris, Gooze, \& Whitaker, 2014). The addition of physical education to school programs in the U.S. during the late 1920s was based on Dewey's theory of education as a process of meaningful activity rather than rote learning. This addition ultimately led to a more progressive educational system (Thorburn \& Macallister, 2013; Wyett, 1998) and to research questions on the benefits of physical play on children's education, health, and development (Pellegrini \& Smith, 1998).

Obesity during early childhood impacts the development of muscle and the skeleton influencing performance in motor function and physical exertion measures (Galvan, Uauy, Lopez-Rodriguez, \& Kain, 2014). Gross motor skills provide the framework and confidence for children to engage in games, sports, and other activities that may help to prevent obesity throughout life (Khalaj \& Amri, 2013). However, research suggests a significant negative correlation between obesity and gross motor development, such that, as BMI levels increase, gross motor skills decrease (Nervik, Martin, Rundquist, \& Cleland, 2011). Children at a healthy weight outperform children with obesity on both gross and fine motor skills (Gentier et al., 2013). Thus, finding ways to improve health habits of children during the early childhood years may help to prevent obesity and allow children to develop the motor skills necessary to maintain a healthy weight throughout their lifetime (Nervik et al., 2011). 


\section{Social-Emotional Development}

The National Heart, Lung, and Blood Institute reports that emotional impacts of obesity for children may include issues with body image, a lack of concern for health, and more risk-taking behaviors as a result of teasing, physical harm, and name calling by their peers (Williams, 2011). Children who are overweight often face social prejudices with their peers resulting in lower self-esteem, greater shame, and teasing than their peers with a healthy weight (Latner \& Stunkard, 2003). For example, research finds preschool children have already formed negative perceptions of peers who are overweight, with results indicating that they perceive them as being 'mean' rather than 'nice' (Su \& Di Sant, 2011), leading to social stigmatization early in life. These findings align with results from studies conducted with older children, which suggest youth who are obese or overweight experience some daily bullying or rejection specifically related to their physical size (Lumeng et al., 2010). In turn, data shows these youth experience an emotional impact from their weight such as body image and lower self-esteem (Williams, 2011). Wang and Veugelers (2008) report from a sample of 4,945 students that engaging in physical activity has a positive effect on self-esteem and better self-esteem helps to protect children from engaging in negative social behaviors. Children who are obese and are stigmatized are more likely to become depressed and face even greater challenges throughout their lifetime regarding their perception of their body (Galvan et al., 2014; Ra, Yun, \& Cho, 2016) than their counterparts. Williams (2011) predicts that by 2040 there could be an increase in social isolation and rejection, depression, suicide, and personality disorders due to the social emotional issues of childhood obesity. These findings 
regarding obesity and the link to self-esteem add evidence to support the promotion of healthy lifestyle habits in the early years.

\section{School Readiness and Academic Achievement}

School readiness, a measure of young children's developmental readiness for formal education, is comprised of not only cognitive abilities, but also social-emotional and physical development (Saluja, Scott-Little, \& Clifford, 2000). Similar to the negative impact of childhood obesity on physical and social-emotional development, cognitive functioning is also affected by overweight and obesity. That is, research finds that obese individuals have an intellectual disadvantage as compared to their non-obese peers (Galvan, Uauy, Corvalan, Lopez-Rodriquez, \& Kain, 2013). Children with obesity tend to be more impulsive, have lower self-regulation, shorter attention spans, and less mental flexibility than their counterparts, all which are important characteristics for academic success (Fields, Sabet, \& Reynolds, 2013). Additionally, longitudinal data indicates the obesity-cognitive functioning link is moderated by gender in that three-year-old boys are at greater risk for negative cognitive outcomes at age five than girls who are classified as obese (Martin et al., 2016).

The LiiNK Project in Texas (modeled after Finland's education system) allows kindergarten and first grade children to have 15-minute unstructured recesses 4 times per day. Initial research analyses reveal children to be more disciplined and focused on tasks in the classroom, and note significant increases in math and reading scores and a reduction in misbehavior during recess (Rhea, Rivchun, \& Pennings, 2016). A metaanalysis of 16 interventions shows a positive correlation between general cognitive function (e.g., perceptual skills, verbal skills, memory, mathematic skills, academic 
readiness and academic achievement) and physical activity (Abadie \& Brown, 2010).

However, other studies suggest that the evidence is unclear as to whether obesity causes cognitive delays or if the delays are a result of socio-economic factors known to increase the likelihood of obesity and impair cognition (Martin et al., 2016). From these research findings, it is evident that obesity impacts physical, social-emotional, and cognitive development in young children and innovative approaches for prevention should be identified and implemented.

\section{Early Education Programs and the Promotion of Healthy Lifestyle Behaviors}

Recent data indicates that approximately 12.5 million preschool children in the U.S. are in some form of early care and education program for at least 33 hours per week (Huye, Bankston, Speed, \& Molaison, 2014). The majority of working parents enroll their preschool children in center-based arrangements such as child care, preschools, or Head Start programs (Larson et al., 2011). Early care professionals who care for children are instrumental in influencing and guiding children's health and development (SigmanGrant, Christiansen, Branen, Fletcher, \& Johnson, 2008). Young children are developing lifestyle behaviors and habits during the first five years of life that will carry them through their lifetime making it the most optimal period for promoting physical activity and healthy sleep (Lanigan, 2012; Natale et al., 2013). However, research with children in 24 early childhood settings finds that up to $89 \%$ of the day is characterized as sedentary and early care professionals rarely encourage children to be physically active or use teacher-directed activities to promote movement (De Marco et al., 2015). A study of 158 African American preschoolers in an urban inner-city attending Head Start indicates that children have limited time to engage in physical movement during the day and the 
physical activity was seldom intense enough to achieve a moderate or vigorous level necessary for health benefits (Shen et al., 2012). During a 50-minute outdoor play period, research showed children were engaged in moderate physical activity for $30 \%$ of the time and children were involved in vigorous physical activity for a quarter of the observation (Dyment \& Coleman, 2012). A similar study of 733 preschool children shows that approximately $14 \%$ of the children did not reach the daily recommendation for moderateto-vigorous physical activity in the early childhood classroom (Vale, Trost, Rego, Abreu, \& Mota, 2015). Given that both parents and early care professionals assume that young children are getting enough physical activity (Corder et al, 2012; Dyment \& Coleman 2012; Tucker et al., 2011), these findings are a cause for concern.

Head Start and Early Head Start are the largest federally funded early childhood programs in the U.S. (Whitaker, Becker, Herman, \& Gooze, 2013) and aim to promote school readiness by providing education, health, nutrition, social, and other services to children from low-income households (Bucholz et al., 2011). Head Start programs reach more than one million low-income children annually and offer an ideal setting to implement obesity prevention programs (Whitaker et al., 2013). Most research on Head Start has focused on cognitive and academic outcomes, while health-related outcomes remain understudied (Lee, Zhai, Han, Brooks-Gunn, \& Waldfogel, 2013). However, recent research suggests that $25 \%$ of Head Start children are obese compared with only 9\% of children age 2 to 5 years-old nationally (Sharma et al., 2013). In a small study of 35 Head Start teachers in Michigan, teachers generally did not agree with the emphasis placed on issues of obesity on the children they work with and expressed beliefs that children generally grow out of preschool weight issues (Lumeng, Kaplan-Sanoff, 
Shuman, \& Kannan, 2008). The early childhood environment, influenced by the beliefs and values of the early care professional, may be contributing to unhealthy behaviors rather than preventing them by the practices early care professionals implement on a daily basis.

\section{The Importance of Establishing Healthy Habits Early in Life}

The first five years of life are the period of time when lifestyle habits, including those related to physical activity and sleep, are established (Freedman \& Alvarez, 2010; Muckelbauer, et al., 2011). Young children are dependent on adults, including early care professionals, to guide them in learning and developing healthy lifestyle behaviors (Natale et al., 2014; Sigman-Grant et al., 2008). Followed by the home, early care facilities are the place children are most likely to learn and develop health behaviors given the large amount of time spent in these settings (Bohn, Haskins, Loo, \& Ahrdendt, 2014). Health and safety are considered one of the key components of quality early care and education and are modeled through a variety of daily activities, such as proper handwashing, choosing healthy foods, and sleep hygiene (Harms, Clifford, \& Cryer, 2005). Research supports that early care professionals, in addition to families, should be a key component of programs designed to improve children's lifestyle behaviors (Summerbell et al., 2012). Thus, early childhood settings are an important avenue to teach children healthy lifestyle behaviors as growing numbers of children attend these programs; however, recent studies suggest that children who attend early care and education programs may be at greater risk for obesity than children who are at home with a parent (Costa, Adams, Phillips, \& Neelon, 2016; Neelon, Taveras, Ostbye, \& Gillman, 2014). 
Current research indicates only 5 out of 16 obesity prevention programs implemented in the early childhood setting have shown positive results in preventing and managing overweight or obesity in preschool children by targeting both nutrition and physical activity using the early care professional as the interventionist (Ling, Robbins, \& Wen, 2016). One reason for the lack of success with the obesity prevention programs in early care settings may in part stem from the early care professionals themselves. The early care professionals' high levels of job stress, lack of knowledge regarding health, and poor personal health are known to affect their ability to serve as a positive role model for healthy behaviors (Zhai, Raver, \& Li-Grining, 2011). These factors may specifically affect their ability to serve as the interventionist in an obesity prevention program. However, no data is known to be available regarding the impact of the early care professionals' own health-related behaviors (Ling et al., 2016) on the promotion of healthy habits within the classroom.

Programs that are successful in assisting children with the development of healthy habits begin early and incorporate an ecological model prove to be the most effective for the long term (Cloutier et al., 2015). A systematic review conducted in 2010 of childhood obesity prevention programs shows that approximately one-third of the programs implemented in early childhood centers improved physical activity levels by implementing multi-faceted approaches to service delivery, such as increases in outdoor time and exercise programs for children targeting both parents and early care professionals (Hesketh \& Campbell, 2010). A similar review finds that intervention programs focused on the micro-environment, including families and early childhood 
programs, show small effects in variables related to obesity, which may serve as protective factors against obesity throughout a lifetime (Monasta et al., 2011).

\section{Early Childhood Professionals and the Promotion of Healthy Lifestyle Behaviors}

A number of obesity prevention programs are designed to be delivered in the early childhood classroom putting early care professionals in an important role in the battle to improve the health of young children (Larson et al., 2011; Story et al., 2006). Seminal research by Calder (1994) suggests the health of early care professionals is critical to their ability to provide appropriate care for the children, as well as model healthy behaviors due in part to the fact that they control the health practices in their classroom. Calder also suggests that early care professionals tend to focus little attention on their own health and even when they possess knowledge about children's health issues, they do not apply the same principles to themselves. Research on the actual health of the early care professional is limited and the health of the adult and the health of the children are not independent (Slack-Smith, Read, Darby, \& Stanley, 2006). Early care professionals spend long periods of time during the work week with children and are keenly aware of their physical activity levels; however, research findings from 1,000 professionals in Georgia show that they do not believe their health impacts the care they provide for the children (Baldwin, Gaines, Wold, Williams, \& Leary, 2007). Baldwin and colleagues (2007) report 50\% of these individuals have a BMI putting them in the overweight or obese category. Research indicates that among Head Start early care professionals in Texas there is a high prevalence of weight issues, with $79 \%$ of the sample reporting being overweight or obese, and that the professionals indicate a desire to lose weight by utilizing a wide variety of weight-loss practices (Sharam et al., 2013). 
Data from the Pennsylvania Head Start Wellness Survey indicates that women working in Head Start and Early Head Start programs have a higher prevalence of physical and mental health issues compared to a national sample of women of similar age, race/ethnicity, and marital status (Whitaker et al., 2013). A recent review of studies on the quality of early childhood environments points out that individual early care professional characteristics are possible predictors of the overall classroom effectiveness (La Paro, Thomason, Lower, Kintner-Duffy, \& Cassidy, 2012).

High quality early childhood education depends on a high-quality staff who are able to take their understanding of child development and apply it in the early childhood classroom to provide developmentally appropriate learning opportunities designed to promote academic learning and healthy lifestyle behaviors (U.S. Department of Health and Human Services, 2018). According to the Center for the Study of Child Care Employment, despite the rising cost of early childhood services since 1977, early care professionals are still earning less than adults who work in the fast food industry, and $46 \%$ of them reside in a family that is receiving support from at least one of four public support programs. The financial stress of early care professionals puts them at risk for physical and mental health issues, which may limit their ability to provide appropriate learning environments for young children in relationship to healthy lifestyle behaviors (Whitebook, Phillips, \& Howes, 2014).

\section{Licensing Regulations and the Impact on Healthy Lifestyle Behaviors}

\section{Diet}

As previously mentioned, diet in the early care facility is addressed in each state with specific standards that must be met (Larson, et al., 2011; Story et al., 2006). In 
addition, the CACFP follows the USDA recommendations for meal and snack components (Bucholz et al, 2011), which helps to ensure that children are receiving a healthy diet while in group care. Early care professionals are unable to impact the menu provided within their individual classroom and training on nutrition has been researched in numerous studies throughout the U.S. (Ford et al., 2013, Fox et al., 2010; Summerbell et al., 2012; Yavuz et al., 2015), thus it will not be a focus of this study.

\section{Physical Activity}

A review of state early care and education program regulations, practices and policies as well as obesity prevention programs indicates the need for improvements regarding the amount of physical activity children receive in early childhood settings (Larson et al., 2011). Licensing guidelines related to physical activity promotion vary widely from state to state with only nine states specifying a minimum amount of time to be spent in active outdoor play (Copeland et al., 2012). The state of Mississippi's child care regulations requires infants to have a minimum of 30 minutes of outdoor play per day and toddler, preschool, and school-age children are required to have a minimum of 2 hours of outdoor activities per day, weather permitting. However, no definition of weather permitting is provided in the regulations. In addition, the regulations state that toddlers and preschool children will be provided opportunities for light physical activity for at least 15 minutes per hour while awake and toddlers should accumulate a minimum of 30 minutes and preschoolers a minimum of 60 minutes of structured moderate to vigorous physical activity per day (Mississippi State Department of Health, 2018).

Early care professionals have some control in their own classroom and can either encourage or discourage physical activity in young children by their own beliefs and 
values (Hesketh et al., 2015). Early care professionals may feel that children are always moving and receiving adequate physical activity throughout the day. Dyment \& Coleman (2012) report that 13 out of 16 early care professionals felt children were engaging in sufficient physical activity while in their care, and all agreed physical activity is extremely important to young children's development. Findings from focus groups conducted with 54 early care professionals in London, Ontario show that $96 \%$ feel it is very important for young children to be physically active, while $63 \%$ perceive children are very active (Tucker et al., 2011). The research supports that early care professionals understand the importance of physical activity, but may feel that the children are receiving enough activity on their own. Research in Ohio with 49 early care and education providers shows that early care professionals feel pressured to focus on academics rather than outdoor and active play opportunities (Copeland et al., 2012). For an early childhood professional who believes that learning can only occur within the classroom, this finding points to the possibility that physical activity may be limited in efforts to incorporate more academic content throughout the day.

\section{Sleep}

Child care licensing regulations in Mississippi address naptime and state that rest periods for preschool children should be for a minimum of one hour and should not exceed two and one-half hours, while infant and toddler naptimes should be individualized to meet the child's needs (Mississippi State Department of Health, 2018). The Institute of Medicine released recommendations in 2011 related to sleep duration and sleep hygiene which include four actions including (1) creating environments to enable restful sleep, (2) encouraging practices that promote sleep behaviors and practices such as 
using a calm naptime routine and avoiding stimulating activities just before naptime, (3) encouraging practices that allow children to self-regulate their need for sleep by putting infants down to nap while drowsy but still awake and helping preschool children to identify being sleepy, and (4) seeking expert consultation on healthy sleepy practices and durations (National Academics of Sciences Engineering, and Medicine, 2017). Findings from research on regulations to promote healthy sleep practices in child care indicate that state regulations address healthy sleep aimed at preventing SIDS, with no state having regulations to address all four or even three of the IOM's recommendations, and only 11 states with regulations addressing two of the four recommendations. Many states $(N=$ 33) have regulations to encourage self-regulation of sleep and 15 states have regulations to create environments designed to encourage restful sleep (Neelon, Duffey, \& Slining, 2014).

The state of Mississippi has clear guidance on both physical activity and naptime; however, the monitoring of these policies is currently conducted semi-annually by individuals with heavy caseloads. Child care regulations are designed to promote and protect healthy development for young children; however, the requirements are difficult to monitor to ensure compliance on a day-to-day basis and may not be as effective as needed. The early care professional could serve as the change agent to guide children to develop healthy habits. However, many early care professionals are unaware of either the latest information on health promotion or ways to implement the information they have received.

Head Start programs are required to meet local state licensing regulations and maintain a state license, in addition to performance standards set by the Administration 
for Children and Families (U.S. Department of Health \& Human Services, 2018).

Programs are also required to meet USDA standards for meal components and adhere to a schedule for all meals and snacks (Office of the Administration for Children \& Families, 2017). Programs are required to spend at least 30 minutes per day outside and early care professionals are not allowed to withhold physical activity as a reward or punishment. The performance standards require programs to provide an age appropriate, intentional approach to provide for children's needs related to nap or rest. For example, they must provide alternative quiet activities for children who do not need a nap. The Head Start performance standards address all three components related to childhood obesity (e.g., nutrition, physical activity, sleep) and is positioned to play a vital role in preventing childhood obesity (Davis et al., 2013).

\section{The Role and Influence of Early Care Professionals' Beliefs}

While state standards guide the practices of the early care and education program, the beliefs that the early care professional holds also impact the implementation of these practices. Beliefs held by early care professionals influence their classroom practices, perceptions, and student outcomes (Xiang, Lowy, \& McBride., 2002). Delineating early care professionals' belief structures is imperative to the development of better professional preparation materials and teaching practices (Calderhead, 1996; Kagan, 1992; Pajares, 1992; Xiang et al., 2002). Subject beliefs refer to what value is placed on the subject matter and if the early care professional is able to engage in classroom practices within that subject area. Research documents the importance of subject beliefs on teaching and the teacher themselves (Calderhead, 1996; Xiang et al., 2002). For example, research with preservice teachers have identified beliefs as a way to understand 
a teacher's willingness to teach, support, and promote the subject within the classroom (Xiang et al., 2002). Thus, understanding early care professionals' beliefs and values on physical activity and sleep in the classroom is an important component to enhancing the health of young children.

Early childhood classrooms appear to be successful sites for intervention programs due to the large numbers of children enrolled in the programs, the amount of time children spend in an early care and education program, the cost-effectiveness of using early care professionals as interventionists, and the natural environment for establishing healthy habits (Ling et al., 2016). Head Start programs are of particularly importance as they reach large numbers of low-income and minority children (Whitaker et al., 2013). The early years of a child's life are the most efficacious years to promote a healthy lifestyle when habits are being formed and research notes that it is easier to adopt new behaviors than to change established ones (Natale et al., 2014). However, given the high rate of childhood obesity in the U.S. (Kids Count, 2016), even in the early childhood years $(23 \%$ of children under the age of 5 being overweight with $8 \%$ obese), these data suggest that children in the U.S. are not developing the habits they need to prevent future health problems. Although it is known that early care and education programs are critical to children developing health habits (Alhassan \& Whitt-Glover, 2014; Annesi, Smith, \& Tennant, 2013; Brewer \& Rieg, 2013; Huye et al., 2014; Natale et. al., 2014; Neelon et al., 2016; Story et al., 2006), little to no knowledge is available on the early care professionals' own beliefs and health as it relates to the early childhood classroom environment and activities offered within the classroom. 


\section{Current Study}

This dissertation contained two studies. Study 1 aims to identify what early care professionals in at-risk communities in Mississippi believe (1) about the role of physical activity and sleep in young children's development, and (2) their role is in assisting young children with establishing healthy habits. Demographic characteristics (i.e., gender, age, body mass index, ethnicity, highest level of education, number of years in early childhood education) and perceptions of their own health were assessed as potential correlates. In Study 1 (manuscript 1), the following research questions were assessed: 1. What do early care professionals in an at-risk county in Mississippi believe about the role of physical activity in young children's development?

2. What do early care professionals in an at-risk county in Mississippi believe about the role of sleep in young children's development?

3. What do early care professionals in an at-risk county in Mississippi believe their role is in assisting young children with establishing health habits?

4. How are the beliefs and values of the early care professionals in an at-risk county in Mississippi about (a) physical activity, (b) sleep, and (c) their role in assisting young children in establishing healthy habits associated with an array of demographic characteristics (e.g., gender, race, experience, level of education, time in current position) as well as perceptions of their own health?

The second study (manuscript 2) built on the first by using the results to create two tailored training modules ( 3 hours per training). The first 3 -hour training focused on the importance of physical activity for development, the role of early childhood professionals in assisting children with establishing healthy habits in early childhood, and 
specific activities and ideas of how to increase the physical activity of young children throughout the school day. The second 3-hour training provided an overview of sleep and its role in healthy development, the importance of good sleep hygiene and suggestions on way to improve sleep in the classroom as well as the home. Information was also included on communicating with parents regarding the importance of sleep and recognizing when their child is not getting adequate sleep. Participants' knowledge about the links between physical activity or sleep was assessed prior to each training. Further evaluation of the effectiveness of the trainings was provided through observations (i.e., at least 3 hours in each selected classroom) conducted at each of the participating Head Start centers by two trained researchers prior to and following the last training. One to two classrooms (based on the size of the Head Start Center) were selected.

Based on available evidence (Gehris et al., 2014; Hall et al., 2011; Ling et al., 2016; Sisson, Smith, \& Cheney, 2017; Spruyt et al., 2015), I hypothesize that prior to the educational program early care professionals will strongly agree with statements that address the importance of physical activity for children's overall development. However, given the lack of attention to sleep in the education of early care professionals, I do not expect early care professionals to be in agreement on the importance of sleep in child development, as this area is often overlooked in training (Neelon, et al., 2014) and thus early care professionals have limited exposure to this information. While I expect the early care professionals to have a basic knowledge about how physical activity, and a lesser extent sleep, impacts child development, research shows that the knowledge does not necessarily translate to the early care professional's lesson plans and classroom environment (Hesketh et al., 2015; Sisson et al., 2017). Based on this available evidence, 
I do not expect early care professionals to strongly believe that they play a critical role in helping children establish healthy habits through the environment and activities they provide in their classroom. I expect that following the educational program developed specifically for the early care professionals from an at-risk community in Mississippi, I will see an increase in overall general knowledge about both domains of health (i.e., physical activity; sleep) in child development. Additionally, I expect early care professionals to increase their ratings of their contributions to the physical activity and sleep of the preschool children in their classroom after their participation in the education program. I also expect to see some change, although not significant, in the classroom, regarding physical activity and sleep habits due to the length of the training. 


\section{REFERENCES}

Abadie, B. R., \& Brown, S. P. (2010). Physical activity promotes academic achievement and a healthy lifestyle when incorporated into early childhood education. Forum on Public Policy. Retrieved from http://files.eric.ed.gov/fulltext/EJ912979.pdxf

Acebo, C., Saden, A., Seifer, R., Tzischinsky, O., Hafer, A., \& Carskadon, M. A. (2005). Sleep/wake patterns derived from activity monitoring and maternal report for healthy 1- to 5-year-old children. Sleep, 28(12), 1568-1577.

Active Living by Design: Low Income Populations. (2017). Retrieved from https://healthyplacesbydesign.org

Adamo, K. B., Langlois, K. A., Brett, K. E., \& Colley, R. C. (2012). Young children and parental physical activity levels findings from the Canadian Health Measures Survey. American Journal of Preventive Medicine, 43(2), 168-175. doi.org/10.1016/j.amepre.2012.02.032

Alhassan, S., \& Whitt-Glover, M. C. (2014). Intervention fidelity in a teacher-led program to promote physical activity in preschool-age children. Preventive Medicine, 69, 534-536. doi.org/10.1016/j.ypmed.2014.07.024

American Academic of Child \& Adolescent Psychiatry. (2011). Retrieved from https://www.aacap.org/

American Academy of Sleep Medicine. (2018). Retrieved from https://aasm.org

Anderson, S. E., Andridge, R., \& Whitaker, R. C. (2016). Bedtime in preschool-aged children and risk for adolescent obesity. The Journal of Pediatrics, 176, 17-22. doi.org/10.1016/j.jpeds.2016.06.005

Annesi, J. J., Smith, A.E., \& Tennant, G. A. (2013). Effects of the Start for Life treatment on physical activity in primarily African American preschool children of ages 3-5 years. Psychology, Health \& Medicine, 18, 300-309. doi.org/10.1080/13548506.2012.712704

Atkinson, G., \& Davenne, D. (2007). Relationships between sleep, physical activity and human health. Physiology \& Behavior, 90, 229-235. 
Bagley, E., J., Kelly, R. J., Buckhalt, J. A., \& El-Sheikh, M. (2015). What keeps low-SES children from sleeping well: the role of presleep worries and sleep environment. Sleep Medicine, 16, 496-502. doi: 10.1016/j.sleep.2014.10.008

Baldwin, D., Gaines, S., Wold, J. L., Williams, A., \& Leary, J. (2007). The health of female child care providers implications for quality of care. Journal of Community Health Nursing, 24, 1-17.

Bellows-Riecken, K.H., \& Rhodes, R. E. (2008). A birth of inactivity? A review of physical activity and parenthood. Preventive Medicine, 46, 99-110. doi: 10.1016/j.ypmed.2007.08.003

Benjamin, S. E., Copeland, K A., Cradock, A., Neelon, B., Walker, E., Slining, M. M., \& Gillman, M. W. (2009). Menus in child care: A comparison of state regulations and national standards. Journal of the American Dietetic Association, 109, 109115. doi: $10.1016 /$ j.jada.2008.10.015

Bohn, C. M., Haskins, D. D., Loo, R. K., \& Ahrendt, L. J. (2014). Evaluation of the South Dakota fitCare child care provider training program targeting nutrition and physical activity. South Dakota Medicine, 67, 305-313.

Braveman, P. A., Cubbin, C., Egerter, S., Williams, D. R., \& Pamuk, E. (2010). Socioeconomic disparities in health in the United States: What the patterns tell us. American Journal of Public Health, 100(S1), 186-196.

Brewer, H., \& Rieg, S. (2013). Preschool staff members' perceptions of the implementation of a grant-funded intervention program to combat childhood obesity: a phenomenological approach. Education, 134, 255-265.

Bronfenbrenner, U. (1974). Developmental research, public policy, and the ecology of childhood. Child Development, 45, 1-5.

Bronfenbrenner, U. (1977). Toward an experimental ecology of human development. American Psychologist, 32, 513-531.

Brown, W. H., Googe, H. S., McIver, K. L., \& Rathel, J. M. (2009). Effects of teacherencouraged physical activity on preschool playgrounds. Journal of Early Intervention, 31, 126-145. doi.org/10.1177/1053815109331858

Bucholz, E. M., Desai, M. M., \& Rosenthal, M. S. (2011). Dietary intake in Head Start vs non-Head Start preschool-aged children: Results from the 1999-2004 National Health and Nutrition Examination Survey. Journal of the American Dietetic Association, 111, 1021-1030. doi: 10.1016/j.jada.2011.04.009

Burnham, M. M., Gaylor, E. E., \& Wei, X. (2016). Toddler naps in child care: Associations with demographics and developmental outcomes. Sleep Health, 2, 25-29. doi.org/10.1016/j.sleh.2015.12.004 
Calder, J. (1994). Occupational health and safety issues for child care providers. Pediatrics, 94(6), 1072-1073.

Calderhead, J. (1996). Teachers: Beliefs and knowledge. In D.C. Berliner and R.C. Calfee (Eds.), Handbook of educational psychology (pp 709-725). New York: Macmillan.

Centers for Disease Control and Prevention. (2018). Retrieved from https://www.cdc.gov

Chen, J. (2017). Complex childcare experiences and sleep outcomes in young children. Sleep Health, 3(5), 373-378. doi.org/10.1016/j.sleh.2017.07.005

Child Care Aware of America. (2015). Retrieved from http://www.usa.childcareaware.org

Choose My Plate. (2018). Retrieved from https://www.choosemyplate.gov

Cloutier, M. M., Wiley, J., Wang, Z., Grant, A., \& Gorin, A. A. (2015). The Early Childhood Obesity Prevention Program (ECHO): An ecologically-based intervention delivered by home visitors for newborns and their mothers. BMC Public Health, 1-13. doi.org/10.1186/s12889-015-1897-9

Coleman, B., \& Dyment, J. E. (2013). Factors that limit and enable preschool-aged children's physical activity on child care center playgrounds. Journal of Early Childhood Research, 11, 203-221. doi.org/10.1177/1476718X12456250

Copeland, K. A., Sherman, S. N., Kendeigh, C. A., Kalkwarf, H. J., \& Saelens, B. E. (2012). Societal values and policies may curtail preschool children's physical activity in child care centers. Pediatrics, 129, 265-274. doi: 10.1542/peds.20112012

Corder, K., Crespo, N. C., van Sluijs, E. M. F., Lopez, N. V., \& Elder, J. P. (2012). Parent awareness of young children's physical activity. Preventive Medicine, 55, 201-205. doi.org/10.1016/j.ypmed.2012.06.021

Costa, S., Adams, J., Phillips, V., \& Neelon, S. E. B. (2016). The relationship between childcare and adiposity, body mass and obesity related risk factors: Protocol for a systematic review of longitudinal studies. Systematic Reviews, 5, (141), 1-7. doi.org/10.1186/s13643-016-0312-7

Crabtree, V. M., Korhonen, J. B., Montgomery-Downs, H. E., Jones, V. F., O’Brien, L. M., \& Gozal, D. (2005). Cultural influences on the bedtime routines of young children. SleepMedicine, 6, 319-324. doi.org/10.1016/j.sleep.2005.02.001

Dahl, R. E. (2008). Biological, developmental, and neurobehavioral factors relevant to adolescent drive risk. American Journal of Preventive Medicine, 35(3S), 278284). doi: 10.1016/j.amepre.2008.06.013 
DataUSA. (2018). Retrieved from http://datausa.io/

Davis, S. M., Sanders, S. G., FitzGerald, C. A., Keane, P. C., Canaca, G. F., \& VolkerRector, R. (2013). CHILE: An evidence-based preschool intervention for obesity prevention in Head Start. Journal of School Health, 83(3), 223-239.

Dawson-Hahn, E. E., Fesinmeyer, M. D., \& Mendoza, J. A. (2015). Correlates of physical activity in Latino preschool children attending Head Start. Pediatric Exercise Science, 27, 372-379. doi.org/10.1123/pes.2014-0144

De Marco, A. C., Zeisel, S., \& Odom, S. L. (2015). An evaluation of a program to increase physical activity for young children in child care. Early Education and Development, 26, 1-26. doi.org/10.1080/10409289.2014.932237

Dolinsky, D. H., Namenek Brouwer, R. J., Evenson, K. R., Siega-Riz, A. M., \& Ostbye, T. (2011). Correlates of sedentary time and physical activity among preschoolaged children. Preventing Chronic Disease, 8, 1-14.

Dyment, J., \& Coleman, B. (2012). The intersection of physical activity opportunities and the role of early childhood educators during outdoor play: Perceptions and reality. Australian Journal of Early Childhood, 37, 90-98.

Elmore-Staton, L. \& Parker, J. (2015). Teachers' perceptions of their role in establishing healthy habits. Paper presented at the meeting of Society for Research in Child Development, Philadelphia, PA.

Esquivel, M. K., Nigg, C. R., Fialkowski, M. K., Braun, K. L., Li, F., \& Novotny, R. (2016). Influence of teachers' personal health behaviors on operationalizing obesity prevention policy in Head Start preschools: A project of the Children's Healthy Living Program (CHL). Journal of Nutrition Education and Behavior, 48, 318-324. doi.org/10.1016/j.jneb.2016.02.007

Fan, M., \& Jin, Y. (2013). Do neighborhood parks and playgrounds reduce childhood obesity? American Journal of Agricultural Economics, (96)1, 26-42. doi.org/10.1093/ajae/aat047

Fields, S. A., Sabet, M., \& Reynolds, B. (2013). Dimensions of impulsive behavior in obese, overweight, and healthy-weight adolescents. Appetite, 70, 60-66. doi: 10.1016/j.appet.2013.06.089

Ford, C. N., Slining, M. M. \& Popkin, B. M. (2013). Trends in dietary intake among US 2- to 6-year-old children, 1989-2008. Journal of the Academy of Nutrition and Dietetics, 113(1), 35-42. doi.org/10.1016/j.jand.2012.08.022 
Fox, M. K., Condon, E., Briefel, R. R., Reidy, K. C., \& Deming, D. M. (2010). Food consumption patterns of young preschoolers: Are they starting off on the right path? Supplement to the Journal of the American Dietetic Association, 110(12), S52-S59. doi: 10.1016/j.jada.2010.09.002

Freedman, M. R., \& Alvarez, K. P. (2010). Early childhood feeding: Assessing knowledge, attitudes, and practices of multi-ethnic child-care providers. Journal of the American Dietetic Association, 110, 447-451. doi:10.1016/j.jada.2009.11.018

Gagne, C., \& Harnois, I. (2014). How to motivate childcare workers to engage preschoolers in physical activity. Journal of Physical Activity and Health, 11, 364-374. doi: 10.1123/jpah.2011-0325

Galland, B. C., Taylor, B. J., Elder, D. E., \& Herbison, P. (2012). Normal sleep patterns in infants and children: A systematic review of observational studies. Sleep Medicine Reviews. 16, 213-222. doi: 10.1016/j.smrv.2011.06.001

Galvan, M., Uauy, R., Corvalan, C., Lopez-Rodriguez, G., \& Kain, J. (2013). Determinants of cognitive development of low SES children in Chile: A posttransitional county with rising childhood obesity rates. Maternal Child Health Journal, 17, 1243-1251. doi: 10.1007/s10995-012-1121-9

Galvan, M., Uauy, R., Lopez-Rodriguez, G., \& Kain, J. (2014). Association between childhood obesity, cognitive development, physical fitness and social-emotional wellbeing in a transitional economy. Annual of Human Biology, 41(2), 99-104. doi: $10.3109 / 03014460.2013 .841288$

Gangwisch, J. E., Malaspina, D., Boden-Albala, B. \& Heymsfield, S. B. (2005). Inadequate sleep as a risk factor for obesity: Analyses of the NHANES I. Sleep, $28,1289-1296$.

Gehris, J. S., Gooze, R. A., \& Whitaker, R. C. (2014). Teachers' perceptions about children's movement and learning in early childhood education programs. Child: Care, Health and Development, 41, 122-131. doi.org/10.1111/cch.12136

Gentier, I., D’Hondt, E. D., Shultz, S., Deforche, B., Augustijn, M., Hoorne, S., . . . Lenoir, M. (2013). Fine and gross motor skills differ between healthy-weight and obese children. Research in Developmental Disabilities, 34, 4043-4051. doi.org/10.1016/j.ridd.2013.08.040

Gooley, J. J. (2014). Good sleep and good health are natural bed partners. Annuals Academy of Medicine, 43(3), 134-135. 
Gutierrez-Repiso, C., Soriguer, F., Rubio-Martin, E., de Antonio, I. E., de Adana, M. S. R., Almaraz, M., . . . Rojo-Martinez, G. (2014). Night-time sleep duration and the incidence of obesity and type 2 diabetes. Findings from the prospective Pizarra study. Sleep Medicine, 15, 1398-1404. doi.org/10.1016/j.sleep.2014.06.014

Halal, C. S. E., Matijasevich, A., Howe, L. D., Santos, I. S., Barros, F. C., \& Nunes, M. L. (2016). Short sleep duration in the first years of life and obesity/overweight at age 4 years: A birth cohort study. The Journal of Pediatrics, 168, 99-103. doi.org/10.1016/j.jpeds.2015.09.074

Hall, W. A., Scher, A., Zaidman-Zait, A., Espezel, H., \& Warnock, F. (2011). A community-based study of sleep and behavior problems in 12- to 36-month-old children. Child: Care, Health and Development, 38, 3, 379-389. doi: 10.1111/j.1365-2214.2011.01252.x

Harms, T., Clifford, R. M., \& Cryer, D. (2005). Early childhood environment rating scale revised edition. New York: Teachers College Press.

Henry, B. W., Umoren, J., Kim, S., Zittel, L., \& Derscheid, L. E. (2017). The Take Action training protocol: A model for teacher professional development. Health Behavior and Policy Review, 4(6), 570-581. doi.org/10.14485/HBPR.4.6.7

Hesketh, K. D., \& Campbell, K. J. (2010). Interventions to prevent obesity in 0-5 year olds: An updated systematic review of the literature. Obesity, 18, 27-35.

Hesketh, K. R., van Slujis, E. M., Blaine, R. E., Taveras, E. M., Gillman, M. W., \& Neelon, S.B. (2015). Assessing care providers; perceptions and beliefs about physical activity in infants and toddlers: Baseline findings from Baby NAP SACC study. BMC Public Health, 15, 1-7. doi: 10.1186/s12889-015-1477-z

Hill, J. O., Droguas, H., \& Peters, J. C. (1993). Obesity Treatment: Can diet composition play a role? Annuals of Internal Medicine, 119(7), 694-698.

Hirshkowitz, M., Whiton, K., Albert, S. M., Alessi, C., Bruni, O., DonCarlos, L., . . .Ware, J. C. (2015). National Sleep Foundation's updated sleep duration recommendations: Final report. Sleep Health, 1, 233-243. doi.org/10.1016/j.sleh.2015.10.004

Hughes, S. O., Patrick, H., Power, T. G., Fisher, J. O., Anderson, C. B., \& Nicklas, T. A. (2007). The impact of child care providers' feeding on children's food consumption. Journal of Developmental \& Behavioral Pediatrics, 28, 100-107.

Huye, H. F., Bankston, S., Speed, D., \& Molaison, E.F. (2014). Evaluation of the Color Me Healthy program in influencing nutrition and physical activity in Mississippi preschool child care facilities. The Journal of Child Nutrition and Management, $38,1-13$. 
Institute for Healthy Metrics and Evaluation. (2018). Retrieved from http://www.healthdata.org/sites/default/files/files/county_profiles/US/2015/

Kagan, D. M. (1992). Implications of research on teacher belief. Educational Psychologist, 27, 65-90.

Khalaj, N., \& Amri, S. (2013). Mastery of gross motor skills among preschool obese children. Science, Movement and Health, 13, 656-661.

Kids Count. (2016). Retrieved from http://datacenter.kidscount.org/data\#MS/2/0/char/0

Knutson, K. L., Spiegel, K., Penev, P., \& Van Cauter, E. (2007). The metabolic consequences of sleep deprivation. Sleep Medicine Reviews, 11, 163-17 doi: 10.1016/j.smrv.2007.01.002

Korenman, S., Abner, K. S., Kaestner, R., \& Gordon, R. A. (2013). The Child and Adult Care Food Program and the nutrition of preschoolers. Early Childhood Research Quarterly, 28, 325-336. doi: 10.1016/j.ecresq.2012.07.007

Kurdziel, L., Duclos, K., \& Spencer, R. M. C. (2013). Sleep spindles in midday naps enhance learning in preschool children. Psychological and Cognitive Sciences, 110(43), 17267-16272. doi.org/10.1073/pnas.1306418110

La Paro, K. M., Thomason, A. C., Lower, J. K., Kintner-Duffy, V. L., \& Cassidy, D. J. (2012). Examining the definition and measurement of quality in early childhood education: A review of studies using the ECERS-R from 2003-2010. Early Childhood Research \& Practice, 14 (1), 1-13.

Lanigan, J. D. (2012). The relationship between practices and child care providers' beliefs related to child feeding and obesity prevention. Journal of Nutrition Education and Behavior, 44, 521-529. doi.org/10.1016/j.jneb.2011.07.008

Larson, N., Ward, D. S., Neelon, S. B., \& Story, M. (2011). What role can child-care settings play in obesity prevention? A review of the evidence and call for research efforts. Journal of the American Dietetic Association, 111, 1343-1362. doi: 10.1016/j.jada.2011.06.007

Latner, J. D., \& Stunkard, A. J. (2003). Getting worse: The stigmatization of obese children. Obesity Research, 11(3), 452-456.

Lee, R., Zhai, F., Han, W., Brooks-Gunn, J., \& Waldfogel, J. (2013). Head Start and children's nutrition, weight, and health care receipt. Early Childhood Research Quarterly, 28, 723-733. doi: 10.1016/j.ecresq/2013.06.003

Ling, J., Robbins, L., \& Wen, F. (2016). Interventions to prevent and manage overweight or obesity in preschool children: A systematic review. International Journal of Nursing Studies, 53, 270-289. doi.org/10.1016/j.ijnurstu.2015.10.017 
Liu, J., Sohi, I., Liu, J., Liese, A. D., Bell, B. A., \& Battersby, S. E. (2014). Differences in food environment perceptions and spatial attributes of food shopping between residents of low and high food access areas. Journal of Nutrition Education and Behavior, 46(4), 241-249.

Liveability. (2018). Retrieved from https://livability.com/

Lo, J. C., Maring, B., Chandra, M., Daniels, S. R., Sinaiko, A., Daley, M. F., .. . Greenspan, L. C. (2013). Prevalence of obesity and extreme obesity in children aged 3-5 years Pediatric Obesity, 9, 165-175. doi: $10.1111 / \mathrm{j} .2047-6310.2013 .00154 \mathrm{x}$

Lumeng, J. C., Forrest, P., Appugliese, D. P., Kaciroti, N., Corwyn, R. F., \& Bradley, R. H. (2010). Weight status as a predictor of being bullied in third through sixth grades. Pediatrics, 125(6), 1-3.

Lumeng, J. C., Kaplan-Sanoff, M., Shuman, S., \& Kannan, S. (2008). Head Start teachers' perceptions of children's eating behavior and weight status in the context of food scarcity. Journal of Nutrition Education and Behavior, 40, 237 243. doi: 10.1016/j.jneb.2007.07.001

Magee, C., Caputi, P., \& Iverson, D. (2014). Lack of sleep could increase obesity in children and too much television could be partly to blame. Foundation Acta Pediatrica, 103, 27-31. doi.org/10.1111/apa.12447

Martin, A., Booth, J. N., Young, D., Revie, M., Boyter, A. C., Johnston, B., . . \& Reilly, J. J. (2016). Associations between obesity and cognition in the pre-school years. Obesity, 24, 207-214. doi.org/10.1002/oby.21329

McNeil, J., Doucet, E., \& Chaput, J. (2013). Inadequate sleep as a contributor to obesity and type 2 diabetes. Canadian Journal of Diabetes, 37, 103-108. doi.org/10.1016/j.jcjd.2013.02.060

Mississippi State Department of Health, 2018. Retrieved from http://www.msdh.state.ms.us

Monasta, L., Batty, G. D., Macaluso, A., Ronfani, L., Lutje, V., Bavcar, A. . . Cattaneo, A. (2011). Interventions for the prevention of overweight and obesity in preschool children: A systematic review of randomized controlled trails. Obesity Reviews, 12, 107-118. doi.org/10.1111/j.1467-789X.2010.00774.x

Moore, L. V., \& Thompson, F. E. (2015). Adults meeting fruit and vegetable intake recommendations - United States, 2013. Morbidity and Mortality Weekly Report, 64(26), 709-713. 
Morgenthaler, T. I., Croft, J. B., Dort, L. C., Loeding, L. D., Mullington, J. M., \& Thomas, S. M.(2015). Development of the national healthy sleep awareness project sleep health surveillance questions. Journal of Clinical Sleep, 11(9), 10571062. doi: $10.5664 /$ jcsm.5026

Muckelbauer, R., Kalhoff, H., Muller-Nordhorn, J., \& Kersting, M. (2011). Childhood overweight and obesity: Introduction into epidemiology and prevention strategies. Current Nutrition \& Food Science, 7(3), 101-199.

Natale, R., Scott, S. H., Messiah, S. E., Schrack, M. M., Uhlorn, S. B., \& Delamater, A. (2013). Design and methods for evaluating an early childhood obesity prevention program in the childcare center setting. BMI Public Health, 13, 1-10. Retrieved from http://www.ncbi.nlm.nih.gov/pmc/articles/PMC3573935/

Natale, R. A., Messiah, S. E., Asfour, L., Uhlhorn, S. B., Delamater, A., \& Arheart, K. L. (2014). Role modeling as an early childhood obesity prevention strategy: Effect of parents and teachers on preschool children's healthy lifestyle habits. Journal of Developmental \&Behavioral Pediatrics, 35, 379-387.

doi: 10.1097/DBP.0000000000000074

National Academics of Sciences, Engineering, and Medicine. (2018). Retrieved from http://www.nationalacademies.org/hmd/Reports/2011/Early-Childhood-ObesityPrevention-Policies.aspx

National Center for Health Statistics. (2018). Retrieved from https://www.cdc.gov/nchs/nhanes/index.htm

National Sleep Foundation. (2018). Retrieved from https://www.sleepfoundation.org

Neelon, S. E. B., Duffey, K., \& Slining, M. M. (2014). Regulations to promote healthy sleep practices in child care. Pediatrics, 134(6), 1-8. doi: 10.1542/peds.2014-0578

Neelon, S. E. B., Taveras, E. M., Ostbye, T., \& Gillman, M. W. (2014). Preventing obesity in infants and toddlers in child care: Results from a pilot randomized controlled trial. Maternal Child Health Journal, 18, 1246-1257. doi: 10.1007/s10995-013-1359-x

Neelon, S. E. B., Ostbye, T., Hales, D., Vaughn, A., \& Ward, D. S. (2016). Preventing childhood obesity in early care and education settings: Lessons from two intervention studies. Child: Care, Health and Development, 42, 351-358. doi.org/10.1111/cch.12329

Nervik, D., Martin, K., Rundquist P., \& Cleland, J., (2011). The relationship between body mass index and gross motor development in children aged 3 to 5 years. Pediatric Physical Therapy, 23, 144-148. doi: 10.1097/PEP.0b013e318218d356 
Odom, S. L., Pungello, E. P., \& Gardener-Neblett, N. (Eds.). (2012). Nutrition and Physical Activity. Infants, Toddlers, and Families in Poverty. New York: The Guilford Press.

Office of the Administration for Children and Families. Retrieved from https://www.acf.hhs.gov/ohs/policy

Office of Disease Prevention and Health. (2018). Retrieved from https://health.gov

Ogden, C.L., Carroll, M. D., Kit, B. K., \& Flegal, K.M. (2014). Journal of American Medical Association, 311, 806-814. doi: 10.1001/jama.2014.732

Ogden, C. L., Carroll, M. D., Lawman, H. G., Fryar, C. D., Kruszon-Moran, D., Kit, B. K., \& Flegal, K. M. (2016). Trends in obesity prevalence among children and adolescents in the United States, 1988-1994 through 2013-2014. Journal of American Medical Association, 315, 2292-2299. doi: 10.1001/jama.2016.6361

Pajares, M. F. (1992). Teachers' beliefs and educational research: Cleaning up a messy construct. Review of Educational Research, 62, 301-332.

Pellegrini, A. D., \& Smith, P. K. (1998). Physical activity play: The nature and function of a neglected aspect of play. Child Development, 69(3), 577-598.

Perry, G. S., Patil, S., \& Presley-Cantrell, L. R. (2013). Raising awareness of sleep as a health behavior. Preventing Chronic Disease, 10, 133-137.

doi.org/10.5888/pcd10.130081

Preskill, H., Jones, N., \& Tengue A. (2013). Markers that matter: Success indicators in early learning and education. Retrieved from http://www.fsg.org/publications/markers-matter

Ra, J. S., Yun, H. J., \& Cho, Y. N. (2016). Teachers' influence on weight perceptions in preschool children. Applied Nursing Research, 31, 111-116. doi: 10.1016/j.apnr.2016.01.005

Rhea, D. J., Rivchun, A. P., \& Pennings, J. (2016). The Liink Project: Implementation of a recess and character development pilot study with grades $\mathrm{K} \& 1$ children. Tahperd Journal, summer issue, 14-17.

Rosa, E. M., \& Tudge, J. (2013). Urie Bronfenbreener's Theory of Human Development: Its evolution from ecology to bioecology. Journal of Family Theory \& Review, 5, 243-258. doi.org/10.1111/jftr.12022

Sahoo, K., Sahoo, B., Choudhury, A., Sufi, N., Kumar, R., \& Bhadoria, A. (2015). Childhood obesity: Causes and consequences. Journal of Family Medicine and Primary Care, 4, 187-192. doi: 10.4103/2249-4863.154628 
Saluja, G., Scott-Little, C., \& Clifford, R. M. (2000). Readiness for school: A survey of state policies and definitions. Early Childhood Research \& Practice, 2(2), 1-54.

Scharf, R. J., \& DeBoer, M. D. (2014). Sleep timing and longitudinal weight gain in 4and 5- year-old children. Pediatric Obesity, 10, 141-148.

doi.org/10.1111/ijpo.229

Shen, B., Reinhart-Lee, T., Janisse, H., Brogan, K., Danford, C., \& Jen, K-L. C. (2012). African American preschool children's physical activity levels in Head Start. Research Quarterly for Exercise and Sport, 83, 168-174.

Sharma, S., Dortch, K. S., Byrd-Williams, C., Truxillio, J. B., Rahman, G. A., Bonsu, P., \& Hoelscher, D. (2013). Nutrition-related knowledge, attitudes, and dietary behaviors among Head Start teachers in Texas: A cross-sectional study. Journal of the Academy of Nutrition and Dietetics, 113, 558-562.

doi: 10.1016/j.jand.2013.01.003

Sigman-Grant, M., Christiansen, E., Branen, L., Fletcher, J., \& Johnson, S. L. (2008). About feeding children: Mealtimes in child-care centers in four western states. Journal of the American Dietetic Association, 108, 340-346.

doi: 10.1016/j.jada.2007.09.006

Sisson, S. B., Smith, C. L., \& Cheney, M. (2017). Big impact on small children: Childcare providers' perceptions of their role in early childhood healthy lifestyle behaviors. Child Care in Practice, 23(2), 162-180.

doi.org/10.1080/13575279.2017.1299111

Slack-Smith, L. M., Read, A. W., Darby, J., \& Stanley, F. J. (2006). Health of caregivers in child care. Child Care, Health \& Development, 32, 111-119.

Snell, E. K., Adam, E. K., \& Duncan, G. J. (2007). Sleep and the body mass index and overweight status of children and adolescents. Child Development, 78(1), 309323.

Spencer, R. M. C., Campanella, C., de Jong, D. M., Desrochers, P., Root, H., Cremone, A., \& Kurdziel, L. B. F. (2016). Sleep and behavior of children under typical and nap-promoted conditions. Sleep Health, 2, 34-41. doi: 10.1016/j.sleh.2015.12.009

Spruyt, K., Alaribe, C. U., \& Nwabara, O. U. (2015). To sleep or not to sleep: A repeated daily challenge for African American children. CNS Neuroscience \& Therapeutics, 21, 23-31. doi: 10.1111/cns.12319

State of Obesity (2018). Retrieved from http://www.stateofobesity.org 
Staton, S. L., Smith, S. S., \& Thorpe, K. J. (2015). "Do I really need a nap?”: The role of sleep science in informing sleep practices in early childhood education and care settings. Translational Issues in Psychological Science, 1(1), 32-44.

doi: $10.1037 /$ tps0000011

Story, M., Kaphingst, K. M., \& French, S. (2006). The role of child care settings in obesity prevention. The Future of Children, 16, 143-168.

Su, W., \& Di Santo, A. (2011). Preschool children's perceptions of overweight peers. Journal of Early Childhood Research, 10(1), 19-31. doi.org/10.1177/1476718X11407411

Summerbell, C. D., Moore, H. J., Vogele, C., Kreichauf, S., Wildruber, A., Manios, Y., . . .Gibson, E. L. (2012). Evidence-based recommendations for the development of obesity prevention programs targeted at preschool children. International Association for the Study of Obesity, 13, 129-132. doi: 10.1111/j.1467-789X.2011.00940.x

Taheri, S., Lin, L., Austin, D., Young, T., \& Mignot, E. (2004). Short sleep duration is associated with reduced leptin, elevated ghrelin, and increased body mass index. PLoS Medicine, 1(3), e62.

Temple, M., \& Robinson, J. C. (2014). A systematic review of interventions to promote physical activity in the preschool setting. Journal for Specialists in Pediatric Nursing, 19, 274-284. doi.org/10.1111/jspn.12081

Thorburn, M., \& Macallister, J. (2013). Dewey, interest, and well-being: Prospect for improving the educational value of physical education. Quest, 65, 458-468. doi.org/10.1080/00336297.2013.805657

Tucker, P. (2008). The physical activity levels of preschool-aged children: A systematic review. Early Childhood Research Quarterly, 23(4), 547-558. doi.org/10.1016/j.ecresq.2008.08.005

Tucker, P., van Zandvoort, M. M., Burke, S. M., \& Irwin, J. D. (2011). Physical activity at daycare: childcare providers' perspectives for improvements. Journal of Early Childhood Research, 9, 207-219. doi.org/10.1177/1476718X10389144

U.S. Department of Health and Human Services (2018). Retrieved from https://www.hhs.gov

U. S. Department of Health \& Human Services \& U. S. Department of Education (2016). High quality early learning settings depend on a high-quality workforce. Low compensation undermines quality. Retrieved from https://www2.ed.gov/about/inits/ed/earlylearning/files/ece-lowcompensatioundermines-quality-report-2016.pdf 
Vale, S., Trost, S., Rego, C., Abreu, S., \& Mota, J. (2015). Physical activity, obesity status, and blood pressure in preschool children. The Journal of Pediatrics, 167, 98-101. doi.org/10.1016/j.jpeds.2015.04.031

Van Cauter, E., \& Spiegel, K. (1999). Sleep as a mediator of the relationship between socioeconomic status and health: A hypothesis. Annuals of the New York Academy of Sciences, 896, 254-61.

Wang, F., \& Veugelers, P. J. (2008). Self-esteem and cognitive development in the era of the childhood obesity epidemic. Obesity Reviews, 9, 615-623.

doi: 10.1111/j.1467-789X.2008.00507.x

Weissbluth, M. (1995). Naps in children: 6 months - 7 years. Sleep, 18(2), 82-87.

Whitaker, R. C., Becker, B. D., Herman, A. N., \& Gooze, R. A. (2013). The physical and mental health of Head Start staff: The Pennsylvania Head Start staff wellness survey, 2012. Preventing Chronic Disease, 10, 1-9. doi.org/10.5888/pcd10.130171

Whitebook, M, Phillips, D., \& Howes, C. (2014). Worthy work, STILL unlivable wages: The early childhood workforce 25 years after the National Child Care Staff Study, Executive Summary. Berkeley, CA: Center for the Study of Child Care Employment, University of California, Berkeley.

Williams, A. (2011). Childhood obesity doomsday. IDEA Fitness Journal, 49-55.

Williams, N. J., Grandner, M. A., Wallace, D. M., Cuffee, Y., Airhilhenbuwa, C., Okuyemi, K., . . . Jean-Louis, G. (2016). Social and behavioral predicators of insufficient sleep among African Americans and Caucasians. Sleep Medicine, 18, 103-107. doi.org/10.1016/j.sleep.2015.02.533

Working Poor Families Project. Retrieved from https://www.workingpoorfamilies.org

Wyett, J. L. (1998). John Dewey \& Earl Kelley: Giants in democratic education. Education, 119(1), 151-162.

Xiang, P., Lowy, S., \& McBride, R. (2002). The impact of a field-based elementary physical education methods course on preschool classroom teachers' beliefs. Journal of Teaching in Physical Education, 21, 145-161.

Xu, S., \& Xue, Y. (2016). Pediatric obesity: Causes, symptoms, prevention and treatment (review). Experimental and Therapeutic Medicine, 11, 15-20. doi.org/10.3892/etm.2015.2853 
Yavuz, H. M., van Ijzendoorn, M. H., Mesman, J., \& van der Veek, S. (2015). Interventions aimed at reducing obesity in early childhood: A meta-analysis of programs that involve parents. Journal of Child Psychology and Psychiatry, 56, 677-692. doi.org/10.1111/jcpp.12330

Zhai, F., Raver, C. C., \& Li-Grining, C. (2011). Classroom-based interventions and teachers' perceived job stressors and confidence: Evidence from a randomized trial in Head Start settings. Early Childhood Research Quarterly, 26, 442-452. doi: 10.1016/j.ecresq.2011.03.003 


\title{
CHAPTER II
}

\section{EARLY CARE PROFESSIONALS’ BELIEFS AND VALUES REGARDING PHYSICAL ACTIVITY AND SLEEP}

\begin{abstract}
Manuscript 1
This study was designed to explore the beliefs and values of early care professionals $(N=39)$ regarding the role of physical activity and sleep in child development, as well as their role in assisting children with establishing healthy behaviors. Analyses were conducted to examine if early childhood professionals' beliefs and values were associated with an array of demographic characteristics of the early care professional (i.e., age, gender, ethnicity, education, and experience in early childhood) and/or the early care professional's perceived personal health and body mass index. Descriptive analyses revealed that early care professionals agree that physical activity and sleep are important contributors to the healthy development of young children, yet agree less on their role in assisting young children with establishing healthy habits. Demographic and health variables of the early childhood professional were not associated with their beliefs and values.
\end{abstract}

\section{Manuscript 1}

The high rates of adult and childhood obesity in the United States (U. S.) and the contributions of obesity to health problems make it a grave concern for American society. 
Recent estimates indicate that $13.9 \%$ of children under the age of 5-years-old are classified as obese (State of Obesity, 2018). These figures are even more disturbing in Mississippi where the state average for childhood obesity is $14.5 \%$, with certain counties in the state having even higher rates (e.g., 15.7\% in Holmes County; State of Obesity, 2018). Childhood obesity is particularly concerning as it is often a marker for adult obesity (Esquivel et al., 2016) and is known to result in severe physical and mental health problems and increased health costs for the nation (Yavuz, van Ijzendoorn, Mesman \& van der Veek, 2015). Thus, it is imperative to understand the contributors to obesity, particularly at young ages when health habits are being formed (Freedman \& Alvarez, 2010; Muckelbauer, Kalhoff, Mueller-Nordhorn, \& Kersting, 2011).

Obesity is a complex health problem that stems from a combination of genetic and environmental factors. The most simplistic description of obesity is when a person ingests more calories than they burn through exercise and therefore the most recognized contributors include food consumption (i.e., nutrition) and energy expenditure (i.e., physical activity; Centers for Disease Control, 2018). These two components have received attention in the media, as there have been government-funded advertisement campaigns and regulations focused on nutrition and physical activity for decades (Centers for Disease Control, 2018). Messages about the health problems associated with overeating or eating unhealthy foods and living a sedentary lifestyle are common, however, it was not until recently that the contribution of sleep to obesity (Morgenthaler et al., 2015) made it into mainstream media. Sleep regulates the appetite hormones, influencing food intake, and sleep loss is linked to reduced physical activity levels (Knutson, Spiegel, Penev, \& Van Cauter, 2007). Thus, these three contributors to obesity 
are inter-related and modifiable behaviors, especially in the early years of life when the Institute of Medicine recommends that obesity prevention interventions begin (Early Childhood Obesity Prevention Policies, 2011).

Given that 12.5 million U.S. children under the age of 5 are spending time in early care and education programs (Huye, Bankston, Speed, \& Molaison, 2014), early childhood environments, including early care professionals, likely play a role in children's healthy behaviors, placing early care professionals in an important role to help improve the overall health of young children (Larson, Ward, Neelon, \& Story, 2011; Story, Kaphingst, \& French, 2006). Approximately 32 obesity interventions have been delivered in the early childhood classroom (see Ling, Robbins, \& Wen, 2016 for review), and it is noted that the early care professional, including their beliefs and values (Wood \& Bennett, 2000), can serve as a gatekeeper of the health science information children receive.

\section{Early Care Professionals' Beliefs and Values}

Early care professionals' thought processes, beliefs, and knowledge are closely related to behaviors and practices within the classroom environment (Wood \& Bennett, 2000). That is, the actions and decisions early care professionals make regarding the activities within the classroom are driven by their beliefs and values, which combine to become a classroom theory (McClintic \& Petty, 2015). Early care professionals’ individual classroom theory is often determined by their personal knowledge and beliefs rather than best-practices for child development (Wood \& Bennett, 2000). Children's experiences (e.g., amount of movement in the classroom) from classroom to classroom can also vary based on the beliefs and values of the early care professional (Copeland, 
Sherman, Kendeigh, Kalkwarf, \& Saelens, 2012). For example, if the early care professional believes that children are always moving and engaged in sufficient physical activity throughout the day (Dyment \& Coleman, 2012; Tucker, van Zandvoort, Burke, \& Irvin, 2011), it is unlikely that they will incorporate lessons with the intent to get children up and moving. Additionally, if early care professionals do not consider part of their job to be ensuring that children receive the recommended time of physical activity, then it could impact the lessons that they incorporate in the classroom.

The beliefs and values of the early care professional regarding physical activity and sleep may directly impact the environment and opportunities they provide for the children in their care and needs to be better understood to guide the development of training around healthy lifestyle behaviors. This is particularly important because the U.S. depends on early care professionals to provide high-quality early care and education to a diverse group of children without providing the necessary training and support to deliver effective services. This situation is problematic given that the lack of training can in turn lead to undermine the healthy development of the children they serve (Center for the Study of Child Care Employment, 2016).

Understanding early care professionals' beliefs and values regarding healthy lifestyle behaviors can provide a clearer direction on designing professional development opportunities that will be successful in implementing positive changes in the early childhood classroom. Unlike physical activity and sleep, beliefs and values of early care professionals related to nutrition are better understood and addressed in trainings related to healthy lifestyle behaviors (Freedman \& Alvarez, 2010; Langian, 2012; Lumeng, Kaplan-Sanoff, Shuman, \& Kannan, 2008). To date, scant information is available 
regarding the beliefs and values early care professionals have about the links between physical activity and child development, including the role that they (the early care professional) play in that association. Even less is known about the beliefs and values of early care professionals regarding sleep and child development.

\section{Early Care Professional's Health and the Classroom}

High quality early childhood education depends on a high-quality staff who are able to take their understanding of child development and apply it to the early childhood classroom. In addition, staff must be adept at providing developmentally appropriate learning opportunities designed to promote academic learning as well as healthy lifestyle behaviors (U.S. Department of Health and Human Services, 2016). Seminal research by Calder (1994) suggests the health of early care professionals is critical to their ability to provide appropriate care for the children, as well as model healthy behaviors. Yet, early care professionals do not always recognize the role their own health and healthy behaviors have on the children in their classrooms (Baldwin, Gaines, Wold, Williams, \& Leary, 2007). Calder (1994) also suggests early care professionals tend to focus little attention on their own health, and even when they possess knowledge about children's health issues they do not apply the same principles to themselves. For example, early care professionals themselves experience high rates of obesity (Acharya, Feese, Franklin, \& Kabagambe, 2011; Baldwin et al., 2007; Sharma et al., 2013; Song, Song, Nieves, Gonzalez, \& Crockett, 2016) and indicate their own physical activity is often limited because they are exhausted at the end of the workday and too tired to exercise (Child Care Aware of America, 2015). Research on the actual health of early care professionals is limited, but important to understand as the health of the early care professional impacts 
the care they provide for children (Slack-Smith, Read, Darby, \& Stanley, 2006). Thus, it is important to delineate how an early childhood professional's own health is associated with their beliefs and values regarding healthy habits and child development.

Early care professionals may be at increased risk for health problems due to a number of common characteristics seen in this population. For example, the majority of the 1.2 million early care professionals in the United States are female (94.7\%), and a large number of them struggle with weight issues (Sharam et al., 2013). According to the Center for the Study of Child Care Employment (2016), despite the rising cost of early childhood services since 1977, early care professionals earn less than adults who work in the fast food industry and they often have benefits that are minimal and inconsistent, with $46 \%$ of them receiving support from at least one of four public support programs. Research shows that early care professionals have higher rates of physical and mental health issues compared to a national sample of women of similar age, race/ethnicity, and marital status (Whitaker, Becker, Herman, \& Gooze, 2013), which may limit their ability to provide appropriate learning environments for young children in relationship to healthy lifestyle behaviors (Whitebook, Phillips, \& Howes, 2014). The stressors early care professionals encounter are negatively associated with job performance and personal health, as well as the quality of care they provide (Zhai, Raver, Li-Grining, 2011). Understanding how these characteristics relate to early care professionals' beliefs and values of health habits in early childhood is pivotal to understanding the healthy habits presented in the early childhood classroom. 


\section{Head Start and the Development of Health Habits}

Head Start programs reach more than one million low-income children annually in the U.S. and provide global services (e.g., education, health, nutrition) to prepare young children for a healthy future (Bucholz, Desai \& Rosenthal, 2011). Past research on Head Start has focused primarily on cognitive and academic outcomes, while healthrelated outcomes remind understudied (Lee, Zhai, Han, Brooks-Gunn, \& Waldfogel, 2013). Recent research suggests that $25 \%$ of Head Start children are obese compared with 9\% of children age 2 to 5 years-old nationally (Shrama et al., 2013). Data from a small study of Head Start staff in Michigan also indicates early care professionals may not agree with the emphasis placed on childhood obesity and believe that children will outgrow weight issues (Lumeng et al., 2008). Healthy lifestyles behaviors are being formed during the first five years of life (Freedman \& Alvarez, 2010; Muckelbauer et al., 2011) and Head Start classrooms are a place these behaviors will be learned and modeled for large numbers of at-risk children (Bohn, Haskins, Loo, \& Ahrdendt, 2014), making it imperative to understand how the beliefs and values of the early care professionals are shaping the environment.

\section{Current Study}

The purpose of the present study was to identify what early care professionals in an at-risk county in Mississippi (i.e., has the highest rate of adult and childhood obesity in the state) believe (1) about the role of physical activity and sleep in young children's development, and (2) their role is in assisting young children with establishing healthy habits. To further delineate these findings, demographic characteristics (i.e., gender, age, body mass index, race, highest level of education, number of years in early childhood 
education), and perceptions of their own health) were assessed as potential correlates of their beliefs and values.

We expect early care professionals to identify the importance of physical activity for children's overall development because they receive some training, although substantially less than nutrition training, on physical activity (Mississippi State Department of Health, 2018). Given the lack of training and education on the value of sleep for children's healthy development, we do not expect the early care professionals to identify sleep as important to development. Although we expect that early care professionals possess a basic knowledge about physical activity, and to a lesser degree sleep, research finds that knowledge does not always translate to early care professionals' lesson plans and actual classroom environment (Hesketh et al., 2015; Sisson, Smith, \& Cheney, 2017). Based on the available evidence, we do not expect to find that early care professionals recognize their role in helping children establish healthy habits through the activities and environment they provide in their classroom on a daily basis. Insofar as the early care professionals' personal characteristics, we expect the early care professionals' health (i.e., global health rating; body mass index) to be related to their beliefs and values. Additionally, we expect higher levels of education and experience to be associated with more optimal beliefs and values about how physical activity and sleep relate to child development and the early childhood classroom given the increased understanding of development. A copy of the timeline for the research project is provided in Appendix A. 


\section{Method}

\section{Overview and setting}

Recruitment for this study occurred through a Head Start consortium in a rural county in Mississippi. The specific county was selected given the high levels of childhood obesity (15.7\%; State of Obesity, 2018), the poverty rate, (i.e., 43\%; Kids Count, 2018) and the high percentage of minority children (i.e., 82.5\%, Kids Count, 2018); all considered risk factors for childhood obesity (Hughes, 2007; Natale, 2014). The Head Start consortium within the county consisted of four centers. The centers serve approximately 720 low-income, preschool-age children (i.e., 36 to 60 months of age). The consortium director was contacted by telephone to request permission to survey the early care professionals. After written permission was received via email, the education director for the program was contacted by telephone to discuss the process for the project. The researcher contacted each of the four center directors by telephone to explain the process with a follow-up email to confirm the date for the surveys to be delivered to the centers. The centers are as follows: Center A ( $n=5$ classrooms), Center B ( $n=6$ classrooms), Center C ( $n=4$ classrooms), and Center D ( $n=3$ classrooms). Each preschool classroom has two early care professionals, a lead and assistant, both of whom were invited to participate in the research study. The Institutional Review Board approved the research study and early care professionals completed a consent prior to participation.

\section{Participants}

Inclusion criteria for participation in the study was full-time employment as a preschool lead or assistant early care professional in one of the Head Start Centers in the 
selected Mississippi county. The population size for the study consisted of 41 early care professionals. Of the 41 early care professionals who were surveyed, 39 (95\%) returned a completed survey.

\section{Procedures}

Paper copies of the surveys were hand-delivered to each of the four Head Start Centers and left with the center administrator for distribution to all early care professionals in the 3- and 4-year-old classrooms. A call was made to each center director one week before the surveys were to be picked up to remind them of the date. After two weeks, the researcher returned to obtain the completed surveys. The individuals completing the survey were placed in a random drawing for a \$50 gift card, with one gift card awarded at each of the four centers.

\section{Measures}

\section{Demographics}

Demographic information was collected on the early care professional's age, gender, and education level $(1=$ high school, $2=$ some college, $3=$ bachelor's degree, 4 $=$ master's degree, $5=$ Ph.D. $)$, ethnicity $(0=$ European American, $1=$ African American $)$, and length of employment in the field of early education. Participants provided information on their weight and height, which was used to determine individual body mass index (BMI) and weight classification per the Centers for Disease Control. Weight classifications were coded as follows: $1=$ underweight, $2=$ normal, $3=$ overweight, $4=$ obese. 


\section{Early Care Professional Health Rating}

Early childhood professionals rated their health using a global health question. The question, developed by the Rand Corporation (1992), is a commonly used measurement of general health that has previously been used in research with early care professionals (Baldwin et al., 2007; Gratz \& Claffey, 1996; Lundberg \& Manderbacka, 1996; McGrath \& Huntington, 2007). Early care professionals were asked to select one of the following ratings to best describe their overall health $(1=$ poor, $2=$ fair, $3=\operatorname{good}, 4=$ excellent), with higher scores indicative of better perceived health status.

\section{Early Childhood Professionals' Beliefs and Values}

A 17-item survey was developed to assess the beliefs and values of early childhood professionals regarding physical activity and sleep in early childhood. The survey was adapted from the Teacher's Perceptions: Early Childhood Physical Activity Values and Belief Scale, which was field tested with an eight-member panel of experienced physical education educators and preservice senior classroom teachers (Xiang et al., 2002). The wording on the survey was modified to be more specific to physical activity and additional statements were added to measure values and beliefs on sleep (e.g., Naps influence classroom behaviors). In addition, items on the surveys related to nutrition were removed. The role of physical activity in early childhood was assessed via seven statements, and the role of sleep assessed with three statements (See Table 1 for all 17 statements). The beliefs and values early care professionals had about their own role in assisting children with establishing health habits was evaluated with four items related to physical activity and three items related to sleep. Consistent with the Xiang and colleagues scale (2002), early care professionals were asked to rate their agreement with 
each statement on a scale from 1 to $6(1=$ strongly disagree; $2=$ moderately disagree; $3=$ slightly disagree; $4=$ slightly agree; $5=$ moderately agree; $6=$ strongly agree). Higher scores were indicative of a greater value on physical education and sleep in a child's development, with the exception of one statement (i.e., Taking away children's opportunities for physical activity is an appropriate form of discipline)

Table 1 Early Care Professionals Beliefs and Values of Healthy Lifestyle Habits

\begin{tabular}{|c|c|}
\hline & Statement \\
\hline Statement 1 & $\begin{array}{l}\text { Physical activity makes important contributions to the development of the whole } \\
\text { child. }\end{array}$ \\
\hline Statement 2 & Physical activity allows children a fun break from regular classroom activities. \\
\hline Statement 3 & $\begin{array}{l}\text { Taking away children's opportunities for physical activity is an appropriate form } \\
\text { of discipline. }\end{array}$ \\
\hline Statement 4 & $\begin{array}{l}\text { Physical activity provides children with opportunities to learn about health and } \\
\text { fitness. }\end{array}$ \\
\hline Statement 5 & $\begin{array}{l}\text { Physical activity is as important as other curriculum areas, such as reading, } \\
\text { math, and science. }\end{array}$ \\
\hline Statement 6 & $\begin{array}{l}\text { Physical activity teaches children motor skills, such as running, jumping, and } \\
\text { throwing. }\end{array}$ \\
\hline Statement 7 & My lesson plans impact children's opportunities for physical activity. \\
\hline Statement 8 & $\begin{array}{l}\text { Physical activity helps children develop social skills, such as sharing, taking } \\
\text { turns, and cooperating with classmates. }\end{array}$ \\
\hline Statement 9 & $\begin{array}{l}\text { Part of my job is to make sure that children get a healthy amount of physical } \\
\text { activity. }\end{array}$ \\
\hline Statement 10 & $\begin{array}{l}\text { Providing children with opportunities to be active is an important aspect of my } \\
\text { job. }\end{array}$ \\
\hline Statement 11 & $\begin{array}{l}\text { When I make an effort to encourage children to be active, they get a lot of } \\
\text { physical activity. }\end{array}$ \\
\hline Statement 12 & Sleep makes important contributions to the development of the whole child. \\
\hline Statement 13 & Naps influence classroom behaviors. \\
\hline Statement 14 & $\begin{array}{l}\text { The classroom environment (e.g., noise, placement of cots, light) can impact a } \\
\text { child's sleep behaviors. }\end{array}$ \\
\hline Statement 15 & Part of my job is to make sure that children get a healthy amount of rest. \\
\hline Statement 16 & My lesson plans impact children's opportunities for sleep. \\
\hline Statement 17 & Providing children with opportunities to rest is an important aspect of my job. \\
\hline
\end{tabular}

Pearson correlations were computed among the 17 statements to determine if they were related. The results of the correlational analysis show that 16 of the 17 correlations were statistically significant. The one statement that was not correlated to the others was 


\section{"Taking away children's opportunities for physical activity is an appropriate form of discipline." The results of the correlational analysis can be found in Table 2 .}

\section{Table 2 Correlations among Beliefs and Values of Healthy Lifestyle Habits}

\begin{tabular}{|c|c|c|c|c|c|c|c|c|c|}
\hline Statement & 1. & 2. & 3. & 4. & 5. & 6. & 7. & 8. & 9. \\
\hline $\begin{array}{l}\text { 1. PA makes important contributions to the } \\
\text { development of the whole child. }\end{array}$ & - & & & & & & & & \\
\hline $\begin{array}{l}\text { 2. PA allows children a fun break from } \\
\text { regular classroom activities. }\end{array}$ & $.725^{* *}$ & - & & & & & & & \\
\hline $\begin{array}{l}\text { 3. Taking away children's opportunities } \\
\text { for PA is an appropriate form of discipline. }\end{array}$ & .101 & .101 & - & & & & & & \\
\hline $\begin{array}{l}\text { 4. PA provides children with opportunities } \\
\text { to learn about health and fitness. }\end{array}$ & $.857^{* * *}$ & $.744 * *$ & .054 & - & & & & & \\
\hline $\begin{array}{l}\text { 5. PA is as important as other curriculum } \\
\text { areas, such as reading, math and science. }\end{array}$ & $.535^{* *}$ & $.468^{* * *}$ & .200 & $.492 * *$ & - & & & & \\
\hline $\begin{array}{l}\text { 6. PA teaches children motor skills such as } \\
\text { running, jumping, and throwing. }\end{array}$ & $.889^{* * *}$ & $.816^{* *}$ & .068 & $.937 * *$ & $.560^{* *}$ & - & & & \\
\hline $\begin{array}{l}\text { 7. My lesson plans impact children's } \\
\text { opportunities for PA. }\end{array}$ & $.652 * *$ & $.546^{* *}$ & .186 & $.700^{* *}$ & $.856^{* *}$ & $.705^{* *}$ & - & & \\
\hline $\begin{array}{l}\text { 8. PA helps children develop social skills } \\
\text { such as sharing, taking turns, and } \\
\text { cooperating with classmates. }\end{array}$ & $.823 * *$ & $.792 * *$ & .090 & $.885^{* *}$ & $.438 * *$ & $.857^{* * *}$ & $.638^{* * *}$ & - & \\
\hline $\begin{array}{l}\text { 9. Part of my job is to make sure that } \\
\text { children get a healthy amount of PA. }\end{array}$ & $.541 * *$ & $.589 * *$ & .055 & $.582 * *$ & $.543 * *$ & $.606^{* *}$ & $.683^{* *}$ & $.547 * *$ & - \\
\hline $\begin{array}{l}\text { 10. Providing children with opportunities } \\
\text { to be physically active is an important } \\
\text { aspect of my job. }\end{array}$ & $.785^{* *}$ & $.583^{* *}$ & .151 & $.729^{* *}$ & $.757 * *$ & $.757 * *$ & $.793^{* *}$ & $.695^{* *}$ & $.682^{* *}$ \\
\hline $\begin{array}{l}\text { 11. When I make an effort to encourage } \\
\text { children to be active, they get a lot of PA. }\end{array}$ & $.735^{* *}$ & $.624 * *$ & .091 & $.838^{* *} *$ & $.550 * *$ & $.756^{* *} *$ & $.755^{* *}$ & $.817 * *$ & $.464^{* *}$ \\
\hline $\begin{array}{l}\text { 12. Sleep makes important contributions to } \\
\text { the development of the whole child. }\end{array}$ & $.832 * *$ & $.698^{* *}$ & .150 & $.854^{* * *}$ & $.534 * *$ & $.896^{* * *}$ & $.686 * *$ & $.756 * *$ & $.597^{* *}$ \\
\hline 13. Naps influence classroom behaviors. & $.345^{*}$ & $.376^{*}$ & .220 & $.402 *$ & $.416^{* *}$ & .313 & $.417 * *$ & $.406 * *$ & .179 \\
\hline $\begin{array}{l}\text { 14. The classroom environment (e.g., } \\
\text { noise, placement of cots, lights) can impact } \\
\text { a child's sleep behaviors. }\end{array}$ & $.347 *$ & .251 & .308 & $.333^{*}$ & $.406 * *$ & $.343^{*}$ & $.485 * *$ & .284 & .167 \\
\hline $\begin{array}{l}\text { 15. Part of my job is to make sure that } \\
\text { children get a healthy amount of rest. }\end{array}$ & $.501^{* *}$ & $.438^{* *}$ & -.052 & $.391 *$ & $.570 * *$ & $.419^{*}$ & $.463 * *$ & $.370^{*}$ & $.433^{* *}$ \\
\hline $\begin{array}{l}\text { 16. My lesson plans impact children's } \\
\text { opportunities for sleep. }\end{array}$ & $.415^{* *}$ & $.499^{*}$ & .114 & $.323^{*}$ & $.607 * *$ & $.330^{*}$ & $.568 * *$ & $.399 *$ & $.561^{* *}$ \\
\hline $\begin{array}{l}\text { 17. Providing children with opportunities } \\
\text { to rest is an important aspect of my job. }\end{array}$ & $.460^{* *}$ & $.422 * *$ & .054 & $.436^{* *}$ & $.761 * *$ & $.464 * *$ & $.715^{* *}$ & $.382 *$ & $.534^{* *}$ \\
\hline
\end{tabular}


Table 2 (continued)

\begin{tabular}{|c|c|c|c|c|c|c|c|c|}
\hline Statement & 10. & 11. & 12. & 13. & 14. & 15. & 16. & 17. \\
\hline $\begin{array}{l}\text { 10. Providing children with opportunities } \\
\text { to be physically active is an important } \\
\text { aspect of my job. }\end{array}$ & - & & & & & & & \\
\hline $\begin{array}{l}\text { 11. When I make an effort to encourage } \\
\text { children to be active, they get a lot of } \\
\text { PA. }\end{array}$ & $.682 * *$ & - & & & & & & \\
\hline $\begin{array}{l}\text { 12. Sleep makes important contributions to } \\
\text { the development of the whole child. }\end{array}$ & $.708 * *$ & $.697 * *$ & - & & & & & \\
\hline $\begin{array}{l}\text { 13. Naps influence classroom } \\
\text { behaviors. }\end{array}$ & .309 & $.416^{*}$ & $.369^{*}$ & - & & & & \\
\hline $\begin{array}{l}\text { 14. The classroom environment (e.g., } \\
\text { noise, placement of cots, lights) can } \\
\text { impact a child's sleep behaviors. }\end{array}$ & .285 & $.341 * *$ & $.475^{* *}$ & $.480^{* *}$ & - & & & \\
\hline $\begin{array}{l}\text { 15. Part of my job is to make sure that } \\
\text { children get a healthy amount of rest. }\end{array}$ & $.407^{*}$ & $.348^{*}$ & $.486 * *$ & $.557 * *$ & $.451^{* *}$ & - & & \\
\hline $\begin{array}{l}\text { 16. My lesson plans impact children's } \\
\text { opportunities for sleep. }\end{array}$ & $.578^{* *}$ & $.455^{* *}$ & $.364^{*}$ & $.426^{* *}$ & $.331 * *$ & $.650 * *$ & - & \\
\hline $\begin{array}{l}\text { 17. Providing children with opportunities } \\
\text { to rest is an important aspect of my job. }\end{array}$ & $.617 * *$ & $.551 * *$ & .551 & $.490 * *$ & $.430^{* * *}$ & $.708 * *$ & $.688^{* *}$ & - \\
\hline
\end{tabular}

Note. $\mathrm{PA}=$ physical activity.

$* p<.05 ; * * p<.01$.

\section{Results}

\section{Early Care Professionals Characteristics}

Approximately $95 \%$ of the population sampled returned a completed survey. Of

those 39 early care professionals who participated, the majority were female $(94.9 \%)$ and African American (80.5\%). Ages of the participants ranged from 25- to 65-years-old with an average age of 42 years. Participants averaged 12.64 years $(S D=10.69$ years $)$ in the early childhood classroom. Of the 36 who reported their level of education, the majority had earned a master's $(n=4)$ or bachelor's degree $(n=18)$, with at least some college $(n$ $=8$ ) or a high school diploma $(n=6)$ reported for the rest. Of the 28 who provided information about weight and height, $64 \%$ were classified as obese $(n=18), 18 \%$ were 
classified as overweight $(n=5)$, and 18\% $(n=5)$ were classified as normal weight. General health ratings of the early care professionals indicated that most of the early care professionals considered themselves to be in good (56\%) or excellent (33\%) health, with the remaining $(11 \%)$ reporting fair health.

\section{Importance of Physical Activity for Child Development}

To understand the beliefs and values of early care professionals regarding the importance of physical activity for healthy child development, seven statements were examined. The findings regarding each statement are presented below. The mean and standard deviation for each statement associated with physical activity and its role in child development is provided in Table 3.

\section{Statement 1. Physical activity makes important contributions to the whole child}

All of the early care professionals agreed that physical activity makes important contributions to healthy development of children. Specifically, 79\% of the early care professionals strongly agreed with the statement and $13 \%$ indicated they moderately agreed. A total of $8 \%$ of the participants slightly agreed with the statement.

\section{Statement 2. Physical activity allows children a fun break from regular classroom activities}

A large majority (95\%) of the early care professionals believed that physical activity provides children with a break from the usual classroom activities. That is, $74 \%$ of the participants strongly agreed with the statement, $13 \%$ moderately agreed and $8 \%$ slightly agreed. Additionally, $2 \%$ of the early care professionals slightly disagreed and $3 \%$ moderately disagreed with the statement. 


\section{Statement 3. Taking away children's opportunities for physical activity is an appropriate form of discipline}

The majority (74\%) of early care professionals disagreed with the statement that taking away a child's opportunity for physical activity is an appropriate form of discipline. Specifically, 53\% strongly disagreed, $11 \%$ moderately disagreed, and 10\% slightly disagreed. While, $10 \%$ slightly agreed, $3 \%$ moderately agreed, and $13 \%$ strongly agreed with the statement.

\section{Statement 4. Physical activity provides children with opportunities to learn about health and fitness}

All of the early care professionals (100\%) believed that children have opportunities to learn about health and fitness during physical activity. A large majority (84\%) strongly agreed, while $13 \%$ moderately agreed with the statement. A small percentage $3 \%$ of the early care professional slightly agreed that physical activity provides children with opportunities to learn about health.

\section{Statement 5. Physical activity is as important as other curriculum areas, such as} reading, math, and science

A majority of the early care professionals (89\%) felt that physical activity is an important curriculum area. Exactly 50\% of the participants strongly agreed with the statement, $29 \%$ moderately agreed, and 10\% slightly agreed. Smaller numbers of early care professionals disagreed that physical activity was as important as more academic areas, with, $5 \%$ selecting that they slightly disagreed, $3 \%$ moderately disagreed, and 3\% strongly disagreed with the statement. 


\section{Statement 6. Physical activity teaches children motor skills, such as running, jumping, and throwing}

The early care professionals all (100\%) agreed that children learn vital motor skills from physical activity. Specifically, $87 \%$ strongly agreed, $8 \%$ moderately agreed, and 5\% slightly agreed. None of the early care professionals disagreed with the statement.

\section{Statement 8. Physical activity helps children develop social skills, such as sharing, taking turns, and cooperating with classmates}

The majority of the early care professionals (97\%) agreed that children learn social skills during physical activity. Specifically, $79 \%$ of the early childhood professionals were in strong agreement with the statement, $10 \%$ were in moderate agreement, and $8 \%$ were in slight agreement. A total of 3\% of the early care professionals slightly disagreed with the statement.

Table 3 Means and Standard Deviations of Beliefs and Values of Physical Activity

\begin{tabular}{|c|c|c|c|}
\hline & Statement & Mean & $\begin{array}{r}\text { Standard } \\
\text { Deviation }\end{array}$ \\
\hline Statement 1 & $\begin{array}{l}\text { Physical activity makes important contributions to the } \\
\text { development of the whole child. }\end{array}$ & 5.71 & .61 \\
\hline Statement 2 & $\begin{array}{l}\text { Physical activity allows children a fun break from } \\
\text { regular classroom activities. }\end{array}$ & 5.52 & .95 \\
\hline Statement 3 & $\begin{array}{l}\text { Taking away children's opportunities for physical } \\
\text { activity is an appropriate form of discipline. }\end{array}$ & 4.60 & 1.82 \\
\hline Statement 4 & $\begin{array}{l}\text { Physical activity provides children with opportunities to } \\
\text { learn about health and fitness. }\end{array}$ & 5.82 & .46 \\
\hline Statement 5 & $\begin{array}{l}\text { Physical activity is as important as other curriculum } \\
\text { areas, such as reading, math, and science. }\end{array}$ & 5.10 & 1.23 \\
\hline Statement 6 & $\begin{array}{l}\text { Physical activity teaches children motor skills, such as } \\
\text { running, jumping, and throwing. }\end{array}$ & 5.82 & .51 \\
\hline Statement 8 & $\begin{array}{l}\text { Physical activity helps children develop social skills, } \\
\text { such as sharing, taking turns, and cooperating with } \\
\text { classmates. }\end{array}$ & 5.66 & .74 \\
\hline
\end{tabular}




\section{Importance of Sleep for Child Development}

To determine the beliefs and values of early care professionals regarding the importance of sleep for healthy child development three statements were examined. Presented below are the findings of each of the three statements. Additionally, the mean and standard deviations of the responses for each statement are presented in Table 4.

\section{Statement 12. Sleep makes important contributions to the development of the whole child}

All of the early care professionals (100\%) agreed that sleep contributes to the healthy development of children. Specifically, 95\% strongly agreed and 5\% moderately agreed. None of the early care professionals disagreed with the statement regarding the contribution of sleep to healthy development.

\section{Statement 13. Naps influence classroom behaviors}

Over three-quarters of the participants $(78 \%)$ believed that naps affected children's behaviors in the classroom. A total of $43 \%$ of the participants strongly agreed, $19 \%$ moderately agreed, and $16 \%$ slightly agreed with the statement. Of the early care professionals responding, 14\% slightly disagreed, 5\% moderately disagreed, and 3\% strongly disagreed that naps influence classroom behaviors.

\section{Statement 14. The classroom environment (e.g., noise, placement of cots, light) can impact a child's sleep behaviors}

The majority (90\%) of the early care professionals agreed that the classroom environment has a role in children's sleep behaviors. Half of the early care professionals $(50 \%)$ strongly agreed, $32 \%$ moderately agreed, and $8 \%$ slightly agreed that the 
classroom environment influences children's sleep. While 3\% of the sample slightly disagreed, $5 \%$ moderately disagreed, and $2 \%$ strongly disagreed with the statement.

Table 4 Means and Standard Deviations of Beliefs and Values of Sleep

\begin{tabular}{llrr}
\hline & Statement & Mean & $\begin{array}{r}\text { Standard } \\
\text { Deviation }\end{array}$ \\
\hline Statement 12 & $\begin{array}{l}\text { Sleep makes important contributions to the } \\
\text { development of the whole child. }\end{array}$ & 5.95 & .23 \\
Statement 13 & $\begin{array}{l}\text { Naps influence classroom behaviors. } \\
\text { Statement 14 }\end{array}$ & $\begin{array}{l}\text { The classroom environment (e.g., noise, placement of } \\
\text { cots, lights) can impact a child's sleep behaviors. }\end{array}$ & 5.73 \\
\hline
\end{tabular}

\section{Early care professionals' role in assisting children in establishing healthy habits}

To understand what the early care professionals believe their role is in assisting young children with establishing healthy habits related to physical activity and sleep, seven statements were examined. Below the findings are provided. The mean and standard deviation of each of the four statements is presented in Table 5.

\section{Statement 7. My lesson plans impact children's opportunities for physical activity}

Most of the participants (97\%) felt that their lesson plans determine the opportunities children have for physical activity. A total of $60 \%$ of the early care professionals strongly agreed with the statement, $24 \%$ moderately agreed, and $13 \%$ slightly agreed. Only $3 \%$ of the participants slightly disagreed with the statement.

\section{Statement 9. Part of my job is to make sure that children get a healthy amount of physical activity}

Most early care professionals (92\%) reported that they believed that part of their job is to ensure that children get a healthy amount of physical activity. Specifically, $71 \%$ 
strongly agreed, $11 \%$ moderately agreed, while $10 \%$ slightly agreed with the statement. Of the participants responding, 5\% slightly disagreed and 3\% strongly disagreed that part of their job was to make sure children get a healthy amount of physical activity.

\section{Statement 10. Providing children with opportunities to be physically active is an important aspect of my job}

The majority of the participants (95\%) agreed that an important aspect of their job is to provide opportunities for children to be physically active during the day. More than half $(68 \%)$ of the early care professionals strongly agreed with the statement, with $19 \%$ moderately agreeing and $8 \%$ slightly agreeing. Only $5 \%$ of the early care professionals slightly disagreed that engaging children in physical activity was an important part of their job.

\section{Statement 11. When I make an effort to encourage children to be active, they get a lot of physical activity}

All of the early care professionals felt that when they make efforts to encourage children to be active, the children engage in more physical activity. Specifically, $65 \%$ strongly agreed, 19\% moderately agreed, and 16\% slightly agreed with the statement. None of the early care professionals disagreed.

\section{Statement 15. Part of my job is to make sure that children get a healthy amount of sleep}

A majority $(82 \%)$ of the early care professionals believed that part of their job is making sure children get a healthy amount of sleep. Specifically, 53\% strongly agreed, $13 \%$ moderately agreed, and $16 \%$ slightly agreed with the statement regarding sleep. A 
total of $13 \%$ slightly disagreed and $5 \%$ moderately disagreed, while none of the early care professionals strongly disagreed.

\section{Statement 16. My lesson plans impact children's opportunities for sleep}

More than half of the participants $(65 \%)$ perceived that their lesson plans

influence the opportunities children have for sleep, while $35 \%$ disagreed. Precisely, $27 \%$

strongly agreed, 24\% moderately agreed, and 14\% slight agreed that their lesson plans

impact children's sleep opportunities. A total of 14\% slightly disagreed, $13 \%$ moderately disagreed, and $8 \%$ strongly disagreed with the statement.

\section{Statement 17. Providing children with opportunities to rest is an important aspect of my job}

A large percentage of the early care professionals surveyed (89\%) felt that an aspect of their job was to provide children with the opportunity to rest. Over half (51\%) strongly agreed with the statement, $14 \%$ moderately agreed, while $24 \%$ slightly agreed. A total of $11 \%$ of the participants slightly disagreed with the statement. 
Table 5 Means and Standard Deviations of Beliefs and Values Regarding Role in Assisting Children in Establishing Health Habits

\begin{tabular}{lllr}
\hline & Statement & Mean & $\begin{array}{r}\text { Standard. } \\
\text { Deviation }\end{array}$ \\
\hline Statement 7 & $\begin{array}{l}\text { My lesson plans impact children's opportunities for } \\
\text { physical activity. }\end{array}$ & 5.40 & .83 \\
Statement 9 & $\begin{array}{l}\text { Part of my job is to make sure that children get a } \\
\text { healthy amount of physical activity. }\end{array}$ & 5.39 & 1.15 \\
Statement 10 & $\begin{array}{l}\text { Providing children with opportunities to be } \\
\text { physically active is an important aspect of my job. }\end{array}$ & 5.49 & .87 \\
Statement 11 & $\begin{array}{l}\text { When I make an effort to encourage children to be } \\
\text { active, they get a lot of physical activity. }\end{array}$ & 5.49 & .77 \\
Statement 15 & $\begin{array}{l}\text { Part of my job is to make sure that children get a } \\
\text { healthy amount of sleep. }\end{array}$ & 4.95 & 1.31 \\
Statement 16 & $\begin{array}{l}\text { My lesson plans impact children's opportunities for } \\
\text { sleep. }\end{array}$ & 4.13 & 1.67 \\
Statement 17 & $\begin{array}{l}\text { Providing children with opportunities to rest is an } \\
\text { important aspect of my job. }\end{array}$ & 5.05 & 1.10 \\
\hline
\end{tabular}

\section{Early care professionals' demographic characteristics associated with beliefs and values}

To determine how early care professionals' beliefs and values regarding their role in assisting young children with establishing health habits were associated with demographic characteristics (e.g., age, gender, BMI classification, race, level of education and number of years of early childhood education experience) and perceptions of their own health, Pearson correlation coefficients were computed for the continuous variables and chi squares were conducted on the categorical variables. Analyses (see Table 6) indicated no significant associations between early care professionals' beliefs and values and their demographic (e.g., age, gender, BMI classification, race, level of education and number of years of early childhood education experience) or perceived health variables. 
Table 6 Correlations among Demographics and Beliefs and Values of Healthy Lifestyle Habits

\begin{tabular}{|c|c|c|c|c|c|c|}
\hline Statement & Gender & Age & BMI & Ed. & Exp. & Health \\
\hline $\begin{array}{l}\text { 1. PA makes important contributions to the development of the } \\
\text { whole child. }\end{array}$ & -.117 & .247 & .065 & .080 & .017 & -.183 \\
\hline $\begin{array}{l}\text { 2. PA allows children a fun break from regular classroom } \\
\text { activities. }\end{array}$ & .130 & .233 & .044 & -.024 & .073 & .027 \\
\hline $\begin{array}{l}\text { 3. Taking away children's opportunities for PA is an } \\
\text { appropriate form of discipline. }\end{array}$ & .041 & .085 & .327 & .146 & .219 & -.320 \\
\hline $\begin{array}{l}\text { 4. PA provides children with opportunities to learn about health } \\
\text { and fitness. }\end{array}$ & -.099 & .053 & .130 & -.075 & -.241 & -.043 \\
\hline $\begin{array}{l}\text { 5. PA is as important as other curriculum areas, such as reading, } \\
\text { math and science. }\end{array}$ & .016 & .235 & .221 & -.061 & .093 & .227 \\
\hline $\begin{array}{l}\text { 6. PA teach children motor skills such as running, jumping, and } \\
\text { throwing. }\end{array}$ & -.088 & .071 & .165 & .083 & -.149 & -.123 \\
\hline 7. My lesson plans impact children's opportunities for PA. & -.033 & .127 & .060 & -.202 & -.010 & .164 \\
\hline $\begin{array}{l}\text { 8. PA helps children develop social skills such as sharing, } \\
\text { taking turns, and cooperating with classmates. }\end{array}$ & .048 & .165 & -.050 & -.180 & -.001 & .052 \\
\hline $\begin{array}{l}\text { 9. Part of my job is to make sure that children get a healthy } \\
\text { amount of PA. }\end{array}$ & -.025 & .025 & .185 & -.167 & -.131 & .119 \\
\hline $\begin{array}{l}\text { 10. Providing children with opportunities to be physically } \\
\text { active is an important aspect of my job. }\end{array}$ & -.008 & .026 & .240 & -.098 & -.124 & .069 \\
\hline $\begin{array}{l}\text { 11. When I make an effort to encourage children to be active, } \\
\text { they get a lot of PA. }\end{array}$ & -.009 & .289 & -.020 & -.235 & .096 & .254 \\
\hline $\begin{array}{l}\text { 12. Sleep makes important contributions to the development of } \\
\text { the whole child }\end{array}$ & -.057 & .170 & .362 & .105 & .171 & -.107 \\
\hline 13. Naps influence classroom behaviors. & .038 & .176 & -.023 & -.327 & .006 & -.057 \\
\hline $\begin{array}{l}\text { 14. The classroom environment (e.g., noise, placement of cots, } \\
\text { lights) can impact a child's sleep behaviors. }\end{array}$ & .110 & -.151 & -.209 & -.048 & .062 & .004 \\
\hline $\begin{array}{l}\text { 15. Part of my job is to make sure that children get a healthy } \\
\text { amount of rest. }\end{array}$ & -.081 & .234 & -.096 & -.200 & -.044 & -.027 \\
\hline 16. My lesson plans impact children's opportunities for sleep. & .238 & .256 & .010 & -.255 & .200 & .201 \\
\hline $\begin{array}{l}\text { 17. Providing children with opportunities to rest is an important } \\
\text { aspect of my job. }\end{array}$ & -.207 & .236 & -.140 & -.112 & .096 & .246 \\
\hline
\end{tabular}

Note. $\mathrm{PA}=$ physical activity, $\mathrm{BMI}=$ body mass index, Ed. $=$ Education, Exp. $=$ Experience. ${ }^{*} p<.05$.

\section{Discussion}

This study aimed to investigate what early care professionals in a county in Mississippi at high risk for childhood obesity believe about the extent of the role of physical activity and sleep play in young children's development, what they believe is their role in assisting children with establishing healthy habits, and how their beliefs and values are associated with demographic characteristics and perceptions of their own health. The study was the first to our knowledge that examined the beliefs and values of 
early childhood professionals in relation to the importance of physical activity and sleep in early childhood and to examine how those beliefs relate to the professionals' health. Consistent with the literature, the results indicated early care professionals believe that physical activity (Coleman \& Dyment, 2013; Dwyer, Higgs, Hardy, \& Baur, 2008; Hesketh et al., 2015; Tucker et al., 2011) and sleep (Pattinson, Staton, Smith, Sinclair, \& Thorpe, 2014) are important contributors to the development of young children, but variations were evident in responses regarding the early care professionals' role or the classroom environments' contributions to these healthy behaviors.

The belief that physical activity was important for not only healthy behaviors and fitness, but also motor skills and social skills was highly recognized by the early care professionals, which is likely a result of the types of trainings on physical activity that they have received. For example, Head Start utilizes an approach to service delivery similar to Bronfenbrenner's ecological model (Bronfrenner, 1977) by providing comprehensive services to low-income children and their families. As a result, Head Start staff are provided with training related to physical activity and development. Head Start early care professionals are also required to hold a bachelor's degree in education or early childhood, while assistant early care professionals must hold a minimum of a Child Development Associate (CDA) credential, indicating more education and training required for this group of early care professionals than those who work in communitybased early care and education programs. However, $26 \%$ of the early care professionals believed that taking away children's opportunities for physical activity was an appropriate form of discipline, indicating that they do not feel that physical activity is as important as other aspects of the program and can be taken away if necessary. This 
finding is concerning given that early care professionals have access to professional development on correct forms of discipline (State Early Childhood Advisory Council of Mississippi, 2018), but may not be applying the information. Taking away physical activity as a consequence also indicates that physical activity is thought of as a fun activity, rather than an important contributor to optimal child development. This finding suggests that the current training available on physical activity is not sufficiently addressing the critical role of physical activity in development. Early childhood educators may benefit from training that demonstrates how physical activity may reduce behavior problems in the classroom while improving academic outcomes for children.

While all of the early childhood educators agreed to some degree that sleep contributed to the development of the whole child, they were much less likely to agree on how the classroom was set up or how the lessons were planned contributed to children's sleep behaviors. Good sleep hygiene recommendations include preparing children mentally and physically (e.g., quiet activities, relaxation techniques), as well as the environment (e.g., dim lights, quiet), for sleep (National Sleep Foundation, 2018). Early care professionals who do not believe that the activities they plan are affecting sleep may be providing activities that stimulate children (e.g., singing and dancing) rather than calming them down (e.g., reading a story) in preparation for rest. Early care professionals may be more concerned about staying on schedule (e.g., meals, snacks) than with providing an appropriate sleep environment. As supported by Bronfenbrenner's exosystem's role in development (Bronfenbrenner, 1977), some of the schedule is mandated by governmental entities such as the USDA (Office of the Administration for Children \& Families, 2017) and child care licensure (Mississippi State Department of 
Health, 2018), yet limited oversight is provided regarding the sleep environment.

Adjusting the classroom environment (e.g., dimming lights, quiet conditions) may not be a priority before and during nap for early care professionals who do not recognize the importance of the immediate environment for sleep. The physical activity and sleep beliefs results highlight that early care professionals have the knowledge about healthy behaviors and their importance for child development, but may not always make the connection between the classroom environment and lesson plans influencing those children's health behaviors. These findings highlight the need for future trainings to incorporate specific examples of how to make the classroom and lesson plans conducive to meeting the recommendations on physical activity and sleep.

The early care professionals strongly agreed that part of their job was to make sure that children receive a healthy amount of physical activity. However, the early care professionals did not agree as strongly that making sure that children receive a healthy amount of sleep was a part of their job. This finding suggests that early care professionals may believe that sleep is more related to the home environment than to the early childhood classroom. The inner most circle of Bronfenbrenner's ecological model (i.e., microsystem) emphasize the immediate environments a child experiences, (i.e., home, early care and learning center) and the importance of the two working together (Bronfenbrenner, 1977). This concept may be particularly important for sleep given that many preschool-aged children have not yet consolidated their sleep to only the nighttime. Thus, to understand if the child is receiving the recommended amount of sleep across the 24-hour period, there must be communication between the two immediate environments (i.e., home, early care and learning center). The finding highlights the need for training 
on sleep, specifically related to the classroom environment and communication with families about the child's daytime sleep habits.

Using self-reported height and weight, the majority of the early care professionals were classified as either overweight or obese, which is consistent with what has been found in previous studies with this population (Acharya et al., 2011; Baldwin et al., 2007; Child Care Aware of America, 2015; Gratz \& Claffey, 1996; Sharma et al., 2013). Given that obesity is associated with a number of health problems (Esquivel et al., 2016; Lo et al., 2013; Xu \& Xue, 2016), it was interesting that more than three-fourths of the sample perceived their health to be good or excellent. These data suggest that the early care professionals may not recognize the role of obesity in overall health (Ogden et al., 2016; Sahoo et al., 2015; Xu \& Xue, 2016). Specifically, early care professionals may not recognize obesity as a health concern until they have medical issues (e.g., high blood pressure, diabetes) associated with their weight. Additionally, these findings further support the idea that the health habits early care professionals learn about for children are not translating to the early care professionals' own lives (Calder, 1994). Although the majority of early childhood professionals were classified as overweight or obese, there was no significant association between their health assessments (i.e., BMI; global health rating) and their beliefs about physical activity and sleep. Additional demographic variables (i.e., gender, age, level of education, experience) were not found to be associated with any of the 17 beliefs and values statements. These associations should be replicated before conclusions are drawn, but it is plausible that the lack of variability in demographic variables (e.g., health rating; gender; education) with this population may be contributing to this finding. 


\section{Strengths and Limitations}

Strengths of this research included the novelty of the study's purpose in an understudied rural southern state that is plagued by higher than U.S. average rates of obesity. While the findings may not be generalizable to other early care professionals throughout the U.S., it does help to understand the actions and beliefs of a specific population and allows for the creation of professional development trainings that are tailored to the clientele. By having insight into the beliefs and values of the early care professionals who work with some of the most at-risk children for obesity, trainings could be potentially more effective for improving the health habits of young children. Another strength of the study was that all but two of the early care professionals in the consortium participated. Obtaining data from $95 \%$ of the population speaks to the strength of the relationships that were established between the researcher and the early care professionals and administrators and bodes well for future willingness of participants to attend trainings based off of these data. The sample represented $48 \%$ of the total early care professionals working in the targeted county at the time. During the research study, there were seven other early care and education programs operating in the county with approximately 40 full-time staff employed.

While the study added to the scant literature that documents beliefs or values of healthy habits of early care professionals, there are some limitations that should be noted. For example, it is possible that asking early care professionals to complete a survey about beliefs and values of healthy lifestyles may have introduced a social desirability bias. That is, given the subjective nature of the data there was no way to verify that what the providers reported about their beliefs were actually accurate. Additionally, the BMI of the 
early care professional was calculated based on self-reported height and weight data and thus obesity rates could have been underreported. However, a large portion of the sample was classified as obese or overweight, which reduces the concern of social desirability bias for that measure. Furthermore, there was not a belief and values assessment measure that focused on physical activity and sleep in the early childhood classroom found in the literature and thus the assessment used was developed for this study and has not been tested for reliability and validity. Future studies need to evaluate the measure with larger samples. The possibility also exists that there was bias reporting due to the use of only one measure of beliefs and that objective assessments of health were not obtained (i.e., actual weight and height readings).

Another possible limitation was two of the statements on the Beliefs and Values survey did not specify a direction of effects and could have been potentially misinterpreted. Specially, all of the other 15 statements included a positive or negative qualifier, but statements 7 and 16 did not. Future work may consider more specifically spelling out the impact of lesson plans on physical activity and sleep.

\section{Future Research}

Future research should assess the beliefs and values, particularly as they relate to physical activity and sleep, of early care professionals using more diverse samples, to fully understand how the early childhood classroom contributes to the development of health habits for young children. Reliability and validity assessments need to be conducted on the beliefs and values survey developed for this study. More objective assessments of early care professionals' health (e.g., health condition checklist; blood pressure; measurement of weight and height) in conjunction with the self-ratings may 
provide more insight into how the health of the caregiver relates to beliefs and values. Additionally, developing trainings that focus on areas where early care professionals' beliefs may not align with best practices may improve children's development of healthy habits and these trainings need to be evaluated.

Limited research has been conducted on how the health of early care professionals impacts the quality of care the children receive in the classroom (Baldwin et al., 2007), yet providing early care professionals with the tools to serve as role models for the children may result in healthier children and adults. Further research should examine if the beliefs and values regarding healthy habits are transferred to the classroom theory like other beliefs and values have been found to be (McClintic \& Petty, 2015). Additionally, examination of the actual behaviors of early care professionals in the classroom as they pertain to lesson plans (e.g., What are they planning for children to do right before nap?; How often are they providing children outside with structured physical activities?), the classroom environment (e.g., Do they dim the lights prior or during nap- time?; Is the classroom set up in a way that allows children the opportunity to move?), and the early care professionals' engagement in healthy behavior modeling may provide greater insight into the understanding of how the early childhood classroom contributes to children's healthy habits.

\section{Implications for Practice}

Using an ecological approach, similar to The Early Childhood Obesity Prevention Program (ECHO; Cloutier, Wiley, Wang, Grant, \& Gorin, 2015) and Be Active Kids (De Marco, Zeisel, \& Odom, 2015), programs need to focus on routine professional development for early care professionals that is tailored to their beliefs and values. 
Programs designed to help teach children healthy lifestyle behaviors should use an integrated curriculum where healthy behaviors are routinely discussed with children through a variety of academic domains and activities. In addition, the connection between home and school should be supported by providing tips to parents (e.g., Extension publications, parent meetings, newsletters) about ways to increase or improve children's healthy habits and understand the time recommendations suggested by professionals. Early care and education programs that are striving to help children develop healthy habits in young children could achieve better outcomes when parents understand the importance of physical activity and sleep. Children who are encouraged to be physically active at home and at school are more likely to meet recommended amounts of activity every day. In addition, when parents and early care professionals understand good sleep hygiene practices children are more likely to receive healthy amounts of sleep in both environments.

In conclusion, the current study provides an extension of the literature on the beliefs and values of early care professionals related to physical activity and sleep and their role in promoting healthy lifestyle habits. The study adds support to existing research in that early care professionals understand the importance of physical activity and to a lesser degree sleep on healthy development of young children. Early care professionals also appear to understand the role they play in helping children develop healthy lifestyle habits, but may be lacking the education and resources needed to implement changes within their classroom. 


\section{REFERENCES}

Acharya, K., Feese, M., Franklin, F., \& Kabagambe, E. K. (2011). Body mass index and dietary intake among Head Start children and caregivers. Journal of the American Dietetic Association, 111(9), 1324-1321. doi.org/10.1016/j.jada.2011.06.013

Baldwin, D., Gaines, S., Wold, J. L., Williams, A., \& Leary, J. (2007). The health of female child care providers implications for quality of care. Journal of Community Health Nursing, 24, 1-17.

Bohn, C. M., Haskins, D. D., Loo, R. K., \& Ahrendt, L. J. (2014). Evaluation of the South Dakota fitCare child care provider training program targeting nutrition and physical activity. South Dakota Medicine, 67, 305-313.

Bronfenbrenner, U. (1977). Toward an experimental ecology of human development. American Psychologist, 32, 513-531.

Bucholz, E. M., Desai, M. M., \& Rosenthal, M. S. (2011). Dietary intake in Head Start vs non-Head Start preschool-aged children: Results from the 1999-2004 National Health and Nutrition Examination Survey. Journal of the American Dietetic Association, 111, 1021-1030. doi: 10.1016/j.jada.2011.04.009

Calder, J. (1994). Occupational health and safety issues for child care providers. Pediatrics, 94(6), 1072-1073.

Center for the Study of Child Care Employment (2016). Retrieved from http://cscce.berkeley.edu

Centers for Disease Control and Prevention. (2018). Retrieved from https://www.cdc.gov

Child Care Aware of America. (2015). Retrieved from http://childcareaware.org

Cloutier, M. M., Wiley, J., Wang, Z., Grant, A., \& Gorin, A. A. (2015). The Early Childhood Obesity Prevention Program (ECHO): An ecologically-based intervention delivered by home visitors for newborns and their mothers. BMC Public Health, 1-13. doi.org/10.1186/s12889-015-1897-9

Coleman, B., \& Dyment, J. E. (2013). Factors that limit and enable preschool-aged children's physical activity on child care center playgrounds. Journal of Early Childhood Research, 11, 203-221. doi.org/10.1177/1476718X12456250 
Copeland, K. A., Sherman, S. N., Kendeigh, C. A., Kalkwarf, H. J., \& Saelens, B. E. (2012). Societal values and policies may curtail preschool children's physical activity in child care centers. Pediatrics, 129, 265-274.

doi: 10.1542/peds.2011-2012

De Marco, A. C., Zeisel, S., \& Odom, S. L. (2015). An evaluation of a program to increase physical activity for young children in child care. Early Education and Development, 26, 1-26. doi.org/10.1080/10409289.2014.932237

Dwyer, G. M., Higgs, J., Hardy, L. L., \& Baur, L. A. (2008). What do parent and preschool staff tell us about young children's physical activity: A qualitative study. International Journal of Behavioral Nutrition and Physical Activity, 5(66), 1-11. doi.org/10.1186/1479-5868-5-66

Dyment, J., \& Coleman, B. (2012). The intersection of physical activity opportunities and the role of early childhood educators during outdoor play: Perceptions and reality. Australian Journal of Early Childhood, 37, 90-98.

Early Childhood Obesity Prevention Policies. (2011). Institute of Medicine, Washington, D.C. Retrieved from http://www.nationalacademies.org/hmd/Reports/2011/EarlyChildhood-Obesity-Prevention-Policies.aspx

Esquivel, M. K., Nigg, C. R., Fialkowski, M. K., Braun, K. L., Li, F., \& Novotny, R. (2016). Influence of teachers' personal health behaviors on operationalizing obesity prevention policy in Head Start preschools: A project of the Children's Healthy Living Program (CHL). Journal of Nutrition Education and Behavior, 48, 318-324. doi.org/10.1016/j.jneb.2016.02.007

Freedman, M. R., \& Alvarez, K. P. (2010). Early childhood feeding: Assessing knowledge, attitudes, and practices of multi-ethnic child-care providers. Journal of the American Dietetic Association, 110, 447-451.

doi: 10.1016/j.jada.2009.11.018

Gratz, R. R., \& Claffey, A. (1996). Adult health in child care: Health status, behaviors, and concerns of teachers, directors, and family child care providers. Early Childhood Research Quarterly, 11, 243-267.

Hesketh, K. R., van Slujis, E. M., Blaine, R. E., Taveras, E. M., Gillman, M. W., \& Neelon, S.B. (2015). Assessing care providers: Perceptions and beliefs about physical activity in infants and toddlers: Baseline findings from Baby NAP SACC study. BMC Public Health, 15, 1-7. doi: 10.1186/s12889-015-1477-z

Hughes, S. O., Patrick, H., Power, T. G., Fisher, J. O., Anderson, C. B., \& Nicklas, T. A. (2007). The impact of child care providers' feeding on children's food consumption. Journal of Developmental \& Behavioral Pediatrics, 28, 100-107. 
Huye, H. F., Bankston, S., Speed, D., \& Molaison, E.F. (2014). Evaluation of the Color Me Healthy program in influencing nutrition and physical activity in Mississippi preschool child care facilities. The Journal of Child Nutrition and Management, $38,1-13$.

Knutson, K. L., Spiegel, K., Penev, P., \& Van Cauter, E. (2007). The metabolic consequences of sleep deprivation. Sleep Medicine Reviews, 11, 163-17 doi.org/10.1016/j.smrv.2007.01.002

Larson, N., Ward, D. S., Neelon, S. B., \& Story, M. (2011). What role can child-care settings play in obesity prevention? A review of the evidence and call for research efforts. Journal of the American Dietetic Association, 111, 1343-1362. doi: 10.1016/j.jada.2011.06.007

Lee, R., Zhai, F., Han, W., Brooks-Gunn, J., \& Waldfogel, J. (2013). Head Start and children's nutrition, weight, and health care receipt. Early Childhood Research Quarterly, 28, 723-733. doi: 10.1016/j.ecresq.2013.06.003

Ling, J., Robbins, L., \& Wen, F. (2016). Interventions to prevent and manage overweight or obesity in preschool children: A systematic review. International Journal of Nursing Studies, 53, 270-289. doi.org/10.1016/j.ijnurstu.2015.10.017

Lo, J. C., Maring, B., Chandra, M., Daniels, S. R., Sinaiko, A., Daley, M. F., .. . Greenspan, L. C. (2013). Prevalence of obesity and extreme obesity in children aged 3-5 years Pediatric Obesity, 9, 165-175. doi: $10.1111 / \mathrm{j} .2047-6310.2013 .00154 \mathrm{x}$

Lumeng, J. C., Kaplan-Sanoff, M., Shuman, S., \& Kannan, S. (2008). Head Start teachers' perceptions of children's eating behavior and weight status in the context of food scarcity. Journal of Nutrition Education and Behavior, 40, 237243. doi: 10.1016/j.jneb.2007.07.001

Lundberg, O., \& Manderbacka, K. (1996). Assessing reliability of a measure of self-rated health. Scandinavian Journal of Public Health. 24(3): 218-224. doi.org/10.1177/140349489602400314

McClintic, S., \& Petty, K. (2015). Exploring early childhood teachers' beliefs and practices about preschool outdoor play: A qualitative study. Journal of Early Childhood Teacher Education, 36, 24-43. doi: 10.1080/10901027.2014.997844

McGrath, B. J., \& Huntington, A. D. (2007). The health and wellbeing of adults working in early childhood education. Australian Journal of Early Childhood, 32(3), 3338.

Mississippi State Department of Health, 2018. Retrieved from http://www.msdh.state.ms.us 
Morgenthaler, T. I., Croft, J. B., Dort, L. C., Loeding, L. D., Mullington, J. M. \& Thomas, S. M.(2015). Development of the national healthy sleep awareness project sleep health surveillance questions. Journal of Clinical Sleep, 11(9), 10571062. doi: $10.5664 /$ jcsm. 5026

Muckelbauer, R., Kalhoff, H., Muller-Nordhorn, J., \& Kersting, M. (2011). Childhood overweight and obesity: Introduction into epidemiology and prevention strategies. Current Nutrition \& Food Science, 7(3), 101-199.

National Sleep Foundation. (2018). Retrieved from https://www.sleepfoundation.org

Office of the Administration for Children \& Families. (207). Retrieved from https://www.acf.hhs.gov

Ogden, C. L., Carroll, M. D., Lawman, H. G., Fryar, C. D., Kruszon-Moran, D., Kit, B. K., \& Flegal, K. M. (2016). Trends in obesity prevalence among children and adolescents in the United States, 1988-1994 through 2013-2014. Journal of American Medical Association, 315, 2292-2299. doi: 10.1001/jama.2016.6361

Pattinson, C., Staton, S., Smith, S., Sinclair, D., \& Thorpe, K. (2014). Emotional climate and behavioral management during sleep time in early childhood education settings. Early Childhood Research Quarterly, 29, 660-668. doi.org/10.1111/1467-8624.00414

Sahoo, K., Sahoo, B., Choudhury, A., Sufi, N., Kumar, R., \& Bhadoria, A. (2015). Childhood obesity: Causes and consequences. Journal of Family Medicine and Primary Care, 4, 187-192. doi: 10.4103/2249-4863.154628

Sharma, S., Dortch, K. S., Byrd-Williams, C., Truxillio, J. B., Rahman, G. A., Bonsu, P., Hoelscher, D. (2013). Nutrition-related knowledge, attitudes, and dietary behaviors among Head Start teachers in Texas: A cross-sectional study. Journal of the Academy of Nutrition and Dietetics, 113, 558-562. doi: 10.1016/j.jand.2013.01.003

Sisson, S. B., Smith, C. L., \& Cheney, M. (2017). Big impact on small children: Childcare providers' perceptions of their role in early childhood healthy lifestyle behaviors. Child Care in Practice, 23(2), 162-180. doi.org/10.1080/13575279.2017.1299111

Slack-Smith, L. M., Read, A. W., Darby, J., \& Stanley, F. J. (2006). Health of caregivers in child care. Child: Care, Health \& Development, 32, 111-119.

Song, W. O., Song, S., Nieves, V., Gonzalez, A., \& Crockett, E. T. (2016). Nutritional health attitudes and behaviors and their associations with the risk of overweight/obesity among child care providers in Michigan Migrant and Seasonal Head Start centers. Biomed Central, 16(648), 1-11. doi: 10.1186/s12889-016-3328-y 
State Early Childhood Advisory Council of Mississippi. Retrieved from https://secac.ms.gov/early-childhood-academy/

State of Obesity. (2018). Retrieved from http://www.stateofobesity.org

Story, M., Kaphingst, K. M., \& French, S. (2006). The role of child care settings in obesity prevention. The Future of Children, 16, 143-168.

Tucker, P., van Zandvoort, M. M., Burke, S. M., \& Irwin, J. D. (2011). Physical activity at daycare: Childcare providers' perspectives for improvements. Journal of Early Childhood Research, 9, 207-219. doi.org/10.1177/1476718X10389144

U.S. Department of Health and Human Services (2016). Retrieved from https://www.hhs.gov

Whitebook, M., Phillips, D., \& Howes, C. (2014). Worthy work, STILL unlivable wages: The early childhood workforce 25 years after the National Child Care Staff Study, Executive Summary. Berkeley, CA: Center for the Study of Child Care Employment, University of California, Berkeley.

Whitaker, R. C., Becker, B. D., Herman, A. N., \& Gooze, R. A. (2013). The physical and mental health of Head Start staff: The Pennsylvania Head Start staff wellness survey, 2012. Preventing Chronic Disease, 10, 1-9. doi: 10.5888/pcd10.130171

Wood, E., \& Bennett, N. (2000). Changing theories, changing practices: Exploring childhood teachers' professional learning. Teacher and Teacher Education, 16, 635-647.

Xu, S., \& Xue, Y. (2016). Pediatric obesity: Causes, symptoms, prevention and treatment(review). Experimental and Therapeutic Medicine, 11, 15-20. doi.org/10.3892/etm.2015.2853

Yavuz, H. M., van Ijzendoorn, M. H., Mesman, J., \& van der Veek, S. (2015). Interventions aimed at reducing obesity in early childhood: A meta-analysis of programs that involve parents. Journal of Child Psychology and Psychiatry, 56, 677-692. doi.org/10.1111/jcpp. 12330

Zhai, F., Raver, C. C., \& Li-Grining, C. (2011). Classroom-based interventions and teachers' perceived job stressors and confidence: Evidence from a randomized trial in Head Start settings. Early Childhood Research Quarterly, 26, 442452.doi.org/10.1016/j. ecresq.2011.03.003

Zhai, F., Raver, C. C., \& Li-Grining, C. (2011). Classroom-based interventions and teachers' perceived job stressors and confidence: Evidence from a randomized trial in Head Start settings. Early Childhood Research Quarterly, 26, 442452.doi.org/10.1016/j.ecresq.2011.03.003 


\title{
CHAPTER III
}

\section{LESSONS ON ESTABLISHING HEALTHY HABITS IN EARLY CHILDHOOD}

\begin{abstract}
Manuscript 2
Using the results from Study 1 to address gaps in professional development on healthy habits in early childhood, Study 2 involved the development, implementation, and evaluation of two, 3-hour professional development trainings each focused on a contributor to the obesity epidemic (i.e., physical activity and sleep). Both trainings included an overview of the state of the science on the topic as it relates to early childhood and the area, recommendations for obesity prevention in the classroom, specific, hands-on examples of the early care professionals' role (i.e., behavioral and environmental) in establishing healthy habits. Pre- and post-surveys were used to assess the effectiveness of the training on knowledge of physical activity and/or sleep as it relates to early childhood. Additionally, two researchers conducted classroom observations prior to and following $(M=4.5$ weeks $)$ the training to assess potential behavior change within the classroom. Paired-samples $t$ tests indicated that early care professionals improved their general knowledge of physical activity and sleep in child development. Results indicated minimal behavioral and environmental changes in the classroom following the professional development.
\end{abstract}




\section{Manuscript 2}

Health habits are behaviors that individuals engage in daily that affect their overall health and well-being (Natale et al., 2014) and include obtaining daily recommended amounts of physical activity and sleep. These habits are established in the first five years of a child's life (Freedman \& Alvarex, 2010; Muchelbauer, Kalhoff, Muller-Nordorhorn, \& Kersting, 2011) and become the foundation for health habits across the lifespan (Esquivel et al., 2016), highlighting the importance of developing healthy habits early. Young children are dependent on the adults in their life to guide them in developing healthy habits (Natale et al., 2014; Sigman-Grant, Christianesen, Branen, Fletcher, \& Johnson, 2008), and given that the majority of children ages 3- to 5years-old are enrolled in non-parental care during the week (Saluja, Early, \& Clifford, 2002), the early childhood classroom would appear to be the ideal setting for helping children learn healthy behaviors (Ling, Robbins, \& Wen, 2016). Unfortunately, early care professionals are not always well equipped to teach healthy habits to children for several reasons, including a lack of knowledge regarding healthy habits and how to apply them in the early childhood classroom (Zhai, Raver, \& Li-Grining, 2011). Thus, ensuring that early care professionals are equipped with the needed knowledge and tools to assist children in developing healthy habits, particularly those children who are most at-risk for poor health (e.g., low income backgrounds), is imperative.

Research suggests that young children in the United States (U.S.) may not be developing the habits that are necessary to lead a healthy life and this is clear when the rates of obesity are examined. Childhood obesity in America is a critical health concern, with $13.9 \%$ of children under age 5 already classified as obese (State of Obesity, 2018). 
The situation is even more dire in heavily impoverished states like Mississippi, where $14.5 \%$ of children under 5 years of age are classified as obese and some counties have rates as high as 15.7\% (State of Obesity, 2018). These staggering rates forecast significant health problems ahead given that childhood obesity is directly tied to adult obesity (Esquivel et al., 2014), and often times results in health problems such as prediabetes (Sahoo et al., 2015), bone and joint problems (Xu \& Xue, 2015), and sleep apnea (Lo et al., 2013). In addition, obese children are subject to social and psychological problems such as poor self-esteem and stigmatization (Ogden et al., 2016), which also puts children at risk for mental health problems later in life.

Research confirms that ethnic-minority children (Natale et al., 2014) and children from low-income families (Hughes et al., 2007) are at a greater risk for obesity than their counterparts. For example, Latino children have the highest rate of childhood obesity (22.4\%), followed closely by African American children (20.2\%; State of Obesity, 2018). One factor contributing to obesity in minority populations is the increased likelihood that they live in low-income households (U.S. Census Bureau, 2018). Families living in poverty face a number of challenges to maintaining a healthy lifestyle and some of these challenges include limited resources, neighborhood safety concerns, chaotic schedules, and a greater likelihood of living in a food desert (Larson, Ward, Neelon, \& Story, 2011). These challenges families living in poverty face can reduce the modeling of healthy habits for children and increase the likelihood that children will not develop healthy lifestyle habits themselves. 


\section{The Role of Head Start}

Head Start and Early Head Start are the largest federally funded early childhood education programs in the U.S. and reach more than one million low-income children annually (Whitaker, Becker, Herman \& Gooze, 2013), providing an excellent opportunity to work with at-risk populations on developing healthy lifestyle behaviors. However, for the Head Start setting to be efficacious in increasing the healthy habits of young children from impoverished backgrounds, the early care professionals need to be knowledgeable of the components of a healthy lifestyle and be willing and able to integrate health lessons throughout the school day. Research suggests that some early care professionals believe that obesity in early childhood is something that a child will grow out of and thus they do not believe that an emphasis should be placed on it (Lumeng, Kaplan-Sanoff, Shuman \& Kanna, 2008).

Given the clear link between childhood obesity and adult obesity (Cloutier, Wiley, Wang, Grant, \& Gorin, 2015), this belief is problematic especially considering that $25 \%$ of Head Start children are obese compared to $9 \%$ of children age $2-5$ nationally (Sharma et al., 2013). These data suggest that the early childhood environment (e.g., schedule, lessons, room design), influenced by the beliefs and values of the early care professionals (Copeland, Sherman, Kendeigh, Kalkwarf, \& Salenens, 2012; McClintic \& Petty, 2015; Wood \& Bennett, 2000), may be contributing to the development of unhealthy habits rather than preventing them. Beliefs of educators are known to influence the classroom environment (McClintic \& Petty, 2015) and can be altered through education and experience (Wood \& Bennett, 2000), providing an avenue of potential change. 
Head Start centers and their early care professionals are in a unique position to offer multilevel approaches to the development of healthy habits by providing classroom activities known to improve health, and communicating with parents on their role in supporting children's health (Henry, Umoren, Kim, Zittel, \& Derscheid, 2017). However, Head Start early care professionals report that they do not feel confident in their ability to promote healthy lifestyle behaviors in their classrooms and indicate that they need educational programs to provide them with the necessary tools to enhance and teach healthy habits in the preschool environment (Davis et al., 2013). Taken together, these findings suggest that early childhood professionals, particularly those who work with atrisk populations, need more resources and support to provide children with an environment that promotes healthy lifestyle behaviors.

\section{Physical Activity and Sleep in the Early Childhood Program}

In addition to nutrition, obesity is directly related to two main behavioral factors that can be found in the early childhood classroom: physical activity (Annesi, Smith, \& Tennant, 2013; De Marco, Zeisel, \& Odom, 2015) and sleep (Gangwisch, Malaspina, Boden-Albala, \& Heymsfield, 2005; Gutierrez-Repiso et al., 2014; Halal et al., 2016). A systematic review of intervention programs designed to prevent obesity in young children found 12 efficacious programs implemented in the early childhood classroom using the early care professional as the interventionist. Each of those 12 programs included both nutrition and physical activity components, but nothing regarding the role of sleep (Ling, Robbins, \& Wen, 2016). This highlights an area that is often overlooked and may be less understood regarding healthy habits. Early childhood care and education programs offer unique opportunities for children to learn the value of good nutrition, appropriate 
physical activity, and adequate sleep. That is, all of these components occur on a daily basis in the early childhood classroom.

\section{Diet}

Diet plays an important role in the prevention of childhood obesity and has been researched in child care settings throughout the U.S. (Ford, Slingin, \& Popkin, 2013; Fox, Condon, Briefel, Reidy, \& Deming, 2010; Summerbell et al., 2012; Yavuz, van Ijzendoorn, Mesman, van der Veek, 2015). Federal programs such as the Child and Adult Care Food Program (CACFP), which provides funding to reimburse early care and education programs for meals and snacks, sets strict standards for the food components (Bucholz, Desai \& Rosenthal, 2011) that participating centers must follow. In addition, each state has an individual set of standards related to the nutrition component of the program which must be met (Larson, Ward, Neelon, \& Story, 2011; Story, Kaphingst, \& French, 2006). These standards limit the early care professionals' ability to implement changes related to improving nutrition for the children in their care (Benjamin et al., 2009), and thus will not be assessed in this study.

\section{Physical Activity}

The importance of physical activity for healthy development and the prevention of obesity is well documented in the literature (Gagne \& Harnois, 2014; Hesketh et al., 2015). Licensing guidelines related to the promotion of physical activity vary from state to state (Larson et al., 2011) and in Mississippi, guidelines address the amount of outdoor time required each day (Mississippi State Department of Health, 2018). Early care professionals are the gatekeepers for children's access to the playground and indoor 
physical activities, resulting in children's experiences from classroom to classroom varying based on the beliefs and involvement of the early care professional (Copeland, Sherman, Kendeigh, Kalkwarf, \& Saelens, 2012). Early care professionals report feeling limited in their ability to promote physical activity and cite a lack of training as one of the reasons (Dyment \& Coleman, 2012). That is, less than half of early care professionals receive physical activity training either in pre- or in-service programs (Kim, Shim, Wiley, Kim, \& McBride, 2012) and when they do the focus is on the importance of movement and early care professional supervision on the playground (Mississippi State Department of Health, 2018; Xiang, Lowy \& McBride, 2002). Early care professionals identify a lack of knowledge of directed physical activities and a belief that unstructured play is more beneficial for young children (O'Conner \& Temple, 2005) as reasons for not planning movement activities.

While early care professionals often recognize the importance of physical activity for children (Dyment \& Coleman, 2012; Hesketh et al., 2015; Tucker, van Zandvoort, Burke \& Irvin, 2011), they may not be aware of the actual amount children are receiving in the classroom (e.g., feel like children are always moving) or understand their role in facilitating active play (e.g., providing structured activities; Tucker et al., 2011). Early care professionals believe preschool children are receiving enough physical activity, but research findings using accelerometry (Vale, Trost, Rego, Abreu, \& Mota, 2015) and direct observation (Dyment \& Coleman, 2012; Tandon, Saelens, \& Christakis, 2015) show children are involved in sedentary activity for long periods of time. Unstructured play tends to lead to less physical activity, as children are not encouraged to move by adults or their peers (Shen et al., 2012). In addition, early care professionals feel 
pressured to promote academic learning (e.g., numbers, shapes, colors) over active physical play (Copeland et al., 2012) and that pressure comes from the guidelines set on the national and state levels (Barros, Silver, \& Stein, 2009) and from parents, both upperincome (Luban, Morgan, Barnett, \& Oakely, 2010) and lower-income (Timmon, Naylor, \& Pfeiffer, 2007). Thus, it is important for trainings to focus on specific activities that early care professionals can implement that not only focus on physical activity (e.g., relay races), but also include an integration of movement with academic learning (e.g., measuring how far a child jumps). Intervention programs designed to increase cognitive skills using physical activity have shown promising results (Draper, Achmat, Forbes, \& Lambert, 2012; Kirk, Vizcarra, Looney, \& Kirk, 2014) and have the potential to help early care professionals meet the goals of physical activity, as well as cognitive enrichment.

\section{Sleep}

Sleep plays a vital role in the health and well-being of adults and children (Gutierrex-Repiso, et al., 2014; Spruyt, Alabribe, \& Nwabara, 2015), particularly obesity. For example, shortened sleep increases the release of hormones (i.e., ghrelin) that signal hunger and decreases the release of hormones that relate fullness (i.e., leptin), resulting in overeating (Spiegel et al., 2004). While nighttime sleep is not occurring in most early care and education programs, early care professionals have the unique opportunity to assist children and families with identifying child sleep difficulties (Hall, Scher, Zardman-Zait, \& Espezl-Warnock, 2011). That is, if early care professionals are knowledgeable on the role of sleep in overall development, the knowledge could be shared with parents. Research shows that there is a gap in parents' knowledge of healthy 
sleep recommendations, including recommended amounts (Bonuck, Schwartz, \& Schechter, 2016), good sleep hygiene practices (e.g., regular bedtime, routines; Owens, Jones, \& Nash, 2011), and sleep consolidation, which is defined as going from multiple sleep episodes across the day to one long sleep period (Acebo et al., 2005; Galland, Taylor, Elder \& Heribson, 2012; Weissbluth, 1995). Many times, parents may also not recognize that their children are not receiving adequate sleep, particularly if they expect their child to be tired when they come home from school. Thus, early care professionals who have knowledge of sleep in early childhood can guide parents on how to promote more optimal development through sleep, similar to how they do with other areas of development. Ultimately, adults who understand the developmental progression of sleep (i.e., sleep consolidation), effects of inadequate sleep on behavior and cognition, and signs of inadequate sleep (e.g., hyperactive, aggression; Burnham, Gaylor, \& Wei, 2016) could improve health outcomes for young children. However, training on sleep for early care professionals is not widely available and often overlooked in pre- as well as inservice training (Staton, Smith, \& Thorpe, 2015), highlighting a programmatic need.

Early care professionals are limited by licensing regulations regarding the scheduling of naptime for the classroom (Mississippi State Department of Health, 2018); however, they can promote age appropriate sleep habits by practicing good sleep hygiene. That is, research indicates that dimming the lights and having a calming routine prior to sleep can help prepare the body for rest (National Sleep Foundation, 2018). Additionally, early care professionals who recognize individual differences in sleep consolidation will be better prepared to assist those children who are transitioning out of naptime by providing them with quiet activities (e.g., books, puzzles) to participate in to keep them 
from disturbing children in the classroom who are napping. Providing early care professionals with training on sleep consolidation and the importance of sleep hygiene for young children could facilitate healthy sleep practices in the classroom.

\section{Staff Development on Healthy Lifestyle Habits}

The beliefs and values of the early care professional impact the practices in the classroom (Xiang et al., 2002), but research suggests these beliefs can be altered by education (e.g., formal coursew ork or professional development) as well as experience in the early childhood classroom (Guo, Piasta, Justice, \& Kadaravek, 2010), particularly when the training is tailored to the audience. Training on physical activity is limited at best (Kim et al., 2012), and training on sleep is even more uncommon (Staton et al., 2015). Physical activity training provided by child care licensure in the state of Mississippi is limited to courses on playground safety and does not include information on the role of movement in the development of healthy habits (Mississippi State Department of Health, 2018),_making it difficult for early care professionals to obtain staff development in the area. The Early Childhood Academy (ECA), Mississippi's family-based unified and integrated early childhood system, provides professional development for all early childhood centers in the state. The training currently offered by the ECA includes a variety of topics (i.e., health and safety, child nutrition, planned learning activities, family relations, guidance, and discipline techniques, etc.) on a rotating basis. The ECA does not provide specific training on physical activity or sleep (State Early Childhood Advisory Council of Mississippi, 2018).

The early care professional, given the right preparation, can set the stage for children to receive appropriate physical activity and sleep opportunities putting them on 
the path to a healthier life. Thus, the purpose of this study was to use the research findings from Study 1 of this dissertation to develop training modules specifically designed for Head Start early care professionals who serve rural, at-risk children to increase knowledge and practices related to assisting children in early childhood with establishing healthy lifestyle habits, particularly as they relate to physical activity and sleep. To determine the effectiveness of the training modules, pre- and post-training early care professional assessments and classroom observations were conducted.

\section{Current Study}

The current study was two-fold. The first phase (i.e., formative) included the development of two tailored healthy habits trainings for Head Start early care professionals in an at-risk county in Mississippi. The second phase (i.e., evaluation) focused on the implementation and evaluation of the two trainings. The two trainings, one focused on physical activity and the other on sleep in the early childhood classroom, were developed utilizing information gathered from beliefs and value surveys completed by the early care professionals in conjunction with classroom observations conducted at each of the Head Start centers. It is our hypothesis that early care professionals will increase their overall knowledge about the role of physical activity and sleep in healthy child development as a result of the training modules and resources provided.

Additionally, we expect early care professionals to model best practices related to healthy habits at a higher rate after their participation in the education program(s). We also expect to see positive change in healthy behaviors in the classroom, although not significant due to the short length of the training, specifically regarding physical activity levels and sleep hygiene. The methods for this dissertation will be presented in two 
distinct sections (i.e., formative and evaluation). The timeline for the research project is provided in Appendix B.

\section{Method}

\section{Overview and setting}

Recruitment for this study occurred through a Head Start consortium operating in an at-risk county in Mississippi. There are four Head Start centers in the rural county, which serve approximately 720 low-income, preschool-age children (i.e., 36 to 60 months of age). The four centers are Center A ( $n=5$ classrooms), Center B $(n=6$ classrooms), Center C ( $n=4$ classrooms), and Center D ( $n=3$ classrooms). Each preschool classroom has two early care professionals, a lead and assistant, both of whom were asked to participate in the research study. The Institutional Review Board at Mississippi State University approved the research study.

\section{Participants}

Inclusion criteria for participation in the study was full-time employment as a lead or assistant early care professional in a Head Start Center located in the target county. The majority of the 39 Head Start early care professionals were female (94.9\%) and African American (80.5\%). Ages of the early care professionals ranged from 25- to 65years-old, with an average age of 42 years. Many of the Head Start professionals had prior experience in the early childhood classroom with a range from 1 to 34 years $(M=$ 12.64 years; $S D=10.69$ years). Reports of 36 Head Start professionals indicated that the majority of the sample had earned a bachelor's or master's degree $(n=22)$, with eight professionals with at least some college education $(n=8)$, and the remaining with a high 
school diploma $(n=6)$. All of the Head Start early care professionals in a preschool (3to 5-year-old classroom) were invited to participate in the education programs. A subset of 12 early care professionals (30\%) were randomly selected for pre-education observations to be used in the development of the two educational trainings (i.e., physical activity, sleep).

\section{Procedures}

Head Start directors were contacted by telephone to explain the process of delivering the surveys to the center. A reminder email was sent to the directors to remind them of the delivery date of the surveys. Paper copies of the surveys were hand-delivered to the participating Head Start Centers and left with the center administrator for distribution to all early care professionals in the 3- and 4-year-old classrooms. Head Start center directors were contacted by telephone and reminded of the date for the surveys to be picked up. After two weeks, the researcher returned to obtain the completed surveys. The individuals completing the survey were placed in a random drawing for a $\$ 50 \mathrm{gift}$ card, with one gift card awarded at each of the four centers.

Classroom observations were scheduled and conducted with a random sample of classrooms on two separate occasions. The first set (pre-observations) was conducted to assist with the design of the trainings and the second set (post-observations) was used in conjunction with the pre-observations to evaluate the trainings' effectiveness on increasing the physical activity and sleep habits in the classroom. The pre-training observations were conducted in six classrooms during the month of February, 2018 and then again in the same classrooms following programming (i.e., April, 2018). Center size was used to determine the number of classrooms that would be observed, with 
researchers conducting observations in two classrooms if the center had five preschoolaged classrooms. One classroom was selected for observations if the center was smaller than five preschool classrooms. Classrooms were selected by a random drawing conducted by the center director in the presence of a researcher; the same classrooms were evaluated following the trainings. Observations times were scheduled to provide ample opportunities to observe scheduled outdoor play and naptimes with at least 45 minutes of indoor classroom activities and 30 minutes of scheduled outdoor time. Observers were instructed to document any activity children were involved in that required movement (e.g., dancing, exercise) and the intensity of the movement (i.e., mild, moderate, vigorous). Observers also documented if the activity was planned or facilitated by the early care professional. Each classroom was observed 10 minutes before nap, during nap and waking up from nap to assess the overall environment related to sleep practices (e.g., lights dimmed, soft music played).

Data from the survey and observations were examined to develop two trainings. Each training was developed as a three-hour interactive educational session, with one addressing physical activity and one focusing on sleep in the early childhood classroom. The trainings dates were scheduled in coordination with the Head Start administration. The physical activity training was scheduled for March 21, 2018 from 3-6 p.m. and the sleep training for March 28, 2018 from 3-6 p.m. The training opportunities were advertised by emails from the Education Director of the Head Start Agency and followup phone calls and emails were made by the researcher. The trainings were delivered at the Head Start center that was centrally located and had availability of a room large enough to conduct the trainings. Each training was scheduled to begin at 3:00 p.m. and 
end at 6:00 p.m. to accommodate the early care professionals' work schedules as discussed with the education director for the Head Start Agency. The early care professionals earned staff development training hours approved by the Child Care Licensure Division of the Mississippi State Department of Health for their attendance. At the beginning of each training, participants completed surveys that aligned with the topic of the training, including a knowledge survey. Knowledge surveys were also administered immediately following the training to determine any change in knowledge. One month following the sleep training, post-observations were conducted using the same design and observation protocol in the classrooms observed prior to the training.

\section{Formative Measures}

\section{Demographics}

Demographic information was collected on the early care professional's age, gender, and ethnicity ( $0=$ European American, $1=$ African American). Early care professionals provided information on their education level $(1=$ high school, $2=$ some college, 3 = bachelor's degree, 4 = master's degree, $5=$ Ph.D.) Information was also gathered on the number of years of experience in the field of early education.

\section{Early Childhood Professionals' Beliefs and Values}

A 17-item survey, created for this project, was used to assess early childhood

professionals' beliefs and values about physical activity and sleep in early childhood. The survey was adapted from the Teacher's Perceptions: Early Childhood Physical Activity Values and Belief Scale and was field tested with an eight-member panel of experienced 
physical education educators and preservice senior classroom teachers. (Xiang, et al., 2002). The wording on the survey was modified to be more specific to physical activity and additional statements were added to measure values and beliefs on sleep (e.g., Naps influence classroom behaviors). In addition, items on the surveys related to nutrition were removed. The responses to these 17 statements were used to develop the trainings. Early care professionals were asked to rate their agreement with each statement on a scale from 1 to $6(1=$ strongly disagree; $2=$ moderately disagree; $3=$ slightly disagree; $4=$ slightly agree; $5=$ moderately agree; $6=$ strongly agree). The role of physical activity in early childhood was assessed via seven statements (e.g., Physical activity makes important contributions to the development of the whole child), and the role of sleep assessed with three statements (e.g., Sleep makes important contributions to the development of the whole child). The beliefs and values the early care professionals had about their own role in assisting children with establishing health habits was evaluated with four items related to physical activity (e.g., Part of my job is to make sure that children get a healthy amount of physical activity) and three items related to sleep (e.g., Part of my job is to make sure that children get a healthy amount of rest). Higher scores were indicative of a greater value on physical education and sleep in a child's development, with the exception of one statement (i.e., Taking away children's opportunities for physical activity is an appropriate form of discipline). The beliefs and values survey also contained open-ended questions designed to provide information on physical activity in the classrooms (e.g., How much time does your class spend outdoors in the morning? Afternoon?; What do you do for physical activity when the weather does not permit taking the children outdoors?). 


\section{Classroom Observations}

An observation form was developed for the study that contained three overarching themes related to healthy habits (i.e., indoor physical activity, outdoor physical activity, daytime sleep). Two researchers conducted observations to reduce mono-observer bias (Harms, Cryer, and Clifford, 2005). Fully crossed inter-rater reliability (IRR) was used to determine the consistency among observational ratings of the two researchers. This design is considered optimal because it allows for systematic bias between codes to be controlled for, which can improve overall IRR (Hallgren, 2012). The IRR design was a fully crossed design with four of the six classrooms observed by both individuals as shown in Table 7.

Table 7 Design for assigning coders to classrooms for fully crossed IRR design

\begin{tabular}{|c|c|c|c|c|}
\hline & $\begin{array}{l}\text { Pre } \\
\text { Observer A }\end{array}$ & $\begin{array}{l}\text { Pre } \\
\text { Observer B }\end{array}$ & $\begin{array}{l}\text { Post } \\
\text { Observer A }\end{array}$ & $\begin{array}{l}\text { Post } \\
\text { Observer B }\end{array}$ \\
\hline Center A - Classroom 1 & $\mathrm{X}$ & $\mathrm{X}$ & $\mathrm{X}$ & $\mathrm{X}$ \\
\hline Center A - Classroom 2 & $\mathrm{X}$ & $\mathrm{X}$ & $X$ & $X$ \\
\hline Center B - Classroom 1 & $\mathrm{X}$ & $\mathrm{X}$ & $X$ & \\
\hline Center B - Classroom 2 & $\mathrm{X}$ & $\mathrm{X}$ & $X$ & \\
\hline Center C-Classroom 1 & & $\mathrm{X}$ & $X$ & $\mathrm{X}$ \\
\hline Center D - Classroom 1 & $X$ & & $X$ & $\mathrm{X}$ \\
\hline
\end{tabular}

The dates and times of the observations, the weather, the classroom and center, as well as the observer were recorded during each observation. Information gathered from the observations was used to design the educational sessions. The details of the observations used in this study are listed below and include observations of the environment and the early care professionals' behaviors. 


\section{Environmental observations}

Researchers evaluated the environment to assess the indoor and outdoor arrangement and materials provided within the environment that promote physical activity. For example, researchers noted if the classroom contained the following categories: jumping toys (e.g., jump ropes), push-pull toys (e.g., brooms), twirling toys (e.g., ribbons), balance toys (e.g., balance beams), and/or tumbling equipment (e.g., tumbling mats). Researchers also documented whether the toys were used or unused during the observation. A total number of toy categories were summed, with higher scores representing greater opportunity for movement through the toys made available in the classroom. To assess the use of the classroom materials that facilitate physical activity, a total number of used materials were calculated, with higher numbers representing greater use. To evaluate the use of classroom space, four characteristics of the classroom were documented. Specifically, researchers documented if (1) there was space for all activities, including jumping, running, and rolling; (2) centers were large enough for play; (3) areas allowed play space for individuals, pairs, small groups, and large groups; and (4) early care professionals altered the classroom space to make room for activities that required a larger area than what was available.

The outdoor space was evaluated for the use of stationary (e.g., swing set, sandbox, climbing structure) and portable (e.g., tricycles, hula hoops, dump trucks) equipment on the playground. A total number of equipment used in each category (i.e., stationary, portable) was calculated, with higher scores representing greater use of that type of equipment. Researchers noted if early care professionals made portable equipment available to children while they were outside on the playground. 
The observation included an assessment of the sleep environment 10 minutes prior to nap, as well as during the nap period. The researchers noted if the following characteristics were present for each of the aforementioned periods: lights dimmed, classroom quiet, soft music playing, and windows covered. If the characteristic was present, a score of one was assigned. A sum for each period was calculated, with higher scores representing a more optimal sleep environment.

\section{Early childhood professional engagement}

Researchers evaluated if early care professionals engaged in the promotion of healthy habits within the classroom. Specifically, researchers documented when they observed the early care professional engaged in physical activity with the children during indoor and outdoor classroom times. Following the observation period, researchers then reached consensus and rated the overall physical activity level of the early care professional during the observation time (i.e., indoor class time; outdoor class time). Early care professionals were rated on a 6 -point Likert scale (i.e., $0=$ sedentary, $1=$ standing, $2=$ little movement, 3 = some movement, 4 = active, 5 = very active), with higher scores indicative of greater amounts of physical activity during that observation time.

To assess the level of encouragement early care professionals offered to children in regards to physical activity, researchers documented each time they observed an early care professional encouraging a child to move during indoor and outdoor classroom times. After observations on the playground were conducted, researchers rated the early care professionals' encouragement. That is, researchers used a 6-point Likert scale $(0=$ none, $1=$ little, $2=$ few, $3=$ some, $4=$ lot, $5=$ whole lot) to rate the degree of 
encouragement they noted from the early care professional, with higher ratings representing more encouragement.

To understand further how early care professionals influenced the sleep of children during naptime, researchers documented early care professional behavior prior to, during, and following naptime. Specifically, researchers recorded what type of activities (e.g., story time) children were engaged in 10 minutes prior to nap. Notes were taken about how early care professionals dealt with children who had trouble falling asleep, who were not sleepy, or who were disruptive during the scheduled naptime. Additionally, the waking process was documented in each classroom.

\section{Formative Results}

\section{Teachers' Perceptions of Healthy Lifestyle Values and Beliefs Survey}

Descriptive results from the Beliefs and Values of Healthy Lifestyle Habits are reported in Table 8 . Results indicate that overall, the majority of early care professionals in the Head Starts in this rural Mississippi county agree that physical activity and sleep are important contributors to early childhood development. Findings also suggest that early care professionals agree that they play a role in assisting children with the development of healthy habits as they relate both to physical activity and sleep, but the degree of agreement about their role in assisting children with healthy habits varied more than their knowledge of the importance of healthy habits. Thus, it was determined that both trainings needed to provide basic information on the links between healthy habits and child development, with a focus on the role and potential influence of the early care provider and the classroom environment. 
Table 8 Early Care Professionals Beliefs and Values of Healthy Lifestyle Habits

\begin{tabular}{|c|c|c|c|c|c|c|c|c|c|}
\hline & Statement & $\mathrm{S} / \mathrm{A}$ & $\mathrm{M} / \mathrm{A}$ & $\mathrm{S} / \mathrm{A}$ & $\mathrm{Sl} / \mathrm{D}$ & $\mathrm{M} / \mathrm{D}$ & $\mathrm{St} / \mathrm{D}$ & $M$ & $S D$ \\
\hline Statement 1 & $\begin{array}{l}\text { PA makes important contributions to the } \\
\text { development of the whole child. }\end{array}$ & $79 \%$ & $13 \%$ & $8 \%$ & $0 \%$ & $0 \%$ & $0 \%$ & 5.71 & .61 \\
\hline Statement 2 & $\begin{array}{l}\text { PA allows children a fun break from regular } \\
\text { classroom activities. }\end{array}$ & $74 \%$ & $13 \%$ & $8 \%$ & $2 \%$ & $3 \%$ & $0 \%$ & 5.52 & .95 \\
\hline Statement 3 & $\begin{array}{l}\text { Taking away children's opportunities for PA is an } \\
\text { appropriate form of discipline. }\end{array}$ & $13 \%$ & $3 \%$ & $10 \%$ & $10 \%$ & $53 \%$ & $0 \%$ & 4.60 & 1.82 \\
\hline Statement 4 & $\begin{array}{l}\text { PA provides children with opportunities to learn } \\
\text { about health and fitness. }\end{array}$ & $84 \%$ & $13 \%$ & $3 \%$ & $0 \%$ & $0 \%$ & $0 \%$ & 5.82 & .46 \\
\hline Statement 5 & $\begin{array}{l}\text { PA is as important as other curriculum areas, such } \\
\text { as reading, math, and science. }\end{array}$ & $50 \%$ & $29 \%$ & $10 \%$ & $5 \%$ & $3 \%$ & $3 \%$ & 5.10 & 1.23 \\
\hline Statement 6 & $\begin{array}{l}\text { PA teaches children motor skills, such as running, } \\
\text { jumping, and throwing. }\end{array}$ & $87 \%$ & $8 \%$ & $5 \%$ & $0 \%$ & $0 \%$ & $0 \%$ & 5.82 & .51 \\
\hline Statement 7 & $\begin{array}{l}\text { My lesson plans impact children's opportunities } \\
\text { for PA. }\end{array}$ & $60 \%$ & $24 \%$ & $13 \%$ & $3 \%$ & $0 \%$ & $0 \%$ & 5.40 & .83 \\
\hline Statement 8 & $\begin{array}{l}\text { PA helps children develop social skills, such as } \\
\text { sharing, taking turns, and cooperating with } \\
\text { classmates. }\end{array}$ & $79 \%$ & $10 \%$ & $8 \%$ & $3 \%$ & $0 \%$ & $0 \%$ & 5.66 & .74 \\
\hline Statement 9 & $\begin{array}{l}\text { Part of my job is to make sure that children get a } \\
\text { healthy amount of PA. }\end{array}$ & $71 \%$ & $11 \%$ & $10 \%$ & $5 \%$ & $0 \%$ & $3 \%$ & 5.39 & 1.15 \\
\hline Statement 10 & $\begin{array}{l}\text { Providing children with opportunities to be active } \\
\text { is an important aspect of my job. }\end{array}$ & $68 \%$ & $19 \%$ & $8 \%$ & $8 \%$ & $0 \%$ & $0 \%$ & 5.49 & .87 \\
\hline Statement 11 & $\begin{array}{l}\text { When I make an effort to encourage children to be } \\
\text { active, they get a lot of PA. }\end{array}$ & $65 \%$ & $19 \%$ & $16 \%$ & $0 \%$ & $0 \%$ & $0 \%$ & 5.49 & .77 \\
\hline Statement 12 & $\begin{array}{l}\text { Sleep makes important contributions to the } \\
\text { development of the whole child. }\end{array}$ & $95 \%$ & $5 \%$ & $0 \%$ & $0 \%$ & $0 \%$ & $0 \%$ & 5.95 & .23 \\
\hline Statement 13 & Naps influence classroom behaviors. & $43 \%$ & $19 \%$ & $16 \%$ & $14 \%$ & $5 \%$ & $3 \%$ & 4.73 & 1.43 \\
\hline Statement 14 & $\begin{array}{l}\text { The classroom environment (e.g., noise, } \\
\text { placement of cots, light) can impact a child's sleep } \\
\text { behaviors. }\end{array}$ & $50 \%$ & $32 \%$ & $8 \%$ & $3 \%$ & $5 \%$ & $2 \%$ & 5.10 & 1.27 \\
\hline Statement 15 & $\begin{array}{l}\text { Part of my job is to make sure that children get a } \\
\text { healthy amount of rest. }\end{array}$ & $53 \%$ & $13 \%$ & $16 \%$ & $13 \%$ & $5 \%$ & $0 \%$ & 4.95 & 1.31 \\
\hline Statement 16 & $\begin{array}{l}\text { My lesson plans impact children's opportunities } \\
\text { for sleep. }\end{array}$ & $27 \%$ & $24 \%$ & $14 \%$ & $14 \%$ & $13 \%$ & $8 \%$ & 4.13 & 1.67 \\
\hline Statement 17 & $\begin{array}{l}\text { Providing children with opportunities to rest is an } \\
\text { important aspect of my job. }\end{array}$ & $51 \%$ & $14 \%$ & $24 \%$ & $11 \%$ & $0 \%$ & $0 \%$ & 5.05 & 1.10 \\
\hline
\end{tabular}

Note. $\mathrm{PA}=$ physical activity $\mathrm{S} / \mathrm{A}=$ strongly agree; $\mathrm{M} / \mathrm{A}=$ moderately agree; $\mathrm{S} / \mathrm{A}=$ slightly agree; $\mathrm{S} 1 / \mathrm{D}=$ slightly disagree; $\mathrm{M} / \mathrm{D}=$ moderately disagree; $\mathrm{St} / \mathrm{D}=$ strongly disagree; $\mathrm{M}=$ mean; $\mathrm{SD}=$ standard deviation.

\section{Environmental Observations}

Results from the observations indicated that of the five categories of indoor toys that promote physical activity (i.e., jumping, push-pull, twirling, balance, tumbling) each classroom contained toys from three types (i.e., jumping toys, push-pull toys, twirling toys). Only two of those categories of toys (i.e., push-pull, twirling toys) were ever used in the classroom during the observation. Specifically, only one classroom was noted as 
using both categories of toys, three classrooms were documented using one of the aforementioned categories, and two classrooms were never seen engaging in any activity that used one of the three categories of indoor toys that promote physical activity. These findings highlight the importance of including how to use available materials within the classroom to promote physical activity indoors.

The classroom space was found to vary by classroom, with some classrooms having ample space for children to run, jump, and play, whereas others were limited on their ability to provide children with room for such physical activity. Variability was documented in how early care professionals utilized the indoor space, yet no early care professionals were observed altering the environment to provide more space for children to engage in physical activity. Tips on how to alter the environment when space is limited were noted as imperative to include in the training session focused on increasing physical activity in the classroom setting.

Outdoor observations indicated that the stationary equipment at all four Head Start centers were identical, with each having a sandbox, a climbing structure, garden area, path for wheeled toys, and an easel. However, observations revealed that researchers did not see more than three of these items used by the children while they were outside. Observational data regarding the use of portable equipment indicated that early care professionals who were part of the observation group did not make items such as tricycles and other portable toys (e.g., parachutes) available to children during the observations. These data highlight the importance of the physical activity training to promote the use of portable toys while children are on the playground. 
Sleep environment observations indicated that early care professionals were not providing an environment that would promote preparation for sleep prior to children lying on their cots. That is, not one preschool classroom had lights dimmed, blinds closed, soft music playing, or a room that was quiet 10 minutes prior to starting naptime. Additionally, only one classroom was noted to have closed the blinds during nap, but all classrooms did turn off the lights after children were on their cots. Noise was noted as a particular problem in certain classrooms. For example, one classroom was positioned near the front door and shared a doorway with the main office. Therefore, the doorbell and the phone, as well as conversations of the office staff, could be heard clearly in the classroom. This arrangement resulted in a lot of noise and disruptions to the sleep environment. Thus, sleep hygiene recommendations were recorded as imperative to include in the sleep training session.

Researchers noted that each classroom schedule posted on the wall of the classroom indicated one hour for nap (i.e., 12:30 - 1:30 p.m.). However, the start of naptime was delayed in each classroom by at least 10 minutes, and some by more than 25 as documented by researchers. The early care professionals woke the children up at exactly 1:30 p.m. to serve snack and prepare for departure. The late onset and prompt waking resulted in children having less than the recommended time for rest each day and thus the importance of the timing was documented as a point of discussion during the training.

\section{Early Care Professional Engagement Observations}

All early care professionals (i.e., lead and assistant) were rated as participating to some degree in physical activity with the children in their classrooms. More specifically, 
lead early care professionals received a mean score of $3.571($ range $=1-5 ; S D=1.397)$, whereas assistant early care professionals received a rating between 2 and 4 , with a $M$ of $3.143(S D=.899)$. In regards to the early care professionals' involvement in physical activity on the playground, three classrooms did not go outside during their scheduled playground time. Of the three classrooms who were observed on the playground, the lead early care professional received a mean rating of $2.200(S D=.836)$ and the assistant early care professional provider received a mean rating of $2.800(S D=.836)$. These data highlight the need to include information during the training on the importance of the early care professional's involvement in physical activities both in the classroom, as well as outdoors.

In regard to ratings of encouraging movement with the children, both lead and assistant early care professionals were noted as encouraging children to move at least one time during the indoor observations. That is, lead early care professionals received slightly higher ratings in their encouragement of young children to move, with a $M$ rating of $3.125(S D=1.642)$ in comparison to assistants $(M=2.75 ; S D=1.388)$. As previously noted, three classrooms did not participate in outdoor play during the observations. Of the three classrooms that were observed on the playground, the early care professionals were noted as encouraging movement, with lead early care professionals receiving a mean rating of $3.0(S D=1.225)$ and assistant early care professionals receiving a mean rating of $3.6(S D=1.140)$. Thus, encouraging children to move was documented as a necessary component to include in the training.

Researchers noted that all of the classrooms engaged in arousing activities prior to nap- time. More specifically, only one classroom was noted as participating in a 
calming activity (e.g., reading a book) within the time between lunch and nap, but after reading the book they sang active songs (e.g., Wheels on the Bus), negating the calming effect of the book. In regards to children who had trouble falling asleep, early care professionals generally reprimanded those children for not being still and quiet. The exception to this observation was one provider was noted as patting a child on the back for a few minutes to help him relax. Early care professionals were not observed to have any quiet activities or procedures regarding how to deal with a child who did not sleep at all during naptime. Finally, researchers documented that in every classroom the early care professionals abruptly stood children up to wake them. Only one classroom was observed as turning the lights on prior to wake time to assist the children with waking. Thus, these data suggest that early care professional need information on how their behaviors and classroom activities influence children's sleep.

\section{Development of Training Modules}

The training modules were developed using best practices for training identified by the National Association for the Education of Young Children (NAEYC) and the National Association of Child Care Resource \& Referral Agencies (NACCRRA). Given that the early care workforce consists of a variety of individuals with various educational backgrounds, diversity in regard to role (e.g., teachers, teacher assistants, care providers), as well as racial, ethnic, cultural, socioeconomic, and linguistic characteristics

(Whitebook, McLean, \& Austin, 2016), it is important that trainings be tailored to meet the needs of the clients. Using the demographic data from the beliefs and values survey, the training was developed to provide information on the educational level of all the early care professionals (e.g., $61 \%$ held a bachelor's or master's degree, $22 \%$ had some 
college, $17 \%$ had a high school diploma). The resource materials used during the training were created using low-cost, readily available materials to meet the needs of the early care professionals. For example, soft balls were made from foam pillow stuffing and panty hose that could be used for throwing and catching indoors. Dancing ribbons were created using a wooden curtain ring and strips of colored ribbon to be used during music time to encourage movement and dance. Careful considerations were made to ensure the training was organized in a way that highlighted the importance of healthy habits, specifically for their county and population, and the critical role the early childhood classroom plays in healthy habits, before providing them with specific instructions on how to implement the knowledge into the classroom. The training was also facilitated in a way that provided interactive learning experiences that linked to best practices during the day-to-day operation of the classroom (Buysse, Winton, \& Rous, 2009).

\section{Physical Activity Training}

A three-hour training module addressing physical activity was created using the aforementioned formative results. That is, the findings from the beliefs and values of healthy lifestyle habits and the classroom observations were used to guide the design of the training. Specifically, results indicated that early care professionals believe physical activity is an important contributor to healthy development in young children and that they recognize, although to a lesser extent, that they play a role in assisting children in developing healthy habits. However, observations suggest that the knowledge and beliefs regarding the importance of physical activity is not translating into the classroom, including during both inside and outside time. Below are the specific findings from the 
observations and how the training incorporated those findings to improve children's engagement in healthy habits within the classroom.

Given the fact that childhood obesity is a major health concern in this county (i.e., $15.7 \%$ for children under the age of 5; State of Obesity, 2018), an overview was provided on obesity (e.g., definition, statistics) to educate the early care professionals attending the training. As aforementioned, early care professionals do not agree with the emphasize placed on childhood obesity (Lumeng et al., 2008) and feel that children will outgrow weight issues (Lanigan, 2012). The information provided was designed to educate the early care professionals on the impacts of obesity on healthy development of children and assist them in recognizing the links between early childhood obesity and adulthood obesity. The training also provided information on the role of the early childhood classroom in childhood obesity (e.g., numbers of children attending programs; costeffectiveness). The three primary causes of obesity were discussed (e.g., diet, physical activity, sleep) and detail was provided on the types and amounts of physical activity recommended for young children.

The barriers to children not getting enough physical activity in the classroom were discussed using information gathered during the classroom observations. The first barrier noted was not enough time during the day to stay on schedule and include all of the components that are expected for them to cover. Based off these comments, suggestions were included on how to integrate movement during the typical daily routines (e.g., center time, circle time). An example from one of the observations was included to showcase how other fellow early care professionals within the same consortium were integrating physical activity. Specifically, the classroom early care professional had 
children act out "The Three Little Pigs", which required children to move about the room during story time. Each child was given a role at some point during story time to be engaged in physical activity. Additionally, special care was given to times in which observers noted children were spending time waiting. For example, none of the classrooms observed had bathrooms within the classroom and thus children were spending a significant amount of time lined up in the hallway multiple times during the school day. Ideas of how early care professionals could use these waiting periods as times to promote physical activity were discussed (e.g., yoga). Suggestions on how to reduce the waiting time for children during routines (e.g., one adult performing routines while the other one engages with the children) were shared.

The lack of space indoors for physical activity was also noted as a barrier to movement. The variation in classroom size noted during the observations was addressed with information on overcoming limited space by moving furniture (e.g., tables and chairs) and increasing the size of learning centers (e.g., dramatic play, blocks) to allow more movement. Suggestions were also included on using other available space within the Head Start center to promote physical activity (e.g., breezeway, empty classrooms). Using a real example and a strength-based approach, the use of space for active movement in the smallest classroom observed was acknowledged during the training as an effective way to facilitate physical activity in a small space. The early care professional in the classroom had the children moving around the tables to music during their indoor physical activity time. This activity allowed the children and adults to be engaged in vigorous physical movement within a very limited amount of space. 
The focus on teaching the children academics was also noted as a barrier to physical activity in the classroom. The beliefs and values survey indicated that early care professionals believe that their lesson plans impact physical activity. However, observers indicated that the lesson plans posted on the walls of the classrooms were often not followed, but the schedule was.

The type of physical activity embedded in the lesson plans that the observers noted included: (1) one classroom took a walk to examine the different types of houses seen from the playground as that was the theme of the week; (2) one classroom acted out the story of The Three Little Pigs; (3) one classroom had children walk to the middle of the classroom when it was their turn to spell their name; (4) four classrooms engaged in dancing during circle time; (5) three classrooms sang songs using hand or body motions (e.g., The Wheels on the Bus). The physical activities observed during the lessons were for short periods of time (i.e., transitions) that did not allow the children to achieve intense movement (i.e., hand motions to songs). Therefore, training included information on the difference between moderate and vigorous activity and how much time preschool children should be involved in each type of activity. Specific suggestions were given on how to increase the length and intensity of the physical activity (e.g., relay races in the classroom; playing matching games inside that require children to move around the room), as well as the role of the early care professional in promoting movement (e.g., participating with the children, wearing comfortable clothing and shoes). Early care professionals were also provided with opportunities to participate in parachute games designed to facilitate vigorous physical activity. For example, using the parachute to do the hokey pokey (e.g., You move the parachute up, you move the parachute down). 
To provide early care professionals with guidance on how to plan for physical activity throughout the day in their lesson plans, the physical activity training included information on how to teach academics (e.g., math, science, literacy) with movement activities. For example, using a yardstick to have children measure how far they can jump and try to surpass their previous distance encourages movement while learning about measurement. To assist children with attention and self-regulation, activities such as "Red Light, Green Light", "Simon Says" or other instructional games (e.g., stand up if you are wearing blue, sit down if you are a boy) were included. Additionally, details on how items in the classroom or the classroom set-up could be used to teach children healthy habits in the classroom (e.g., books, fitness center in the classroom) was included in the training. Using a strength-based approach, the facilitator incorporated positive examples of how physical activity was embedded into academic lessons during the observations (e.g., going for a walk to discuss types of homes).

Researchers noted that children had access to only two of the five categories of indoor toys designed to promote movement during the pre-training observations. To this end, the educational session included information on how early care professionals could promote additional physical activity in the classroom by insuring that toys that require physical movement and are already a part of the classroom inventory (e.g., brooms; large push-pull toys) were made readily available in the classroom. To provide early care professionals with additional experiential learning experiences during the training, materials and instructions were included to create low-cost, homemade toys that promote physical activity. For example, soft balls were made from knee high stockings and pillow 
stuffing to be used in the classroom to promote movement in a variety of ways (e.g., tossing them into a bucket, throwing them to each other).

The four Head Start centers all had identical stationary equipment (i.e., sandbox, climbing structures, garden area, path for wheeled toys, easel) on the playground, but only three pieces were noted as used by children during the playground observations. The three pieces of equipment used included the climbing structures (i.e., rock climbing wall, tunnel, spring riding toys), sandboxes, and bike paths, the latter as an activity area. Additionally, portable equipment (e.g., wheeled toys, balls) was not used by any of the observed classrooms, but in one instance, the equipment was made available for another group of children (not the one being observed). The presence of portable equipment (e.g., ball, wheeled toy) has been shown to increase physical activity (McWilliam et al., 2009; Smith et al., 2014) during outdoor play, especially for boys, and this finding was highlighted during the training.

Research shows that early care professionals believe that preschool children are active enough on their own and do not require encouragement to move (De Craemer et al., 2013; Gehris, Gooze, \& Whitaker, 2014). Thus, a section of the physical activity training focused on encouraging movement on the playground using the available equipment with specific suggestions on taking portable equipment outdoors (e.g., parachute, hula hoops) or removing it from the storage sheds (e.g., tricycles). The training included examples of organized games (e.g. parachute pokey; bank with drive-thru window) that could be played using portable equipment.

Inclement weather was reported by early care professionals as a barrier to children not getting enough physical activity each day. During observations, researchers noted that 
three of the six classrooms did not go outside during their scheduled playground time because the early care professionals considered it to be too cool (i.e., 38 degrees and sunny). To highlight when weather conditions are dangerous to take children outside in, the training included time for discussion about conditions such as heat advisories. Further information was imbedded into the professional development training that highlighted the importance of dressing children appropriately for the weather (e.g., hats, gloves, and coats on cold days) and reducing rather than eliminating time outdoors when weather conditions are just unfavorable.

The lack of early care professional engagement in physical activity with the children, as well as a lack of encouragement for children to move was also noted as a barrier to physical activity. Researchers recorded that early care professionals were involved to a limited degree in movement with the children during indoor and outdoor times. Studies show that early care professionals believe their role on the playground is as a safety monitor rather than an active participant with the children (Copeland et al., 2012; Lanigan, 2014), and the pre-observations supported this finding. In regards to the early care professionals, physical activity engagement and encouragement of children to engage in physical activity was rated higher by observers during indoor rather than outdoor activities. For example, early care professionals were observed as regularly participating in movement during sing-alongs or dance times and requiring student participation in those indoor activities. However, on the playground early care professionals were noted as standing in designated safety monitoring zones around the playground for the entire outdoor play time, without engaging in or encouraging children to be active. To encourage early care professionals to engage in more physical activity 
with their students, information on the amount and types of physical activity

recommended for adults and children was presented. Organized games were used as experiential learning activities during the training to get early care professionals to recognize how they can encourage children to move. For example, each early care professional at the training was given a slip of paper with the picture of a barnyard animal on it. They were told to make the sound of the animal and move around to find others making the same sound until all of the animals were separated by group. An example of outdoor engagement included in the training was the use of spoon balance relay.

Information was also provided to help early care professionals understand the importance of encouraging children to move throughout the day (e.g., transition songs), not just at the typical times during the day (e.g., outdoor time; circle time). The outline of the physical activity training is provided below.

I. Introduction and pre-test

10 minutes

II. Overview of obesity

A. What is obesity?

B. Facts about obesity

C. The role of the early childhood classroom

D. Obesity in the county and state

E. Impacts of obesity

20 minutes

III. Establishing healthy lifestyle habits

A. The role of the early childhood classroom

B. Physical activity

C. Sleep

D. Diet

20 minutes

IV. Physical activity

A. What is physical activity?

B. How much physical activity do we need?

C. Types and amounts of physical activity

D. Levels of physical activity

15 minutes

V. Barriers to physical activity
A. Time
B. Space
C. Focus on academics
D. Inclement weather

E. Lack of early care professional's encouragement

20 minutes

VI. Overcoming barriers to physical activity
A. Time
B. Space 

C. Focus on academics
D. Inclement weather
E. Lack of early care professional encouragement 20 minutes
V. Materials for physical activity
A. Using classroom materials
B. Adding classroom materials
VI. Teaching academics with movement
A. Math
B. Science
C. Literacy
VII. Encouraging movement on the playground
25 minutes
A. Dramatic play
B. Sand and water play
C. Organized games
15 minutes
VIII. Teaching children healthy habits in the classroom
A. Books
B. Fitness theme
10 minutes
IX. Questions and post-test
10 minutes

\section{Sleep Training}

A three-hour training module addressing sleep was created using the beliefs and values survey and classroom observation results. As previously noted, early care professionals believed that sleep was important to the healthy development of children and to a lesser degree that they play a role in helping children develop healthy habits related to sleep. However, observations did not support the idea that early care professionals recognized sleep as an important aspect of the early childhood classroom. Below documents how the training was developed to promote more optimal sleep habits within the classroom.

The definition of sleep, as well as how sleep is constructed on both biological and sociocultural levels was incorporated into the training. The training also included information on signs and symptoms of sleepiness and/or sleep deprivation and how those signs may look different in children than they do in adults. For example, while as adults we often think of yawning and being sluggish as signs of sleepiness, for children that may 
actually present itself as hyperactivity and aggression. These distinctions were included to assist early care professionals in recognizing sleep issues, not only for the purposes of the classroom, but also to assist parents with recognizing if their child was obtaining sufficient sleep at night. Additionally, information on sleep apnea and snoring was highlighted as problematic, as observers noted a number of children who were snoring during naptime. Information was also shared regarding inadequate sleep throughout life related to emotional health (e.g., irritability, negative emotions; Spruyt et al., 2015), physical health (e.g., immune system, obesity; Halal et al., 2016; McNeil, Doucet, \& Chaput, 2013), and cognition (e.g., reaction time, memory consolidation; Fields, Sabet \& Reynolds, 2013).

While the beliefs and values survey indicated that early care professionals recognized the contributions sleep makes to the development of the whole child, the classroom sleep environment was not one that was conducive to optimal sleep duration and quality. Specifically, in regards to duration of sleep, the scheduled start time for naptime was often delayed resulting in less, many times substantially less, than an hour of rest time. The delay also resulted in a number of children being awoken after being asleep for only 5-20 minutes, a time in which many were just reaching a deep stage of sleep. Thus, information on the recommendations of sleep amounts for different ages as well as a discussion of sleep stages and their contributions to health and development were incorporated into the training.

The beliefs and values survey indicated that the early care professionals recognized that the classroom environment can impact a child's sleep behaviors, but observations did not show that these beliefs were being consistently practiced in the 
classroom. Researchers noted that 10 minutes prior to naptime (1) lights were not dimmed in four of the six classrooms; (2) all of the rooms were noisy and busy; (3) soft music was not played in any of the classrooms; and (4) in two of the classrooms children were actively involved in arousing activities (e.g., songs involving movement) just prior to laying down on their cots. Researchers observed that it was difficult to maintain a quiet environment during nap due to a half-wall in one classroom, the use of the walkietalkies/intercom in three classrooms, and adults (e.g., janitorial staff, parents) entering the room in three classrooms.

Researchers included the strengths they observed in the classroom as it related to sleep hygiene. That is: (1) lights were turned off once children were on their cots in five of the six classroom; (2) blinds were closed in two of the six rooms; (3) children were told they did not have to sleep, but that they had to rest their bodies in two classrooms; (4) early care professionals promoted a quiet environment (e.g., spoke in low voices) in two classes; (5) soft music was played in two classrooms; (6) cots were placed for privacy in all classrooms.

To accommodate for individual differences in sleep need throughout the day, the training included a discussion about the need for a quiet place where a child can rest outside of the nap-time portion of the day. Suggestions were also incorporated on ways to handle children who did not nap (e.g., examples of quiet activities that could be provided) or were disruptive during nap. Further, the training included examples of how early care professionals can assist children when they have difficulty relaxing. Information was also provided on appropriate ways to wake children from nap (e.g., turning on the lights), as the observations revealed children having difficulty with the current process. 
Recommended sleep hygiene practices (e.g., lights dimmed, blinds closed, quiet) prior to and during nap were defined and discussed in the training. Information was included on the components of a quality sleep environment. For example, classrooms that are cluttered and filled with bright colors can overstimulate children and reduce their ability to get good quality sleep. To ensure that participants could identify "good" from "poor" sleep environments, pictures of appropriate and inappropriate classroom environment during naptime were shared and participants were asked to apply their newly obtained sleep knowledge by selecting "good" and "bad" components in each of the classroom photos. Discussion also included ways the "bad" components could be adapted for the sleep environment.

The beliefs and values survey indicated the early care professionals recognized their lesson plans impact children's opportunities for sleep, but the professionals were not engaging in optimal sleep hygiene practices in the classroom during observations. The early care professionals often engaged their students in stimulating activities just prior to rest time, which increases the time it takes for a child to calm down. Thus, the importance of preparing the children for nap through calming and relaxing activities (e.g., yoga, story time) was emphasized. Each participant received resource materials for the classroom (i.e., books related to sleep) and a book for each child that details the best practices in nighttime sleep routines and sleep tips for parents. Each classroom with an early care professional present received a set of Yoga for the Classroom (http://www.yoga4classrooms.com/activity-card-deck) instruction cards or CD. An outline of the training is provided below. 
$\begin{array}{lll}\text { I. } & \text { Introduction and pre-test } & 10 \text { minutes } \\ \text { II. } & \text { Review from previous training }\end{array}$

A. Obesity

B. Healthy lifestyle habits

15 minutes

III. Overview of sleep - what is sleep

A. What is sleep?

B. Stages of sleep

C. Quantity and quality of sleep

D. Biological mechanisms of sleep 25 minutes

IV. Importance of sleep

A. Why is sleep important?

B. Sleep in preschool children

C. The results of reduced sleep

1. Emotional development

2. Cognitive development

3. Physical health

4. Parent education on sleep

5. Naptime considerations

V. Sleep Hygiene

30 minutes

A. What is sleep hygiene

B. Improving sleep hygiene for adults and children 25 minutes

VI. Sleep environments

A. Sleep environments in the room

B. Sleep environments in the classroom

1. Preparing children for naptime

2. Adjusting for different sleep needs

3. During and after nap consideration

C. Looking at classroom environments

V. Teaching children healthy habits in the classroom

25 minutes

A. Yoga for relaxation and transitions

B. Teaching children health habits

25 minutes

VI. The early care professional

A. Impact of inadequate sleep on the classroom

B. Foods to help with sleep

C. Tips for taking care of yourself

15 minutes

VII. Questions and post-test

10 minutes

\section{Process Evaluation Measures for Physical Activity and Sleep}

\section{Demographics}

Demographic information was collected on the early care professional's age, gender, and ethnicity $(0=$ European American, $1=$ African American $)$. Early care professionals provided information on their education level $(1=$ high school, $2=$ some college, 3 = bachelor's degree, $4=$ master's degree, $5=\mathrm{Ph}$.D.) Information was also gathered on the number of years of experience in the field of early education. 


\section{Education Session Evaluation}

To assess the overall quality of each of the trainings, an evaluation adapted from the Mississippi State University Extension Service was used. The program evaluation used a four-point Likert scale $(0=$ strongly disagree, $1=$ disagree, $2=$ neutral, $3=$ agree, $4=$ strongly agree) of 11 statements to measure the instructor (e.g., The instructor was knowledgeable of the subject matter), the content (e.g., The content was relevant to my needs.), and the value (e.g., Attending the program was worth my time.) of the training. Open-ended questions (e.g. What could be added to the workshop to make the presentation better?) provided opportunities for participants to make suggestions for improvement of the training and to indicate changes they plan to implement in their daily routine. A copy of the program evaluation can be found in Appendix C.

\section{Physical Activity Training Measures}

\section{Early Care Professional Physical Activity Knowledge Rating}

The recommendations from the Center for Disease Control (2018) regarding physical activity were used as a guide to develop a 10-question knowledge survey administered prior to and after the program. The quiz contained questions on physical activity needs of young children, the role of physical activity in child development, and the early care professional's role in promoting physical activity (e.g., Providing children with opportunities to be physically active throughout the day can: (a) improve classroom behaviors; (b) disrupt naptime; (c) can interfere with academic programming; (d) all of the above.) Each question was given 1 point for the correct answer, with higher numbers representing higher levels of physical activity knowledge. A copy of the quiz is included in Appendix D. 


\section{Sleep Training Measures}

\section{Early Care Professional Sleep Knowledge Rating}

To assess general knowledge on sleep, 10 multiple choice questions based on current recommendations for sleep amounts and sleep hygiene from the National Sleep Foundation (2018) were developed (e.g., Children between the ages of 3 and 5 should have ___ hours of sleep per 24 hours. (a) between $8-10$, (b) between $10-11$, (c) between $10-13$, (d) between $9-13$ ). The quiz was administered before and immediately following the training. Each correct answer was given 1 point, with higher total scores indicative of greater sleep knowledge. The sleep quiz can be found in Appendix E.

\section{Early Care Professional Sleep Beliefs Rating}

To assess early care professionals' sleep beliefs, the Sleep Beliefs Scale (SBS; Adan, Fabbri, Natale, \& Prat, 2006) was used as a pre- and post-assessment tool. The SBS consists of 20 questions on how certain behaviors (e.g., Drinking alcohol in the evening) can influence the quality and amount of sleep an individual receives. Each question was scored on a three-point-scale $(0=$ negative effect, $1=$ neither effect, $2=$ positive effect) with higher scores representing a greater understanding of sleep beliefs. The SBS has been used in the literature to evaluate education programs (Shahid, Wilkinson, Marcu, \& Shapiro, 2011) and is validated for persons 18 - 33 years of age with an internal consistency of .71. Each participant's pre- and post-score was calculated and used to measure change in sleep beliefs. Cronbach's alpha was .752 indicating an acceptable level of reliability. A copy of the SBS is included in Appendix F. 


\section{Evaluation Results}

\section{Early Care Professionals Characteristics - Physical Activity Training}

A total of 31 early care professionals attended the training. The early care professionals represented Center A $(n=17)$, Center B $(n=5)$, Center C $(n=4)$, and Center $\mathrm{D}(n=5)$. A majority $(n=18 ; 58 \%)$ of those in attendance completed the entire training, however, $42 \%(n=13)$ did not complete a post-quiz or evaluation due to an event at the local school system. Of those 31 early care professionals who participated, the majority were female (93\%) and African American (97\%). Ages of the participants ranged from 23 to 68 years with a mean of 45.8 years. The early care professionals averaged 16.7 years $(S D=12.42)$ in the early childhood classroom, with the majority having 9.48 years $(S D=10.30)$ in their current position. Of the 28 who reported their level of education, the majority had earned a bachelor's or master's degree $(n=15)$. The remaining early care professionals reported some college $(n=5)$ or a high school diploma $(n=8)$. It is important to note that due to a scheduling conflict with the local school system (i.e., early care professionals had to go to the local school to pick up their children's report cards), the program was shortened to 2 hours.

\section{Early Care Professional Physical Activity Knowledge Rating}

Paired-samples $t$ test analyses found a statistically significant improvement in overall knowledge of physical activity following the training. That is, the mean score after training $(M=5.56, S D=1.61)$ was significantly greater than the mean before training $(M=4.72, S D=1.27), t(17)=-2.41, p=.027$. This finding suggests that the early care professionals gained knowledge regarding physical activity. 


\section{Classroom Observations for Physical Activity}

Paired-samples $t$ tests were conducted to evaluate changes in the classroom environment related to physical activity 4.5 weeks following the training. The results indicated that there were significant changes in the classroom environment before and after the training for two of the indicators; however, the changes were in a negative direction. That is, the mean before training for the lead early care professional encouraging children to move indoors $(M=3.12, S D=1.64)$ was significantly greater than the mean after the training $(M=2.5, S D=1.31), t(5)=-2.74, p=.041$. The mean for the assistant early care professional's involvement in outside play before the training ( $M$ $=2.8, S D=.84)$ was significantly greater than the mean after the training $(M=1.83, S D$ $=1.60), t(3)=5.2, p=.014$.

A positive trend was noted in the use of portable equipment outdoors following the training. The mean use of portable equipment outdoors before the training was .25 $(S D=.71)$ compared to after training $(M=1.14, S D=.90), t(3)=-3.00, p=.058$. This finding suggests that the early care professionals recognize the importance of using portable equipment after the training.

\section{Education Session Evaluation for Physical Activity}

We conducted a descriptive analysis on each of 13 statements on the program evaluation (e.g., The instructor was knowledgeable of the subject manner.) to measure the overall quality of the physical activity training. Results of the evaluation confirmed the training was well received by the participants. The mean and standard deviation for each statement for the physical activity program is provided in Table 9. 
Table 9 Means and Standard Deviations for Program Evaluation of Physical Activity Training

\begin{tabular}{lcc}
\hline Statement & $M$ & $S D$ \\
\hline The instructor was knowledgeable of the subject matter. & 3.82 & .39 \\
The instructor related content to real-life situations. & 3.76 & .43 \\
The instructor showed respect for all persons in attendance. & 3.82 & .39 \\
The content was relevant to my needs. & 3.76 & .44 \\
The content was at an understandable level. & 3.76 & .44 \\
The content was well-organized. & 3.71 & .47 \\
The content was credible, up-to-date information. & 3.82 & .39 \\
Attending the program was worth my time. & 3.71 & .59 \\
I would recommend this program to others. & 3.71 & .59 \\
I increased my knowledge in the program. & 3.82 & .39 \\
I learned new skills related to this area. & 3.70 & .47 \\
I will use the things I learned. & 3.77 & .44 \\
I will tell others what I learned. & 3.76 & .43 \\
\hline
\end{tabular}

\section{Early Care Professionals Characteristics - Sleep Training}

A total of 22 lead and assistants early care professionals attended the sleep training from Center A $(n=5)$, Center B $(n=4)$, Center D $(n=4)$, and Center E Early Head Start $(n=8)$. Complete data was collected on $21(95 \%)$ of the early care professionals attending the training. The majority of the early care professionals were female (91\%) and African American (95\%). Participants' ages ranged from 26 to 68 years, with a mean of 48.9 years. Participants averaged 15.4 years ( $S D=5.05$ years) in the early childhood classroom and 5.05 years $(S D=5.74$ years $)$ in their current position. Of the 20 who reported their level of education, the majority (70\%) reported some college $(n=3)$ or a high school diploma $(n=11)$. The remaining early care professionals reported having earned a bachelor's or master's degree $(n=6)$. 


\section{Early Care Professional Sleep Knowledge Rating}

A paired-samples $t$ test was conducted to evaluate whether each of the early care professionals increased their overall sleep knowledge. The results indicated that the mean knowledge before $(M=5.29, S D=1.64)$ training was significantly less than the mean after training $(M=7.29, S D=1.41), t(20)=-5.382, p<.00$, indicative of knowledge gained. This finding suggests that the early care professionals increased their sleep knowledge after the training.

\section{Early Care Professional Sleep Beliefs Rating}

To measure the change in sleep beliefs after the training for the 14 early care professionals completing the 20 -item survey, a paired samples $t$ test was conducted. The results indicated that the mean after the training $(M=12.29, S D=4.95)$ was significantly greater than before the training $(M=10.50, S D=3.71), t(13)=-2.96, p=.001$, suggesting a positive increase in sleep beliefs. These results suggest that the training improved the early care professionals' sleep knowledge.

\section{Classroom Observations for Sleep Training}

Paired-samples $t$ tests were conducted to evaluate changes in the classroom environment related to sleep 4.5 weeks following the training. Two variables were collected by the observers (1) the classroom environment prior to naptime, and (2) the classroom environment during naptime. The results indicated that there were no significant changes after the training for either of these variables. 


\section{Education Session Evaluation for Sleep Training}

To evaluate the overall quality of the sleep training, we conducted a descriptive analysis on each of 13 statements on the evaluation tool. The results indicate the training was well received. The mean and standard deviation for each statement for the sleep education program can be found in Table 10.

Table 10 Means and Standard Deviations for Program Evaluation of Sleep Training

\begin{tabular}{lcc}
\hline Statement & $M$ & $S D$ \\
\hline The instructor was knowledgeable of the subject matter. & 3.90 & .30 \\
The instructor related content to real-life situations. & 3.90 & .30 \\
The instructor showed respect for all persons in attendance. & 3.85 & .36 \\
The content was relevant to my needs. & 3.90 & .30 \\
The content was at an understandable level. & 3.86 & .36 \\
The content was well-organized. & 3.81 & .40 \\
The content was credible, up-to-date information. & 3.86 & .48 \\
Attending the program was worth my time. & 3.90 & .30 \\
I would recommend this program to others. & 3.86 & .36 \\
I increased my knowledge in the program. & 3.86 & .36 \\
I learned new skills related to this area. & 3.90 & .30 \\
I will use the things I learned. & 3.90 & .30 \\
I will tell others what I learned. & 3.81 & .51 \\
\hline
\end{tabular}

\section{Discussion}

This study is the first, to our knowledge, to develop a healthy habits education program individualized for Head Start professionals that focused on physical activity and sleep in the early childhood classroom. More specifically, not one sleep education program in the literature was found to target early childhood professionals, highlighting the significance of this work in filling a gap in the literature. Similar to many reported findings on education programs (e.g., Henry, Umoren, Kim, Zittel, \& Derscheidet, 2017; Sheridan, Edwards, Marvin, \& Knoche, 2009; Wilson, Miller, Bonuck, Lumeng, \& Chervin, 2014), results showed an increase in knowledge following the early care 
professionals participation in both workshops, yet knowledge increases did not result in many significant behavior changes within the early childhood classroom, especially for outcomes associated with sleep. These findings emphasize the importance of repeated exposure to novel information and highlight the need for more intensive, individualized programming on health habits for early childhood professionals.

Even though the early childhood professionals agreed that physical activity is important for healthy child development, observations prior to programming replicated prior research that found early care professionals were focused on safety during times of physical activity (Dyment \& Coleman, 2012). Given that research also indicates educators overestimate the amount of physical activity children are engaged in throughout the day and therefore do not recognize the need for adult involvement (Dyment \& Coleman, 2012; Hesketh et al., Tucker et al., 2011), the importance of modeling physical activity was emphasized throughout the training on physical activity. However, the focus on early care professional involvement in physical activity during the training did not translate to changes in how early care professionals interacted and encouraged children during times of physical activity. These findings point to the need for more intense, ongoing training to change beliefs and facilitate change in classroom practices.

Related to physical activity, the pre- and post-classroom observations supported the hypothesis that the limited educational opportunity ( 2 hours) would not result in significant changes in behavior (Sheridan et al., 2009). Each of the classrooms follow the same lesson plan and schedule provided by the consortium. The children have 30 minutes of outdoor play scheduled each day, which meets the licensing requirement for the hours 
of operation. However, the children did not receive the full 30 minutes of physical activity during any of the observations. The weather was a factor on a few days with rainy conditions, however, on several occasions, the weather was sunny and cool, (i.e., 38 degrees) but children were not taken outdoors. During inclement weather, the level of physical activity indoors was limited in both time and intensity due in part to a lack of space. Early care professionals were not noted as altering the classroom space to increase the area for physical movement on the days that the weather did not allow outdoor play, a reason the activity was so limited on bad weather days. Additionally, the playground was shared by at least two classrooms at a time resulting in approximately 40 children on the equipment, which limited the access for the children and increase the time in which they were sedentary. It was observed that there was an increase in the use of portable equipment after the training; however, the increase was not statistically significant. The consortium provided portable equipment at each center (e.g., parachutes, riding toys), but children do not have access to the materials on a regular basis. This finding does suggest that providing on-going educational opportunities around the use of portable equipment could result in children having access to more toys and materials that could facilitate greater movement.

The four centers involved in the study were located in highly impoverished, rural areas and the buildings had been adapted to become an early care facility. Therefore, the physical space indoors varied in size from classroom to classroom, resulting in limited space for physical activity indoors in most of the classes. The post-observations did not provide evidence that the early care professionals had applied suggestions provided during the educational program on physical activity (e.g., increasing learning center size, 
moving furniture to provide space). Studies show that on-site technical assistance or coaching combined with group training results in more effective results in raising quality than group training along (Smith, Robbins, Schnieder, Kreader, \& Ong, 2012). The addition of technical assistance to the educational program could result in better use of the available classroom space allowing more opportunities for physical activity.

The scheduling of routines (e.g., toileting, toothbrushing, mealtimes) influenced the amount of time children had to engage in physical activity as children were often involved in sedentary activities during these times. It was observed that in several classrooms, both the lead and assistant early care professional were involved in cleaning up after meals during which time the children waited with limited opportunities for appropriate activities (e.g., story time before nap as opposed to a classroom dance party). Literature supports that school policies and practices in Head Start programs throughout the U.S. leave early care professionals with no flexibility in their schedule, limited physical space, or few resources to provide children with adequate physical activity (Shen et al., 2011). The lack of flexibility, physical space restrictions, and resources is also supported by Bronfenbrenner's theory of the exosystem's role in development (Bronfenbrenner, 1977). The role of government policies in early care and education programs is not something that an individual can change; however, it does impact their experiences. As previously mentioned, on-site technical assistance could provide suggestions and modeling to improve the scheduling and process of routine activities allowing for children to be more physically active throughout the day.

The results from the evaluation of the physical activity training indicates the training was well received by the early care professionals. With one exception (e.g., 
Attending the program was worth my time.), the participants agreed $100 \%$ with the statements regarding the instructor and the content. The only suggestions for improvement were to start earlier and have a larger room for the training. Of note, the start time was determined by the Head Start administration, but involving early care professionals in those decisions may increase the participation and address some of the concerns they had. Participants praised the organization, clarity, and information on how to use to use equipment available to them in the classroom.

There was also an improvement in the general knowledge of sleep health as well as positive changes in the sleep beliefs scale before and after the training. The improvement in scores from pre- to post-training suggest that the early care professionals gained knowledge on the amount of sleep young children need, information on sleep consolidation, and sleep hygiene. Head Start serves children from low socioeconomic status, who, as the literature, shows are at greater risk for sleep problems (Bagley, Kelly, Buckhalt, \& El-Sheikh, 2015) and have parents who may not understand the importance of sleep health (Bonuck et al., 2016). Information shared during the educational program on sleep included communicating with parents regarding sleepiness and indicators of sleep disorders (i.e., snoring), which may lead early care professionals to help in the identification of sleep issues for young children. The child's home and the early care and education program interact frequently during the early years of life and sharing information may serve to help young children establish healthy lifestyle habits (Bronfenbrenner, 1997). Although parents were not assessed in this study, a story book that detailed a recommended bedtime routine was sent home and on the last pages 
information for how parents can improve children's sleep was included, strengthening the school-to-home connection.

The pre- and post-classroom observations supported the hypothesis that the limited educational opportunity would not result in significant changes related to sleep in the classroom environment (Sheridan et al., 2009). The results from the observation indicate that the children in the Head Start classrooms had an hour of scheduled naptime from 12:30 p.m. until 1:30 p.m. each day. However, it was noted that at pre- and postobservation the start time for naptime was highly variable, while the ending time for nap was consistent, resulting in shorter than recommended quiet times for preschool children. Children started the process of trying to go to sleep approximately 15 minutes after the scheduled start of naptime. One reason for the delay that was noted by researchers was the early care professional required tasks (e.g., group toileting and teeth brushing; cleaning up after meals) that had to be completed prior to naptime. The number of tasks that early care professionals needed to complete and the involvement of both the lead and assistant in routines (e.g., cleaning up after meals, group toileting) resulted in the delayed start of naptime. Because of this delay, children were not given the full hour for nap. Researchers noted at the post observation that the majority (48\%) of the children were asleep within 10 minutes of lying down on their cot and $85 \%$ of the children slept during naptime indicating the need for daytime sleep. There were indications that some children were sleepy before naptime (e.g., rubbing their eyes, putting their head down on the table) and had difficulty waking up after nap (e.g., unable to wake up easily, putting their head down on the table). Data obtained from the survey for Study 1 confirmed early care professionals believe the environment has an impact on naptime; however, pre- and post- 
observations found that good sleep hygiene practices, even after early care professionals were made aware of best practices in the classroom, were not being followed on a regular basis (e.g., windows were not typically covered; the classroom was not kept quiet). Lead and assistant early care professionals were not observed helping the children to relax as needed (e.g., rubbing their backs, sitting next to them) and children who did not sleep were not provided with quiet activity, but rather were expected to lay still on their cot. Additionally, one grave area of concern was that given the strict timeframe of activities following naptime (i.e., snack; bus departure), early care professionals were adamant about waking children on time. This urgency to stay on task resulted in children being abruptly awoken from their nap to the detriment of the child. For example, and noted across classrooms, early care professionals were standing sleeping children up, removing their cots, and directing a child to go sit at the table without the child having a proper amount of time to transition from sleep to wake. The sleepy state of the children transitioning to snack from nap was a safety concern and should be addressed in future trainings.

Intense and on-going staff development around good sleep hygiene could improve sleep outcomes for Head Start children. The improvement of sleep conditions for children could also result in a calmer classroom environment (Spruyt et al., 2015) allowing more time for academic instruction and physical activity, rather than discipline. Providing technical assistance to model good sleep hygiene (e.g., quiet, dim lights) could allow for a more conducive environment for rest and allow for the transfer of knowledge to the classroom. 
The training delivered on sleep was well received by the early care professionals as noted by the evaluations. All of the participants (100\%) agreed with the statements regarding the instructor and the content with the exception of two statements (e.g., I will tell others what I learned; The content was credible, up-to-date information). Suggestions for improving the training included adding more activities, increasing the length of the training, and having more information on all races not just focused on sleep issues of African American populations. Of note, given that the majority of the children served in these Head Start Centers were African American, a discussion about higher rates of sleep apnea in African American populations were highlighted.

The Head Start model is based on a multi-tiered model with performance standards guiding the manner in which services are delivered within a program. Head Start administrators have expectations placed on the overall program operation by performance standards (Office of Head Start, 2018), which impact the actions of the center director, and ultimately the early care professional's behaviors. Bronfrenbrenner's ecological model refers to this as the exosystem and while the early care professional may not have direct contact with the Head Start administrator, they are still influenced by them which in turn influences the children in their care (Bronfrenbrenner, 1977). The early care professionals may have gained knowledge regarding physical activity and sleep, but may not feel they possess the self-efficacy to implement changes within the classroom.

\section{Strengths and Limitations}

A strength of the study was the inclusion of both subjective assessments of knowledge change and objective assessments of behavior change. However, the 
observations had some limitations that need to be discussed. Namely, the classrooms from each center were randomly selected prior to any programming so that researchers could understand what classroom activities and behaviors needed to be addressed in the trainings. While this pre-selection method was imperative, it did have some limitations. For example, two of the classrooms observed did not have an early care professional (lead or assistant) attend either of the trainings; one classroom had an assistant participate in training, but not the lead while another classroom had the lead, but not the assistant attend. The different combination of lead and assistant early care professionals attending the training may have impacted the degree of change in behaviors related to physical activity and sleep, as the lead early care professional is the individual in charge of classroom activities. Attending the training was heavily encouraged by the administrators, but the training was not mandatory, thus variability in the training attendance likely impacted the objective results. Further, upon initial observation, the early care professionals were not aware of who the researchers were and they assumed they were being evaluated by the monitoring agency. Once early care professionals attended the training, they were aware that the researchers were separate from their employers. This acknowledgement had positives and negatives for the study. Early care professionals may have felt more at ease during the follow-up observations given that they now understood that their jobs were not at-risk based on their behaviors, which may have provided a more realistic classroom atmosphere. Conversely, it is also a concern that early care professionals may have known what the observers were looking for after completing the training and acted in a socially desirable way. However, results from the 
post-observations indicated that they were not substantially different from the preobservations, which reduces the concern.

The observations were done by two highly qualified early childhood professionals with years of experience. The observers were able to identify areas of strength in the programs unrelated to physical activity and sleep as well as areas needing improvement. Program reviews for Head Start are routinely conducted by child care licensure and peers; however, these reviews evaluate specific elements of the program and may not provide information on other areas of strength or concern. The findings from the post observations confirm the need for more in-depth training on physical activity and sleep, as well as other topics including effective transitions, time management of staff, positive interactions, and specific health (e.g., proper handwashing, correct sanitizing procedures) procedures.

The research study had several limitations. The study sample came from one rural county in the state of Mississippi, and the results cannot be generalized to other groups. However, the study did include the entire population of early care professionals working in a consortium. During the research study, there were six community based early care and education programs operating in the county with approximately 40 full-time staff employed. In all early care and education programs, staff are directly related to children's outcomes and the content of the program. Information gathered from the study can be used in other similar counties in the Mississippi Delta to provide education in developing healthy lifestyle habits for the children most at-risk for obesity in the state. The physical activity and sleep knowledge quizzes were not standardized nor tested before being used. The educational program was limited to two hours in length rather than three hours due to 
work obligations of the Head Start staff that were not disclosed prior to the training. The shortened length of the training may have impacted the depth of the material that was covered during the training. Plans were to allow more time between the educational programs and the post-observations; however, the Head Start program closed for the summer in early May, 2018 requiring post-observations to occur two weeks following the training. The short amount of time between the training and the observations may have caused the early care professionals to recall the information and make changes accordingly. The study did not consider the weather or season and the impact on classroom observations (e.g., one center experienced rain on both observation dates which may not have represented a typical day). The weather may have influenced the amount of time that children spent outdoors. The research was restricted to a sample of three to five-year-old children which means that findings may not generalize to children of other ages or settings other than Head Start.

\section{Future Research}

Future research should be conducted to understand how the early care professional's own physical activity and sleep quality impact the classroom environment they provide for children. Literature supports the role that early care professionals have in establishing healthy habits; however, little is known about the physical activity and sleep habits of these individuals. Actigraphy data can provide information on actual amounts of physical activity the early care professionals are receiving and their quality of sleep to determine the relationship of the lifestyle habits of the early care professional on the environment they are providing for young children. Data on the early care professionals' physical activity and sleep could provide information on the health of the early care 
workforce and provide insight to develop intervention programs designed to improve healthy lifestyle habits.

To date, the research on physical activity and sleep in early care and education has focused primarily on children ages 3 - 5 while limited data has been gathered on infants and toddlers despite the fact that they too spend large amounts of time in out-ofhome care. The sleep needs of infants and toddlers are uniquely different from those of preschool children (Galland et al., 2012) and research can identify how early care and education programs are addressing these needs. In addition, the opportunities for physical activity for infants and toddlers is significantly impacted by the early care professional and need to be researched to determine strategies to improve outcomes for young children.

Further research is needed to guide early education programs in decision-making concerning sleep policy and practices. Of particular importance are studies focused on the effects of enforcing naptime for children who have transitioned away from naps. Research should also address individual differences of children (e.g., temperament, culture, social) within the early care and education program related to sleep practices. Research on beliefs and values on healthy lifestyle behaviors of early care professionals working in programs other than Head Start could also provide data to develop specific educational programs to meet the needs of this unique population.

\section{Implications for Practice}

Future training programs should utilize an ecological approach similar to the HipHop to Health, Jr. Intervention Program and Mighty Moves Intervention (Ling et al., 2016) to address the establishment of healthy lifestyle habits in young children. These 
programs promote a school to home connection by providing parents with tips on improving children's healthy habits and understanding recommendations for physical activity and sleep using a variety of approaches (e.g., newsletters, text messages, Extension publications). Healthy lifestyle habits should be taught in the classroom through an integrated curriculum across all domains providing repeated exposure to the material. Additionally, early care professionals should receive on-going professional development on promoting healthy lifestyle habits to help ensure that the information is retained and implemented.

Given the increased focus on academic achievement paired with the obesity epidemic in the U.S., the use of intervention programs designed to promote physical activity and increase cognitive skills may prove to be cost effective during the early childhood years. These programs use teacher-directed and readily available materials to provide children with on-going information regarding healthy habits. Professional development should focus on incorporating movement into learning activities for young children. Understanding how physical movement is linked to literacy, math and science could greatly improve cognitive outcomes for all children, but particularly for at-risk children. Combining training programs with technical assistance to model effective practices could result in better classroom outcomes related to healthy lifestyle habits as well as academics.

Providing sleep education programs for families during the early childhood years, when sleep habits are being established, could also provide a low-cost intervention to improve children's overall health for a lifetime. Health care professionals, especially those serving at-risk children, should be providing caregivers with information on the 
importance of good sleep hygiene and indications of sleep disorders, such as snoring. In addition, evidence-based recommendations for healthy sleep practices in early care and education program child should be researched and recommended by public health professionals and early care professionals. Incorporating sleep health education into preservice and in-service education for early care professionals may help set the stage for establishing healthy sleep habits for a lifetime.

Early care professionals need to develop the confidence to promote healthy behaviors in their classroom. Professional development should equip early care professionals with the capacity to improve the healthy lifestyle habits of at-risk preschoolers they work with in their classrooms. In addition, early care professionals need training to understand the importance of not only teaching healthy lifestyle habits, but applying the practices to their own life.

In summary, we found that the early care professional showed a significant increase in post-scores on both the physical activity and sleep knowledge quizzes suggesting that they increased their overall knowledge of both topics. The early care professionals also showed an increase in sleep beliefs knowledge after the sleep training. As expected, no significant improvement was noted in the classroom environment after the two educational opportunities, although there was a positive trend indicating that early care professionals understood the information but may need more exposure to the information (e.g., on-going training, technical assistance) before implementing changes. 


\section{REFERENCES}

Acebo, C., Saden, A., Seifer, R., Tzischinsky, O., Hafer, A., \& Carskadon, M. A. (2005). Sleep/wake patterns derived from activity monitoring and maternal report for healthy 1-to 5-year-old children. Sleep, 28(12), 1568-1577.

Adan, A., Fabbri, M., Natale, V., \& Prat, G. (2006). Sleep beliefs scale (SBS) and circadian typology. Journal of Sleep Research, 15(2), 125-132. doi.org/10.1111/j.1365 2869.2006.00509.x

Annesi, J. J., Smith, A.E., \& Tennant, G. A. (2013). Effects of the Start for Life treatment on physical activity in primarily African American preschool children of ages 3-5 years. Psychology, Health \& Medicine, 18, 300-309.

doi: 10.1080/13548506.2012.712704

Bagley, E., J., Kelly, R. J., Buckhalt, J. A., \& El-Sheikh, M. (2015). What keeps low-SES children from sleeping well: The role of presleep worries and sleep environment. Sleep Medicine, 16, 496-502. doi: 10.1016/j.sleep.2014.10.008

Barros, R. M., Silver, E. J., \& Stein, R. E. (2009). School recess and group classroom behavior. Pediatrics, 123(2), 431-436. doi: 10.1542/peds.2007-2825

Benjamin, S. E., Copeland, K A., Cradock, A., Neelon, B., Walker, E., Slining, M. M., \& Gillman, M. W. (2009). Menus in child care: A comparison of state regulations and national standards. Journal of the American Dietetic Association, 109, 109115. doi: 10.1016/j.jada.2008.10.015

Bonuck, K. A., Schwartz, B., \& Schechter, C. (2016). Sleep health literacy in head start families and staff: Exploratory study of knowledge, motivation, and competencies to promote healthy sleep. Sleep Health, 2, 19-24. doi: 10.1016/j.sleh.2015.12.002

Bronfenbrenner, U. (1977). Toward an experimental ecology of human development. American Psychologist, 32, 513-531.

Bucholz, E. M., Desai, M. M., \& Rosenthal, M. S. (2011). Dietary intake in Head Start vs non-Head Start preschool-aged children: Results from the 1999-2004 National Health and Nutrition Examination Survey. Journal of the American Dietetic Association, 111, 1021-1030. doi: 10.1016/j.jada.2011.04.009

Burnham, M. M., Gaylor, E. E., \& Wei, X. (2016). Toddler naps in child care: Associations with demographics and developmental outcomes. Sleep Health, 2, 25-29. doi.org/10.1016/j.sleh.2015.12.004 
Buysse, V., Winton, P. J., \& Rous, B. (2009). Reaching consensus on a definition of professional development for the early childhood field. Topics in Early Childhood Education, 28(4), 235-243. doi.org/10.1177/0271121408328173

Centers for Disease Control and Prevention. (2018). Retrieved from https://www.cdc.gov

Cloutier, M. M., Wiley, J., Wang, Z., Grant, A., \& Gorin, A. A. (2015). The Early Childhood Obesity Prevention Program (ECHO): An ecologically-based intervention delivered by home visitors for newborns and their mothers. BMC Public Health, 1-13. doi: 10.1186/s12889-015-1897-9

Copeland, K. A., Sherman, S. N., Kendeigh, C. A., Kalkwarf, H. J., \& Saelens, B. E. (2012). Societal values and policies may curtail preschool children's physical activity in child care centers. Pediatrics, 129, 265-274.

doi: 10.1542/peds.2011-2102

Davis, S. M., Sanders, S. G., FitzGerald, C. A., Keane, P. C., Canaca, G. F., \& VolkerRector, R. (2013). CHILE: An evidence-based preschool intervention for obesity prevention in Head Start. Journal of School Health, 83(3), 223-239.

De Craemer, M., De Deckler, E., De Bourdeaudhuij, I., Deforche, B., Vereechen, C., Duvinage, K., ... Cardon, G. (2013). Physical activity and beverage consumption in preschoolers: Focus groups with parents and teachers. BMI Public Health, 13, $2-13$.

De Marco, A. C., Zeisel, S., \& Odom, S. L. (2015). An evaluation of a program to increase physical activity for young children in child care. Early Education and Development, 26, 1-26. doi.org/10.1080/10409289.2014.932237

Draper, C. E., Achmat, M., Forbes, J., \& Lambert, E. (2012). Impact of a programme for motor development on gross motor skills and cognitive function in preschool children from disadvantaged settings. Early Child Development and Care, 182(1), 137-152.

Dyment, J., \& Coleman, B. (2012). The intersection of physical activity opportunities and the role of early childhood educators during outdoor play: Perceptions and reality. Australian Journal of Early Childhood, 37, 90-98.

Esquivel, M. K., Nigg, C. R., Fialkowski, M. K., Braun, K. L., Li, F., \& Novotny, R. (2016). Influence of teachers' personal health behaviors on operationalizing obesity prevention policy in Head Start preschools: A project of the Children's Healthy Living Program (CHL). Journal of Nutrition Education and Behavior, 48, 318-324. doi.org/10.1016/j.jneb.2016.02.007

Fields, S. A., Sabet, M., \& Reynolds, B. (2013). Dimensions of impulsive behavior in obese, overweight, and healthy-weight adolescents. Appetite, 70, 60-66. doi: 10.1016/j.appet.2013.06.089 
Ford, C. N., Slining, M. M. \& Popkin, B. M. (2013). Trends in dietary intake among US 2- to 6-year-old children, 1989-2008. Journal of the Academy of Nutrition and Dietetics, 113(1), 35-42. doi: 10.1016/j.jand.2012.08.022

Fox, M. K., Condon, E., Briefel, R. R., Reidy, K. C., \& Deming, D. M. (2010). Food consumption patterns of young preschoolers: Are they starting off on the right path? Supplement to the Journal of the American Dietetic Association, 110(12), S52-S59. doi: 10.1016/j.jada.2010.09.002

Freedman, M. R., \& Alvarez, K. P. (2010). Early childhood feeding: Assessing knowledge, attitudes, and practices of multi-ethnic child-care providers. Journal of the American Dietetic Association, 110, 447-451.

doi: 10.1016/j.jada.2009.11.018

Gagne, C., \& Harnois, I. (2014). How to motivate childcare workers to engage preschoolers in physical activity. Journal of Physical Activity and Health, 11, 364-374. doi: 10.1123/jpah.2011-0325

Galland, B. C., Taylor, B. J., Elder, D. E., \& Herbison, P. (2012). Normal sleep patterns in infants and children: a systematic review of observational studies. Sleep Medicine Reviews, 16, 213-222. doi: 10.1016/j.smrv.2011.06.001

Gangwisch, J. E., Malaspina, D., Boden-Albala, B. \& Heymsfield, S. B. (2005). Inadequate sleep as a risk factor for obesity: Analyses of the NHANES I. Sleep, $28,1289-1296$.

Gehris, J. S., Gooze, R. A., \& Whitaker, R. C. (2014). Teachers' perceptions about children's movement and learning in early childhood education programs. Child: Care, Health and Development, 41, 122-131. doi: 10.1111/cch.12136

Guo, Y., Piasta, S. B., Justice, L. M., \& Kaderavek, J. N. (2010). Relations among preschool teachers' self-efficacy, classroom quality, and children's language and literacy gains. Teaching and Teacher Education, 26, 1094-1103. doi: 10.1016/j.tate.2009.11.005

Gutierrez-Repiso, C., Soriguer, F., Rubio-Martin, E., de Antonio, I. E., de Adana, M. S. R., Almaraz, M., . . Rojo-Martinez, G. (2014). Night-time sleep duration and the incidence of obesity and type 2 diabetes. Findings from the prospective Pizarra study. Sleep Medicine, 15, 1398-1404. doi.org/10.1016/j.sleep.2014.06.014

Halal, C. S. E., Matijasevich, A., Howe, L. D., Santos, I. S., Barros, F. C., \& Nunes, M. L. (2016). Short sleep duration in the first years of life and obesity/overweight at age 4 years: A birth cohort study. The Journal of Pediatrics, 168, 99-103. doi.org/10.1016/j.jpeds.2015.09.074 
Hall, W. A., Scher, A., Zaidman-Zait, A., Espezel, H., \& Warnock, F. (2011). A community-based study of sleep and behavior problems in 12- to 36-month-old children. Child: Care, Health and Development, 38, 3, 379-389.

doi: $10.1111 / \mathrm{j} .1365-2214.2011 .01252 . x$

Hallgren, K. A. (2012). Computing Inter-Rater Reliability for Observational Data: An overview and tutorial. Tutorials in Quantitative Methods for Psychology, 8(1), 2324.

Harms, T., Clifford, R. M., \& Cryer, D. (2005). Early childhood environment rating scale revised edition. New York: Teachers College Press.

Henry, B. W., Umoren, J., Kim, S., Zittel, L., \& Derscheid, L. E. (2017). The Take Action training protocol: A model for teacher professional development. Health Behavior and Policy Review, 4(6), 570-581. doi.org/10.14485/HBPR.4.6.7

Hesketh, K. R., van Slujis, E. M., Blaine, R. E., Taveras, E. M., Gillman, M. W., \& Neelon, S.B. (2015). Assessing care providers; perceptions and beliefs about physical activity in infants and toddlers: Baseline findings from Baby NAP SACC study. BMC Public Health, 15, 1-7. doi: 10.1186/s12889-015-1477-z

Hughes, S. O., Patrick, H., Power, T. G., Fisher, J. O., Anderson, C. B., \& Nicklas, T. A. (2007). The impact of child care providers' feeding on children's food consumption. Journal of Developmental \& Behavioral Pediatrics, 28, 100-107.

Kim, J., Shim, J. E., Wiley, A. R., Kim, K., \& McBride, B. A. (2012). Is there a difference between center and home care providers' training, perceptions, and practices related to obesity prevention? Maternal and Child Health Journal, 16(8), 1559-1566. doi: 10.1007/s10995-011-0874-X

Kirk, S. M., Vizcarra, C. R., Looney, E. C., \& Kirk, E. P. (2014). Using physical activity to teach academic content: A study of the effects on literacy in Head Start preschoolers. Early Childhood Education Journal, 42, 181-189. doi.org/10.1007/s10643-013-0596-3

Lanigan, J. D. (2012). The relationship between practices and child care providers' beliefs related to child feeding and obesity prevention. Journal of Nutrition Education and Behavior, 44, 521-529. doi.org/10.1016/j.jneb.2011.07.008

Lanigan, J. (2014). Physical activity for young children: A quantitative study of child care providers' knowledge, attitudes, and health promotion practices. Early Childhood Education Journal, 42, 11-18. doi.org/10.1007/s10643-013-0583-8

Larson, N., Ward, D. S., Neelon, S. B., \& Story, M. (2011). What role can child-care settings play in obesity prevention? A review of the evidence and call for research efforts. Journal of the American Dietetic Association, 111, 1343-1362. doi: 10.1016/j.jada.2011.06.007 
Ling, J., Robbins, L., \& Wen, F. (2016). Interventions to prevent and manage overweight or obesity in preschool children: A systematic review. International Journal of Nursing Studies, 53, 270-289. doi.org/10.1016/j.ijnurstu.2015.10.017

Lo, J. C., Maring, B., Chandra, M., Daniels, S. R., Sinaiko, A., Daley, M. F., . . Greenspan, L. C. (2013). Prevalence of obesity and extreme obesity in children aged 3-5 years. Pediatric Obesity, 9, 165-175.

doi: 10.1111/j.2047-6310.2013.00154x

Lubans, D. R., Morgan, P. J., Cliff, D. P., Barnett, L. M., \& Okely, A. D. (2010). Fundamental movement skills in children and adolescents: Review of associated health benefits. Sports Medicine, 40(12), 1019-1035.

Lumeng, J. C., Kaplan-Sanoff, M., Shuman, S., \& Kannan, S. (2008). Head Start teachers' perceptions of children's eating behavior and weight status in the context of food scarcity. Journal of Nutrition Education and Behavior, 40, 237243. doi: 10.1016/j.jneb.2007.07.001

McClintic, S., \& Petty, K. (2015). Exploring early childhood teachers' beliefs and practices about preschool outdoor play: A qualitative study. Journal of Early Childhood Teacher Education, 36, 24-43. doi: 10.1080/10901027.2014.997844

McNeil, J., Doucet, E., \& Chaput, J. (2013). Inadequate sleep as a contributor to obesity and type 2 diabetes. Canadian Journal of Diabetes, 37, 103-108. doi.org/10.1016/j.jcjd.2013.02.060

McWilliams, C., Ball, S. C., Benjamin, S. E., Hales, D., Vaughn, A., \& Ward, D. S. (2009). Best-practices guidelines for physical activity at child care. Pediatrics, 124(6), 1650-1659. doi: 10.1542/peds.2009-0952

Mississippi State Department of Health. (2018). Retrieved from http://www.msdh.state.ms.us

Muckelbauer, R., Kalhoff, H., Muller-Nordhorn, J., \& Kersting, M. (2011). Childhood overweight and obesity: Introduction into epidemiology and prevention strategies. Current Nutrition \& Food Science, 7(3), 101-199.

Natale, R. A., Messiah, S. E., Asfour, L., Uhlhorn, S. B., Delamater, A., \& Arheart, K. L. (2014). Role modeling as an early childhood obesity prevention strategy: Effect of parents and teachers on preschool children's healthy lifestyle habits. Journal of Developmental \& Behavioral Pediatrics, 35, 379-387.

doi: 10.1097/DBP.0000000000000074

National Sleep Foundation. (2018). Retrieved from http://www.sleepfoundation.org

O'Connor, J. \& Temple, V. (2005). Constraints and facilitators for physical activity in family daycare. Australian Journal of Early Childhood, 30(4), 1-9. 
Ogden, C. L., Carroll, M. D., Lawman, H. G., Fryar, C. D., Kruszon-Moran, D., Kit, B. K., \& Flegal, K. M. (2016). Trends in obesity prevalence among children and adolescents in the United States, 1988-1994 through 2013-2014. Journal of American Medical Association, 315, 2292-2299. doi: 10.1001/jama.2016.6361

Owens, J. A., Jones, C., \& Nash, R. (2011). Caregivers' knowledge, behavior, and attitudes regarding healthy sleep in young children. Journal of Clinical Sleep Medicine, 7(4), 345-350. doi: 10.5664/JCSM.1186

Sahoo, K., Sahoo, B., Choudhury, A., Sufi, N., Kumar, R., \& Bhadoria, A. (2015). Childhood obesity: Causes and consequences. Journal of Family Medicine and Primary Care, 187-192. doi: 10.4103/2249-4863.154628

Saluja, G., Early, D. M., \& Clifford, R. (2002). Demographic characteristics of early childhood teachers and structural elements of early care and education in the United States. Early Childhood Research \& Practice, 4(1), 1-20.

Shahid A., Wilkinson K., Marcu S., Shapiro C.M. (2011) Dysfunctional Beliefs and Attitudes About Sleep Scale (DBAS). In: Shahid A., Wilkinson K., Marcu S., Shapiro C.(eds) STOP, THAT and One Hundred Other Sleep Scales. Springer, New York, NY.

Sharma, S., Dortch, K. S., Byrd-Williams, C., Truxillio, J. B., Rahman, G. A., Bonsu, P., \& Hoelscher, D. (2013). Nutrition-related knowledge, attitudes, and dietary behaviors among Head Start teachers in Texas: A cross-sectional study. Journal of the Academy of Nutrition and Dietetics, 113, 558-562.

doi: 10.1016/j.jand.2013.01.003

Shen, B., Reinhart-Lee, T., Janisse, H., Brogan, K., Danford, C., \& Jen, K-L. C. (2012). African American preschool children's physical activity levels in Head Start. Research Quarterly for Exercise and Sport, 83, 168-174.

Sheridan, S. M., Edwards, C. P., Marvin, C. A., \& Knoche, L. L. (2009). Professional development in early childhood programs: Process issues and research needs. Early Education and Development, 20(3), 377-401. doi: 10.1080/10409280802582795

Sigman-Grant, M., Christiansen, E., Branen, L., Fletcher, J., \& Johnson, S. L. (2008). About feeding children: Mealtimes in child-care centers in four western states. Journal of the American Dietetic Association, 108, 340-346. doi: 10.1016/j.jada.2007.09.006

Smith, S., Robbins, T., Schneider, W., Kreader, J. L., \& Ong, C. (2012). Coaching and quality assistant in early care and education programs and home-based settings. Retrieved from www.nccp.org. 
Smith, W. R., Moore, R., Cosco, N., Wesoloski, J., Danninger, T., Ward, D. S., ...Ries, N. (2014). Increasing physical activity in childcare outdoor learning environments: The effect of setting adjacency relative to other built environment and social factors. Environment and Behavior, 48(4), 1-29.

doi: 10.1177/0013916514551048

Spiegel, K., Leproult, R., L’Hermite-Baleriaux, M., Copinschi, G., Penex, P. D., \& Van Cauter,E. (2004). Leptin levels are dependent on sleep duration: Relationships with sympathovagal balance, carbohydrate regulation, cortisol, and thyroptropin. The Journal of Clinical Endocrinology, 89(11), 5762-5771. doi: 10.1210/jc.2004-1003

Spruyt, K., Alaribe, C. U., \& Nwabara, O. U. (2015). To sleep or not to sleep: A repeated daily challenge for African American children. CNS Neuroscience \& Therapeutics, 21, 23-31. doi:10.1111/cns.12319

State Early Childhood Advisory Council of Mississippi. Retrieved from https://secac.ms.gov/early-childhood-academy/

State of Obesity. (2018). Retrieved from http://www.stateofobesity.org

Staton, S. L., Smith, S. S., \& Thorpe, K. J. (2015). "Do I really need a nap?": The role of sleep science in informing sleep practices in early childhood education and care settings. Translational Issues in Psychological Science, 1(1), 32-44. dx.doi.org/10.1037/tps0000011

Story, M., Kaphingst, K. M., \& French, S. (2006). The role of child care settings in obesity prevention. The Future of Children, 16, 143-168.

Summerbell, C. D., Moore, H. J., Vogele, C., Kreichauf, S., Wildruber, A., Manios, Y., . . .Gibson, E. L. (2012). Evidence-based recommendations for the development of obesity prevention programs targeted at preschool children. International Association for the Study of Obesity, 13, 129-132. doi: 10.1111/j.1467-789X.2011.00940.x

Tandon, P. S., Saelens, B. E., \& Christakis, D. A. (2015). Active play opportunities at child care. Pediatrics, 135(6), E1425-E1431. doi: 10.1542/peds.2014-2750

Timmons, B. W., Naylor, P. J., \& Pfeiffer, K. A. (2007). Physical activity for preschool how much and why? Canadian Journal of Public Health, 98, 122-134.

Tucker, P., van Zandvoort, M. M., Burke, S. M., \& Irwin, J. D. (2011). Physical activity at daycare: Childcare providers' perspectives for improvements. Journal of Early Childhood Research, 9, 207-219. doi: 10.1177/1476718X10389144

U.S. Census Bureau. (2018). Retrieved from http://www.census.gov 
Vale, S., Trost, S., Rego, C., Abreu, S., \& Mota, J. (2015). Physical activity, obesity status, and blood pressure in preschool children. The Journal of Pediatrics, 167, 98-101. doi.org/10.1016/j.jpeds.2015.04.031

Weissbluth, M. (1995). Naps in children: 6 months - 7 years. Sleep, 18(2), 82-87.

Whitaker, R. C., Becker, B. D., Herman, A. N., \& Gooze, R. A. (2013). The physical and mental health of Head Start staff: The Pennsylvania Head Start staff wellness survey, 2012. Preventing Chronic Disease, 10, 1-9. doi: 10.5888/pcd10.130171

Wilson, K. E., Miller, A.L., Bonuck, K., Lumeng, J. C., \& Chervin, R. D. (2014). Evaluation of a sleep education program for low-income preschool children and their families. Sleep 37(6), 111-7-1125. doi.org/10.5665/sleep.3774

Whitebook, M., McLean, C., \& Austin, L J. E. (2016). Early Childhood Workforce Index - 2016. Berkley, CA: Center for the Study of Child Care Employment, University of California, Berkeley.

Wood, E. \& Bennett, N. (2000). Changing theories, changing practices: Exploring childhood teachers' professional learning. Teacher and Teacher Education, 16, 635-647.

Yavuz, H. M., van Ijzendoorn, M. H., Mesman, J., \& van der Veek, S. (2015). Interventions aimed at reducing obesity in early childhood: A meta-analysis of programs that involve parents. Journal of Child Psychology and Psychiatry, 56, 677-692. doi: 10.1111/jcpp. 12330

Xiang, P., Lowy, S., \& McBride, R. (2002). The impact of a field-based elementary physical education methods course on preschool classroom teachers' beliefs. Journal of Teaching in Physical Education, 21, 145-161.

Xu, S., \& Xue, Y. (2015). Pediatric obesity: Causes, symptoms, prevention and treatment (review). Experimental and Therapeutic Medicine, 11, 15-20. doi.org/10.3892/etm.2015.2853

Zhai, F., Raver, C. C., \& Li-Grining, C. (2011). Classroom-based interventions and teachers' perceived job stressors and confidence: Evidence from a randomized trial in Head Start settings. Early Childhood Research Quarterly, 26, 442-452. doi: 10.1016/j.ecresq.2011.03.003 
APPENDIX A

TIMELINE FOR STUDY 1 


\section{TIMELINE FOR STUDY 1}

\section{March 2017}

Contacted Head Start consortium director by telephone to request approval to invite early care professionals to participate in research study using Beliefs and Values Survey

$\square$ Received written permission by email from Head Start consortium director to conduct survey

\section{April 2017}

Contacted Head Start directors by telephone to explain the process of delivering the surveys to each center

Followed-up with an email to Head Start directors to confirm the date for surveys to be delivered to centers

$\square$ Collated surveys and consent forms

Delivered surveys to Head Start centers

\section{May 2017}

Contacted Head Start directors by telephone to remind them of the pick-up date for surveys

Picked up completed Beliefs and Values Surveys from Head Start centers

\section{December 2017}

Dissertation proposal approved on December 13.

$\square$ Received approval from Head Start consortium to provide training on physical activity and sleep at agency wide training scheduled for February and March

\section{January 2018}

Beliefs and Values survey data analyzed 
APPENDIX B

TIMELINE FOR STUDY 2 


\section{TIMELINE FOR STUDY 2}

\section{March 2017}

Contacted Head Start consortium director by telephone to request approval to invite early care professionals to participate in research study using Beliefs and Values Survey

Received written permission by email from Head Start consortium director to conduct survey

\section{April 2017}

Contacted Head Start directors by telephone to explain the process of delivering the surveys to each center

Followed-up with an email to Head Start directors to confirm the date for surveys to be delivered to centers

$\square$ Collated surveys and consent forms

Delivered surveys to Head Start centers

\section{May 2017}

Contacted Head Start directors by telephone to remind them of the pick-up date for surveys

Picked up completed Beliefs and Values Surveys from Head Start centers

\section{December 2017}

Dissertation proposal approved on December 13.

Received approval from Head Start consortium to provide training on physical activity and sleep at agency wide training scheduled for February and March

\section{January 2018}

Beliefs and Values survey data analyzed

Pre-observations scheduled with Head Start directors by telephone for February 
Researchers contacted by Head Start consortium and told that agency wide training requirements had been changed and physical activity and sleep training would need to be rescheduled

\section{February 2018}

Rescheduled physical activity training for March 21 and sleep training for March 28

Contacted Head Start directors by email to invite their staff to attend the training

$\square$ Contacted Head Start directors by telephone two days prior to scheduled observation date to confirm visits

Pre-observations conducted in five classrooms randomly selected on the date of the visit

February 2 Center B

February 9 Center A

February 26 Center D

Observation data analyzed

Developed physical activity and sleep training workshops

Prepared pre- and post-training materials

Purchased training supplies and materials to be provided during the training

\section{March 2018}

Pre-observations conducted in one classroom randomly selected on the date of the visit

\section{March $7 \quad$ Center C}

Contacted Head Start directors by telephone one week prior to training to remind them of dates and obtain list of staff attending

Conducted physical activity training on March 21

$\square$ Conducted sleep training on March 28

Post-observations scheduled by telephone with Head Start directors for April 


\section{April 2018}

Contacted Head Start directors by telephone two days prior to scheduled observation date to confirm visits

Post-observations conducted in the same six classrooms randomly selected in February

$\begin{array}{ll}\text { April 25 } & \text { Center B } \\ \text { April 26 } & \text { Center D } \\ \text { April 27 } & \text { Center C } \\ \text { April 30 } & \text { Center A }\end{array}$


APPENDIX C

\section{PROGRAM EVALUATION}


Program Evaluation

Age

Race

Position held at Head Start

Length of time at Head Start

Please indicate your response for each item.

\begin{tabular}{|l|c|c|c|c|c|}
\cline { 2 - 6 } \multicolumn{1}{c|}{} & $\begin{array}{c}\text { Strongly } \\
\text { Disagree } \\
\text { (SD) }\end{array}$ & $\begin{array}{c}\text { Disagree } \\
\text { (D) }\end{array}$ & $\begin{array}{c}\text { Neutral } \\
\text { (N) }\end{array}$ & $\begin{array}{c}\text { Agree } \\
\text { (A) }\end{array}$ & $\begin{array}{c}\text { Strongly } \\
\text { Agree } \\
\text { (SA) }\end{array}$ \\
\hline 1. The instructor & SD & D & N & A & SA \\
\hline $\begin{array}{l}\text { a. was knowledgeable of the } \\
\text { subject matter. }\end{array}$ & SD & D & N & A & SA \\
\hline $\begin{array}{l}\text { b. related program content to } \\
\text { real-life situations. }\end{array}$ & SD & D & N & A & SA \\
\hline $\begin{array}{l}\text { c. showed respect for all persons } \\
\text { in attendance. }\end{array}$ & SD & D & N & A & SA \\
\hline 2. The content & SA & D & N & A & SA \\
\hline a. was relevant to my needs. & SD & D & N & A & SA \\
\hline b. was at an understandable level & SD & D & N & A & SA \\
\hline c. was well-organized. & SD & D & N & A & SA \\
\hline $\begin{array}{l}\text { d. was credible, up-to-date } \\
\text { information }\end{array}$ & SD & D & N & A & SA \\
\hline $\begin{array}{l}\text { 3. Attending the program was } \\
\text { worth my time. }\end{array}$ & SD & D & N & A & SA \\
\hline $\begin{array}{l}\text { 4. I would recommend this } \\
\text { program to others. }\end{array}$ & SD & D & N & A & SA \\
\hline $\begin{array}{l}\text { 5. I increased my knowledge in the } \\
\text { program }\end{array}$ & SD & D & N & A & SA \\
\hline $\begin{array}{l}\text { 6. I learned new skills related to } \\
\text { this area. }\end{array}$ & SD & D & N & A & SA \\
\hline 7. I will use the things I learned. & SD & D & N & A & SA \\
\hline 8. I will tell others what I learned. & SD & D & N & A & SA \\
\hline
\end{tabular}

\begin{tabular}{|l|l|l|l|c|}
\hline 9. How much of the content covered did you already know? & None & A little & Some & A lot \\
\hline 10. How many of the resource materials will you use? & None & A little & Some & A lot \\
\hline 11. How well did the information presented meet your needs? & None & A little & Some & A lot \\
\hline
\end{tabular}




\section{Participant Comments}

12. Indicate two main things that you learned or gained from the workshop.

a.

b.

13. What, if anything, will you implement in your daily routine that you learned in from the workshop?

a.

14. What could be added to the workshop to make the presentation better?

a.

15. What did you like best about the workshop?

a.

16. If you could change anything about the project, what would it be?

a.

17. Additional Comments

a. 
APPENDIX D

EARLY CARE PROFESSIONAL PHYSICAL ACTIVITY KNOWLEDGE RATING 


\section{Physical Activity Knowledge Quiz}

1. Children should have minutes or more of physical activity each day.
a. $\quad 60$ minutes
b. $\quad 30$ minutes
c. $\quad 90$ minutes
d. $\quad 45$ minutes

2. Children should have opportunities for muscle strengthening activities (such as yoga) per week.
a. 5
b. 2
c. 3
d. 1

3. Children should have opportunities for bone-strengthening activities (such as running) per week.
a. 5
b. 2
c. 3
d. 1

4. Physical activity can
a. reduce your risk of some types of cancer
b. improve your mental health and mood
c. increase your chances of living longer
d. all of the above

5. Muscle-strengthening activities can include the following:
a. household chores such as cooking and cleaning
b. yoga
c. running
d. all of the above

6. Teachers can encourage preschool children to be physically active by:
a. using transition times to move
b. observing the children on the playground
c. providing outdoor art activities everyday
d. all of the above 
7. Providing preschool children with opportunities to be physically active throughout the day can:
a. improve classroom behaviors
b. disrupt naptime
c. can interfere with academic programming
d. all of the above

8. When weather does not permit outdoor play, it is best to:
a. increase center time
b. play games such as musical chairs
c. move the furniture and dance
d. all of the above

9. To ensure that children get enough physical activity, I can:
a. be active on the playground with them
b. include physical activity in my lesson plans
c. limit the use of screen time
d. all of the above

10. As young children's physical activity increases, also increases.
a. cognitive development
b. social development
c. fine motor development
d. all of the above 
APPENDIX E

EARLY CARE PROFESSIONAL SLEEP KNOWLEDGE RATING 


\section{Sleep Health Knowledge Quiz}

1. Children between the ages of 3 and 5 should have hours of sleep per 24 hours including naps.
a. between $8-10$
b. between 10-11
c. between $10-13$
d. between $9-13$

2. Most children discontinue the need for naps between the ages of
a. $\quad 2$ and 5
b. $\quad 3$ and 5
c. $\quad 4$ and 5
d. $\quad 3$ and 4

3. Preparing the children for naptime includes all but the following:
a. dimming the lights prior to getting their cots out
b. reading a calming book, playing soft music or nature sounds, or doing light stretches
c. covering the windows to block out natural light
d. having children engage in vigorous physical activity for 5 minutes before nap- time to get all their energy out

4. Children who are tired during the day may:
a. act out or misbehave as a result of not getting enough sleep
b. seem clumsy or uncoordinated because they haven't slept enough
c. be hyper and unable to sit still
d. all of the above

5. Large numbers of young children in the United States are getting:
a. too much sleep when naps and nighttime sleep amounts are added together
b. less sleep than is recommended in a 24-hour period
c. the recommended amount of sleep in a 24-hour period
d. the right amount of daytime (napping) sleep, but not enough nighttime sleep

6. To allow for individual needs for sleep it is important to:
a. have a cozy place to rest in the classroom if they are tired before/after naptime
b. make all children close their eyes during naptime
c. wake everyone up from naptime on schedule
d. only allow a child to sleep during naptime 
7. When preparing the classroom for naptime, it is important to remember
a. that the light from the window might disrupt children's rest
b. some light, either from the window or overhead lights, is needed for supervision purposes
c. the position of the children's mats/cots doesn't have to be the same each day
d. all of the above

8. When a child is very upset during naptime and is disturbing the other children the best thing to do is
a. have the child remain on his cot and sit with him to until he has calmed down
b. remove the child from the classroom to prevent disturbing the other children
c. ignore the child and let him calm down on his own
d. let the child get up and play while the other children are resting

9. If a child needs help to relax at naptime, the following could help
a. allow the child to have a soft toy to cuddle with
b. play soft music
c. rub the child's back or hand
d. all of the above

10. If a child is tired before naptime, it is best to
a. $\quad$ keep her busy until naptime so she will sleep while the other children sleep
b. allow her to rest in the cozy area
c. engage her in physical activity to get her awake
d. talk to the parent to see if she was up late the night before 
APPENDIX F

\section{EARLY CARE PROFESSIONAL SLEEP BELIEFS RATING}




\section{THE SLEEP BELIEFS SCALE}

This is a survey of the effects of selected behaviors upon sleep. We are interested in knowing your opinion about whether any of these behaviors may influence the quality and/or quantity of sleep. For the following list of behaviors, please indicate whether you believe they produce a "positive" effect, a "negative" effect, or "neither" effect on sleep. Please do not make references to how they influence your sleep in particular, but to the effects you think these behaviors have on people in general. Please answer ALL statements by checking the appropriate box, even if you are not completely sure of the answer.

\begin{tabular}{|l|l|l|l|}
\hline & $\begin{array}{l}\text { Positive } \\
\text { effect }\end{array}$ & $\begin{array}{l}\text { Neither } \\
\text { effect }\end{array}$ & $\begin{array}{l}\text { Negative } \\
\text { effect }\end{array}$ \\
\hline $\begin{array}{l}\text { 1. Drinking alcohol in the evening } \\
\text { dinner }\end{array}$ & & & \\
\hline 3. Doing intense physical exercise before going to bed & & & \\
\hline 4. Taking a long nap during the day & & & \\
\hline 5. Going to bed and waking up always at the same hour & & & \\
\hline $\begin{array}{l}\text { 6. Thinking about one's engagements for the next day } \\
\text { before falling asleep }\end{array}$ & & & \\
\hline 7. Using sleep medication regularly & & & \\
\hline 8. Smoking before falling asleep & & & \\
\hline $\begin{array}{l}\text { 9. Diverting one's attention and relaxing before } \\
\text { bedtime }\end{array}$ & & & \\
\hline 10. Going to bed 2 hours later than the habitual hour & & & \\
\hline 11. Going to bed with an empty stomach & & & \\
\hline $\begin{array}{l}\text { 12. Using the bed for eating, calling on the phone, } \\
\text { studying and other non-sleep activities. }\end{array}$ & & & \\
\hline $\begin{array}{l}\text { 13. Trying to fall asleep without having a sleep } \\
\text { sensation }\end{array}$ & & & \\
\hline 14. Studying or working intensely until late night & & & \\
\hline 15. Getting up when it is difficult to fall asleep & & & \\
\hline $\begin{array}{l}\text { 16. Going to bed 2 hours earlier than the habitual } \\
\text { hour }\end{array}$ & & & \\
\hline 17. Going to bed immediately after eating & & & \\
\hline $\begin{array}{l}\text { 18. Being worried about the possibility of getting } \\
\text { enough sleep }\end{array}$ & & & \\
\hline 19. Sleeping in a quiet and dark room & & & \\
\hline 20. Recovering lost sleep by sleeping for a long time & & & \\
\hline Adn A. Fabri, & & & \\
\hline
\end{tabular}

Adan, A., Fabbri, M., Natale, V., \& Prat, G. (2006). Sleep beliefs scale (SBS) and circadian typology. Journal of Sleep Research, 15(2)m 125-132. 